\author{
UNIVERSIDADE DE SÃO PAULO \\ ESCOLA DE ENGENHARIA DE SÃO CARLOS \\ DEPARTAMENTO DE ENGENHARIA DE TRANSPORTES
}

ANTHONY GOMES DOS SANTOS

Estudo teórico do efeito da interação entre camadas no comportamento estrutural de pavimentos asfálticos

São Carlos, SP

2018 



\section{ESTUDO TEÓRICO DO EFEITO DA INTERAÇÃO ENTRE CAMADAS NO COMPORTAMENTO ESTRUTURAL DE PAVIMENTOS ASFÁLTICOS}

Dissertação submetida ao Departamento de Transportes da Escola de Engenharia de São Carlos - Universidade de São Paulo (STT/EESC/USP) como parte dos requisitos para obtenção do título de Mestre em Ciências.

Programa de Pós-Graduação em Engenharia de Transportes.

Área de concentração: Infraestrutura de Transportes.

Orientador: Prof. Dr. José Leomar Fernandes Júnior

São Carlos, SP

2018 
AUTORIZO A REPRODUÇ̃̃O TOTAL OU PARCIAL DESTE TRABALHO, POR QUALQUER MEIO CONVESNCIONAL OU ELETRÔNICO, PARA FINS DE ESTUDO E PESQUISA, DESDE QUE CITADA A FONTE.

Ficha catalográfica elaborada pela Biblioteca Prof. Dr. Sérgio Rodrigues Fontes da EESC/USP com os dados inseridos pelo(a) autor(a).

SANTOS, ANTHONY GOMES DOS

Estudo teórico do efeito da interação entre camadas no comportamento estrutural de pavimentos asfálticos / ANTHONY GOMES DOS SANTOS; orientador José Leomar FERNANDES JÚNIOR. São Carlos, 2018.

Dissertação (Mestrado) - Programa de Pós-Graduação em Engenharia de Transportes e Área de Concentração em Infraestrutura de Transportes - - Escola de Engenharia de São Carlos da Universidade de São Paulo, 2018.

1. Métodos Empírico-Mecanísticos. 2. aderência entre camadas. 3. Método dos Elementos Finitos. 4. resposta estrutural. 5. resposta estrutural, fadiga. 6. deformação permanente. I. Título. 


\section{FOLHA DE JULGAMENTO}

Candidato: Engenheiro ANTHONY GOMES DOS SANTOS.

Título da dissertação: "Estudo do efeito da interação entre camadas no comportamento estrutural de pavimentos asfálticos".

Data da defesa: 26/02/2018.

\section{Comissão Julgadora:}

Prof. Titular José Leomar Fernandes Júnior (Orientador)

(Escola de Engenharia de São Carlos/EESC)

Prof. Dr. Francis Massashi Kakuda

(Universidade Federal de São Carlos/UFSCar)

Prof. Dr. Jesner Sereni Illdefonso

(Universidade Estadual de Maringá/UEM)
Resultado:

A P NOVADO

ABROVADO APROVA DO

Coordenadora do Programa de Pós-Graduação em Engenharia de Transportes:

Profa. Associada Ana Paula Camargo Larocca

Presidente da Comissão de Pós-Graduação:

Prof. Associado Luis Fernando Costa Alberto 

Ao professor José Leomar Fernandes Júnior, pela confiança, pela dedicação, paciência e motivação ao longo de toda a pesquisa.

A meus pais, Edson e Josefa, pelo amor incondicional, apoio e incentivo constantes

Aos meus irmãos, Jhonathan e Lídia, pelo amor, pelo suporte e pelo exemplo

A minha sobrinha Melissa pelos muitos "quando você volta tio Toni? Tô com saudades"

Aos meus parceiros de morada Alisson Alberto, Andressa NG, Artur Piatti e Flávio Maffioletti pelo apoio, pela parceria longo de toda essa jornada e pelos e almoços em família.

A Andrise Buchweitz, pelo suporte direto e principalmente pelo carinho e incentivo

A Tiago Torquato e Fabiane Queiroz pelo esforço e apoio prestado nessa caminhada

Aos meus companheiros de orientação, Jorge Braulio Cossío Durán, Loana Henriquez, Maria José Zagatto Penha, Rossuel Krum Mathias de Assis, Danilo Bisconsini, Ricardo Gonçalves e Marilia Gabriela pelos conselhos, pelas muitas discussões que contribuíram com essa pesquisa, pelos socorros prestados e pela amizade

Aos colegas do Departamento de Transportes, em especial a galera do café, pelos bons momentos divididos

Aos professores do Departamento de Transportes pelo empenho em compartilhar o conhecimento não só durantes as aulas

A todos os funcionários do Departamento de Transporte pelo apoio direto e indireto durante todo o trabalho 

SANTOS, A. G. (2018). Estudo teórico do efeito da interação entre camadas no comportamento estrutural de pavimentos asfálticos. Dissertação (Mestrado) Departamento de Engenharia de Transportes, Escola de Engenharia de São Carlos, Universidade de São Paulo, São Carlos, SP. 2018.

Os métodos empírico-mecanísticos de projeto de pavimentos admitem perfeita aderência entre as camadas, o que pode não ocorrer no campo, conforme evidenciam defeitos relacionados diretamente à falha de aderência entre as camadas, como a corrugação e as trincas por deslizamento. Neste trabalho, com o programa de elementos finitos ABAQUS, o comportamento mecânico de pavimentos asfálticos é avaliado sob diferentes níveis de aderência entre as camadas: total, parcial e nula. As análises foram realizadas para diferentes níveis de rigidez do material asfáltico e a estimativa do desempenho de pavimentos flexíveis, tanto à fadiga das camadas asfálticas e cimentadas quanto à deformação permanente, foi baseada em equações empírico-mecanísticos que consideram, respectivamente, as respostas estruturais: deformação horizontal de tração na fibra inferior das camadas asfálticas e deformação vertical de compressão no topo do subleito. Os resultados mostraram que em 14 das 19 respostas estruturais analisadas, a condição de completa aderência resulta em menores deformações e que a influência da condição de interface na estrutura do pavimento é maior com camadas asfálticas mais rígidas. A interação entre as camadas afetou não só o revestimento do pavimento como também as camadas inferiores. A condição de interface entre as camadas afetou mais a vida do pavimento à fadiga do que à deformação permanente e, na maioria dos casos estudados, a consideração de perfeita aderência entre as camadas resultou na previsão de um pavimento com vida em serviço expressivamente maior. Portanto, a constatação de que a aderência entre as camadas de um pavimento está diretamente relacionada à duração da vida em serviço ressalta a importância de sua correta consideração em todo o processo, desde o dimensionamento até as etapas construtivas.

Palavras-chave: Métodos Empírico-Mecanísticos, aderência entre camadas, Método dos Elementos Finitos, resposta estrutural, fadiga, deformação permanente. 

SANTOS, A. G. (2018). Theoretical study of the effect of layers interaction on the asphalt pavement structural behavior. Dissertation (Master) - Department of Transportation Engineering, São Carlos School of Engineering, University of São Paulo, São Carlos, SP. Brazil.

The empiric-mechanistic methods of pavement design admit perfect adherence between the layers, which may not occur in the fields, as evidenced by distresses related directly to the failure of adhesion between the layers, such as corrugation and sliding cracks. In this work, with the use of ABAQUS, a finite element program, it is evaluated the mechanical behavior of asphalt pavements under different levels of adhesion between the layers: total, partial and zero. The analyzes were carried out for different levels of stiffness of the asphalt material and the estimation of the performance of flexible pavements, in terms of fatigue of the asphaltic and cemented layers and permanent deformation, was based on empiric-mechanistic equations that consider, respectively, the structural responses: horizontal tensile strain at the bottom fiber of the asphalt layers and vertical compressive strain at the top of the subgrade. The results showed that in 14 of the 19 structural responses analyzed, the condition of complete adhesion results in lower strain and that the influence of the interface condition on the pavement structural behavior is greater with more rigid asphalt layers. The interaction between layers affected not only the surface layer but also the lower layers. The interface condition between the layers affected the fatigue life more than the permanent deformation and, in the majority of the studied cases, the consideration of perfect adherence between the layers resulted in the prediction of a pavement with significantly greater service life. Therefore, the observation that the adhesion between the layers of a pavement is directly related to the duration of the service life highlights the importance of its correct consideration in the whole process, from the design to the constructive stages.

Keyswords: empiric-mechanistic methods, adherence layers, Finite Element Method, structural answers, fatigue, permanent deformation. 

1. INTRODUÇÃO 9

1.1 Objetivo Geral 10

1.2 Objetivos específicos 10

2. REVISÃO BIBLIOGRÁFICA 11

2.1 Métodos Empírico-Mecanísticos de Dimensionamento de Pavimentos 11

2.1.1 Determinação das respostas estruturais de pavimentos flexíveis 12

2.1.2 Modelos de previsão de desempenho 14

2.2 Interface entre as camadas 17

2.2.1 Modelagem da interface entre camadas 19

2.2.2 Os efeitos da aderência entre camadas no desempenho dos pavimentos 21

2.2.3 Interface no ABAQUS 24

3. MÉTODO 27

3.1 Estruturas dos pavimentos 27

3.2 Modelagem 30

3.2.1 Estrutura e materiais 30

3.2.2 Carregamento 31

3.2.3 Condições de contorno __ 32

3.2.4 Malha de elementos finitos__ 32

3.2.5 Interação entre as camadas ___ 33

3.3 Dados de saída do ABAQUS __ 33

4. RESULTADOS: SIMULAÇÕES COMPUTACIONAIS ___ 35

4.1 Respostas estruturais do pavimento com base granular simples __ 35

4.1.1 Estrutura I__ 35

4.1.2 Estrutura II _ 37

4.1.3 Estrutura III __ 41 
5. ANÁLISE ESTATÍSTICA

5.1 Análise de Significância ___ 44

5.2 Análise de Regressão___ 45

5.3 Comparação entre as condições de interface___ 50

5.3.1 Estrutura I_ 50

5.3.2 Estrutura II _ 53

5.3.3 Estrutura III _ 57

5.4 Efeito da condição de interface na vida do pavimento ___ 61

5.4.1 Previsão de desempenho à fadiga __ 65

5.4.2 Previsão de desempenho à deformação permanente ___ 68

6. Conclusões ___ 71

7. Referências ___ 74 
Figura 1. Método empírico-mecanístico de dimensionamento de pavimentos (Huang, 2004) 11

Figura 3. Sistema de camadas elásticas generalizado (Yoder e Witczak, 1975) 12

Figura 4. Trincas por deslizamento na interface inferior do revestimento asfáltico de uma rodovia em Nevada, USA (Chamort et al., 2005) 18

Figura 5. Modos de separação entre camadas (adaptado de Sutanto, 2010) 18

Figura 6. (a) Curva tensão x deslocamento típica, (b) modelo constitutivo de dois estágios (adaptado de Romanoschi e Metcalf, 2001a) 20

Figura 7. Analogia de um sistema de camadas com vigas bi apoiadas sob diferentes condições de aderência (adaptado de Tschegg, 1995) 21

Figura 8. Tensão de cisalhamento na interface x deslizamento entre as superfícies no modo Friction (ABAQUS, 2014a) 25

Figura 9. Estrutura I (adaptado de PACHECO, 2014) 27

Figura 10. Estrutura II (adaptado de PACHECO, 2014) 27

Figura 11. Estrutura III (adaptado de PACHECO, 2014) 28

Figura 12. Disposição espacial da estrutura-orientação dos eixos 30

Figura 13. Área de contato pneu-pavimento (adaptado de HUANG, 2004) 31

Figura 14. Carregamento empregado nas modelagens 31

Figura 15. Condições de contorno das estruturas modeladas 32

Figura 16. Tamanho dos elementos finitos por camada 32

Figura 17. Simetria do quadro de deformações 35

Figura 18. Curva de deflexão da estrutura com BGS 36

Figura 19. Curva de deflexão da estrutura com BGTC 36

Figura 20. Curva de deflexão da Estrutura II com base de BGS 38

Figura 21. Curva de deflexão da Estrutura II com base de BGTC 38

Figura 22. Curva de deflexão da Estrutura III com base de BGS 41

Figura 23. Curva de deflexão da Estrutura III com base de BGTC 41

Figura 24. Deformação horizontal no revestimento do pavimento com base de BGS 51

Figura 25. Deformação vertical no subleito do pavimento com base de BGS 51

Figura 26. Deformação horizontal no revestimento do pavimento com base de BGTC 52

Figura 27. Deformação horizontal na base do pavimento com base de BGTC 52

Figura 28. Deformação vertical no subleito do pavimento com base de BGTC 52

Figura 29. Deformação horizontal no revestimento do pavimento com base de BGS 53

Figura 30. Deformação horizontal na camada asfáltica inferior do pavimento com base de BGS 54

Figura 31. Distribuição de tensões ao longo da espessura das camadas asfálticas 54

Figura 32. Deformação vertical no subleito do pavimento com base de BGS 55 
Figura 33. Deformação horizontal no revestimento do pavimento com base de BGTC

Figura 34. Deformação horizontal na camada asfáltica inferior do pavimento com base de BGTC _ 56

Figura 35. Deformação horizontal na base do pavimento com base de BGTC ___ 56

Figura 36. Deformação vertical no subleito do pavimento com base de BGTC ___ 57

Figura 37. Deformação horizontal no revestimento do pavimento com base de BGS ___ 58

Figura 38. Deformação horizontal no binder do pavimento com base de BGS ___ 58

Figura 39. Deformação vertical no subleito do pavimento com base de BGS ___ 58

Figura 40. Deformação horizontal no revestimento do pavimento com base de BGTC ___ 59

Figura 41. Deformação horizontal no binder do pavimento com base de BGTC _ 60

Figura 42. Deformação horizontal na base do pavimento com base de BGTC ___ 60

Figura 43. Deformação vertical no subleito do pavimento com base de BGTC ___ 60

Figura 44. Curva de fadiga da Estrutura I com base de BGS___ 66

Figura 45. Curva de fadiga da Estrutura I com base de BGTC ____ 66

Figura 46. Curva de fadiga da Estrutura II com base de BGS ___ 67

Figura 47. Curva de fadiga da Estrutura II com base de BGTC____ 67

Figura 48. Curva de fadiga da Estrutura III com base de BGS ___ 67

Figura 49. Curva de fadiga da Estrutura III com base de BGTC ____ 68

Figura 50. Curva de deformação permanente da Estrutura I com base de BGS___ 69

Figura 51. Curva de deformação permanente da Estrutura I com base de BGTC __ 69

Figura 52. Curva de deformação permanente da Estrutura II com base de BGS __ 69

Figura 53. Curva de deformação permanente da Estrutura II com base de BGTC __ 70

Figura 54. Curva de deformação permanente da Estrutura III com base de BGS __ 70

Figura 55. Curva de deformação permanente da Estrutura III com base de BGTC ___ 70 
Tabela 1. Critérios de ruptura de métodos de dimensionamento de pavimentos asfálticos (adaptado de Monismith e Brown, 1999)

Tabela 2. Parâmetros $a$ e $b$ da expressão de previsão de desempenho da deformação permanente (Monismith e Brown, 1999) 16

Tabela 3. Casos de condições de aderência (adaptado de Ziari e Khabiri, 2007) 22

Tabela 4. Estrutura dos pavimentos com uma camada de revestimento 28

Tabela 5. Estruturas dos pavimentos com duas camadas iguais de revestimento 28

Tabela 6. Estruturas dos pavimentos com duas camadas diferentes de revestimento 29

Tabela 7. Condições de aderência nas interfaces 29

Tabela 8. Deformações máximas da Estrutura I com base de BGS (micro deformações) 37

Tabela 9. Deformações máximas da Estrutura I com base de BGTC (micro deformações) 37

Tabela 10. Deformações máximas da Estrutura II com base de BGS (micro deformações) 39

Tabela 11. Deformações máximas da Estrutura II com base de BGTC (micro deformações) 40

Tabela 12. Deformações máximas da Estrutura III com base de BGS (micro deformações) 42

Tabela 13. Deformações máximas da Estrutura III com base de BGTC (micro deformações) 43

Tabela 14. P-Valor dos fatores-Estrutura I 45

Tabela 15. P-Valor dos fatores-Estrutura II 45

Tabela 16. P-Valor dos fatores-Estrutura III 45

Tabela 17. Valor médio dos coeficientes de cada fator-Estrutura I 48

Tabela 18. Valor médio dos coeficientes de cada fator-Estrutura II 48

Tabela 19. Valor médio dos coeficientes de cada fator-Estrutura III 49

Tabela 20. Coeficientes de determinação dos modelos de regressão da Estrutura I 49

Tabela 21. Coeficientes de determinação dos modelos de regressão da Estrutura II 49

Tabela 22. Coeficientes de determinação dos modelos de regressão da Estrutura III 49

Tabela 23. Deformações máximas da Estrutura I com base de BGS (micro deformações) 61

Tabela 24. Deformações máximas da Estrutura I com base de BGTC (micro deformações) 61

Tabela 25. Deformações máximas da Estrutura II com base de BGS (micro deformações) 62

Tabela 26. Deformações máximas da Estrutura II com base de BGTC (micro deformações) 63

Tabela 27. Deformações máximas da Estrutura III com base de BGS (micro deformações) 64

Tabela 28. Deformações máximas da Estrutura III com base de BGTC (micro deformações) 65 


\section{INTRODUÇÃO}

A estrutura de um pavimento é dimensionada para resistir às solicitações provenientes do tráfego e do clima com um nível mínimo de desempenho durante a vida útil de projeto. Contudo, segundo a CNT (2017a), aproximadamente 26\% e 16\% da extensão rodoviária sob gestão pública e concedida, respectivamente, apresentaram defeitos estruturais, como trincas e afundamento na trilha de roda e, $53 \%$ e $46 \%$ já apresentam condições de desgaste.

Em geral, a degradação do pavimento provém do acumulo do dano gerado pelas solicitações do tráfego e do clima. Esses danos, associados à falta ou deficiência na manutenção das rodovias, levam o pavimento à necessidade de atividades de reabilitação, como o recapeamento, em que uma nova camada de revestimento é construída sobre a camada já existente. Nesse tipo de intervenção, DNIT (2006) e DER-SP (2005) recomendam que a nova camada esteja completamente aderida à camada existente para que o pavimento se comporte como uma única estrutura. Essa recomendação ainda se estende à interação entre as camadas de um pavimento novo.

Além disso, também é notado em alguns pavimentos o aparecimento de defeitos antes do tempo estimado para as atividades de manutenção e reabilitação. O surgimento desses defeitos prematuros pode estar relacionado à falha construtiva, à característica inadequada dos materiais ou ao método de dimensionamento.

No Brasil, atualmente é utilizado um método empírico de dimensionamento de pavimentos. No entanto, há uma busca constante pela redução do empirismo no modo de dimensionar os pavimentos, exemplo disso é o novo método empírico-mecanístico de dimensionamento de pavimentos asfálticos proposto pelo DNIT. O método foi desenvolvido em parceria com a COOPE-UFRJ e a Rede Temática de Asfalto e será implantado ainda em 2018 (CNT, 2017b).

Os métodos empírico-mecanísticos de dimensionamento determinam as espessuras das camadas e a rigidez do material para que as tensões e deformações sofridas pela estrutura sejam menores que os valores máximos admissíveis. Uma das suposições dos métodos empíricomecanísticos é que as camadas dos pavimentos estejam completamente aderidas, o que facilita a modelagem e o cálculo das tensões e deformações da estrutura. No entanto, mesmo com o auxílio de recursos como a pintura de ligação, uma conexão adequada nem sempre é alcançada 
e problemas relacionados diretamente à falha de aderência entre as camadas já foram reportados por diversos pesquisadores.

O desempenho dos pavimentos indica que as camadas nem sempre trabalham de forma monolítica o que altera a distribuição dos esforços internos da estrutura e resulta no comprometimento do pavimento. Em função da dificuldade de alcançar em campo a condição ideal de aderência entre as camadas, ressalta-se a importância de se incorporar aos métodos de dimensionamento de pavimento fatores relacionados ao contato entre as camadas. Para isso, é fundamental compreender melhor os efeitos da interação entre as camadas no comportamento estrutural dos pavimentos e consequentemente no seu desempenho.

\subsection{Objetivo Geral}

O objetivo deste trabalho é estudar como a condição de aderência entres as camadas afeta o comportamento estrutural dos pavimentos asfálticos quando solicitados pelo tráfego.

\subsection{Objetivos específicos}

Para alcançar o objetivo principal da pesquisa, busca-se:

1. Modelar computacionalmente um pavimento com três diferentes condições de contato entre as camadas: não aderidas, parcialmente aderidas e completamente aderidas.

2. Determinar o estado de tensões, deformações e deslocamentos do pavimento, sob diferentes condições de contato entre duas camadas asfálticas e entre a camada asfáltica e a camada de base;

3. Verificar a influência da rigidez do material asfáltico no efeito da aderência entre camadas no comportamento estrutural do pavimento.

4. Analisar estatisticamente o efeito da condição de contato entre as camadas na previsão de desempenho dos pavimentos. 


\section{REVISÃO BIBLIOGRÁFICA}

\subsection{Métodos Empírico-Mecanísticos de Dimensionamento de Pavimentos}

Revisão Bibliográfica

Os métodos empírico-mecanísticos assumem que os pavimentos devem ser dimensionados da mesma forma que qualquer outra estrutura da engenharia civil. $\mathrm{O}$ procedimento para determinação da estrutura de um pavimento, conforme Huang (2004) é esquematizado na Figura 1.

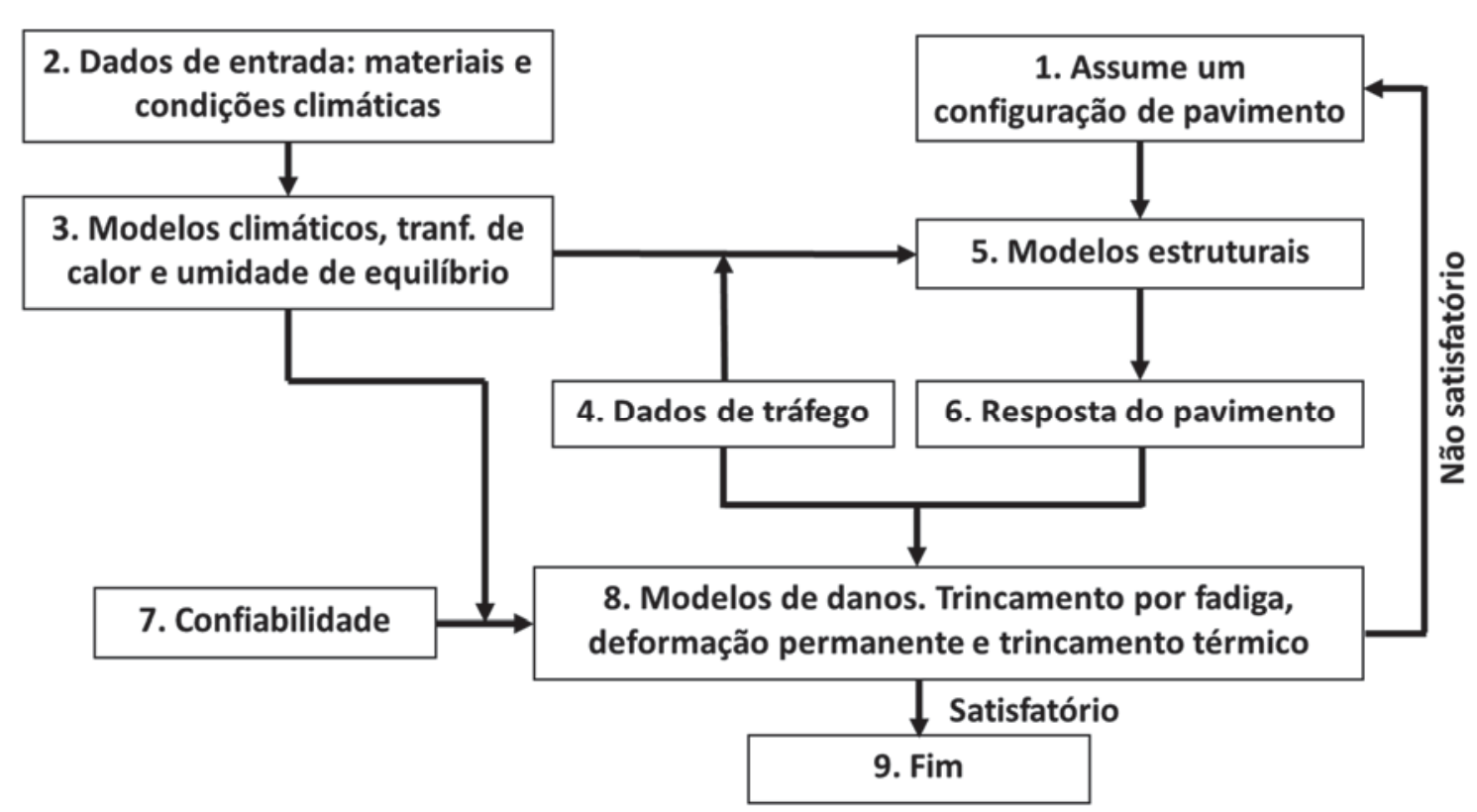

Figura 1. Método empírico-mecanístico de dimensionamento de pavimentos (Huang, 2004)

Descreve-se o procedimento básico dos métodos empírico-mecanísticos de dimensionamento de pavimentos com os seguintes passos:

a) Reunir os dados referentes aos materiais disponíveis, tráfego e condições ambientais;

b) Adotar uma estrutura: determinar as dimensões e estimar, por meio de ensaios de laboratório, as propriedades dos materiais de cada camada;

c) Analisar a estrutura: calcular as tensões, deformações e deslocamentos da estrutura sob carregamento; 
d) Utilizar os modelos de previsão de desempenho para relacionar comportamento estrutural dos pavimentos com a sua capacidade de resistir aos mecanismos de deterioração;

e) Verificar se o desempenho previsto é satisfatório.

\subsubsection{Determinação das respostas estruturais de pavimentos flexíveis}

O estado de tensões, deformações e deslocamentos da estrutura de um pavimento tem sido determinado por meio de duas abordagens de cálculo diferentes: a abordagem analítica e a numérica, que são descritas a seguir.

\subsubsection{Abordagem Analítica}

Boussinesq, em 1885, considerou o pavimento como um semiespaço homogêneo e elástico linear, quando apresentou uma solução analítica para o problema do sistema de uma camada ao aplicar a teoria da elasticidade combinada às relações constitutivas e cinemáticas do problema (Kim, 2007). Segundo Huang (2004), Burmister, em 1943, a partir de Boussinesq, apresentou a teoria das camadas elásticas com solução para um sistema de duas e três camadas e posteriormente para um sistema de múltiplas camadas (Figura 2).

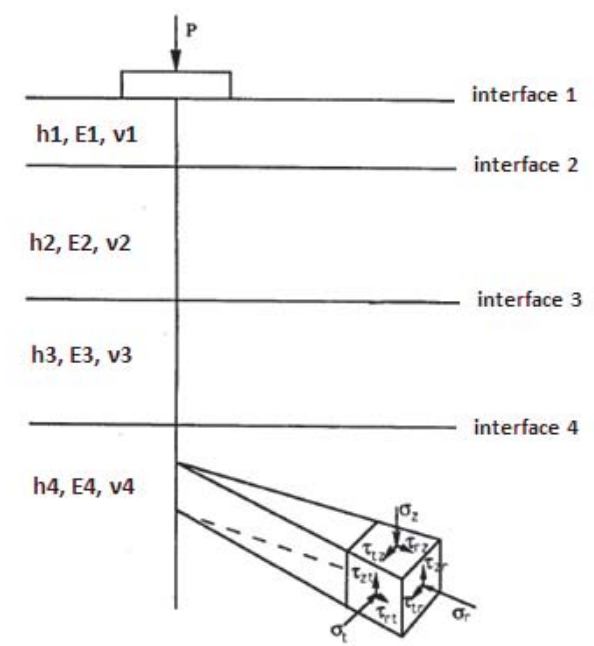

Figura 2. Sistema de camadas elásticas generalizado (Yoder e Witczak, 1975)

Em que h, E e v são, respectivamente, a espessura, o módulo de elasticidades e o coeficiente de Poisson de cada camada.

A teoria das camadas elásticas parte de algumas hipóteses que tornam a solução das equações relativamente simples (Yoder e Witczak, 1975): 
1. Carregamento estático uniformemente distribuído sobre uma área de contato circular;

2. Material homogêneo, isotrópico, elástico linear e que atende à lei de Hooke;

3. Continuidade na interface entre as camadas, ou seja, aderência completa;

4. Camadas com rigidez finita, com exceção do subleito.

5. Superfície livre de tensão de cisalhamento;

6. Extensão infinita no plano horizontal.

O conhecimento do comportamento mecânico dos materiais de cada camada é fundamental para a análise estrutural. O comportamento dos materiais é caracterizado por duas propriedades mecânicas: o módulo de resiliência e o coeficiente de Poisson. No entanto, tais propriedades não são constantes podendo se dar em função da temperatura e da frequência de carregamento, nos casos de materiais viscoelásticos como o asfalto (Yao et al., 2012), e do estado de tensões quando o material é elástico não linear, como os materiais granulares e coesivos (Franco, 2004).

De forma geral, as características dos materiais, a geometria do pavimento e as condições de carregamento da estrutura real de um pavimento contrariam todas as premissas dessa teoria (Fernandes Jr., 1994). Contudo, diversos pesquisadores (Haas et al., 1994; Huang, 2004; Yoder e Witczak, 1975) apontaram a teoria das camadas elásticas como uma boa solução para estimar o comportamento estrutural dos pavimentos flexíveis.

\subsubsection{Abordagem numérica}

A complexidade de parâmetros como a geometria, as condições de contorno e os modelos constitutivos específicos dos materiais empregados na pavimentação, junto ao desenvolvimento computacional, impulsionaram a implementação de programas que facilitam a determinação das tensões, deformações e deslocamentos. Esses programas calculam o estado tensional dos pavimentos por meio de métodos numéricos, como o Método dos Elementos Finitos (MEF).

A utilização dessas ferramentas proporciona economia de tempo e maior versatilidade nas análises, à medida que permite contornar algumas das simplificações adotadas no método analítico (Medina e Motta, 2015).

A versatilidade das análises computacionais fica mais evidenciada com a utilização de programas de proposta mais geral (não específicos para a pavimentação) como o ABAQUS. 
O ABAQUS é o programa de uso geral mais utilizado para resolver problemas de engenharia como análise de tensões de deformações com base no Método dos Elementos Finitos (Hibbit, 2005). Com uma grande variedade de ferramentas em suas análises, o programa permite uma melhor representação da condição real do pavimento e, diversos estudos têm recorrido à utilização de ferramentas com uma proposta de análise mais ampla (Zaghloul et al., 1993; Cho, 1996; Yassenn et al., 2015; Uddim et al., 1994; Sukumaran, 2004; Kim, 2007; Feyssa, 2009). Dentre as diversas aplicações do software à pavimentação, destaca-se nesta pesquisa a possibilidade de simular diferentes condições de interface entre as camadas do pavimento.

\subsubsection{Modelos de previsão de desempenho}

Os métodos de dimensionamento relacionam a vida do pavimento com a magnitude das tensões e deformações máximas na estrutura, considerando funções de transferência (os modelos de previsão de desempenho) para estimar o desempenho do pavimento por meio do número de solicitações necessários para se atingir a ruptura da estrutura.

A ruptura do pavimento pode ser funcional ou estrutural e está associada à fatores como técnica construtiva, clima e, principalmente, às passagens dos veículos (solicitações do tráfego). Cada passagem de um eixo sobre o pavimento é responsável por uma parcela de dano à estrutura que, com a repetição das solicitações, leva o pavimento ao fim da vida em serviço (Franco, 2007).

A ruptura funcional refere-se à condição de conforto e segurança do rolamento dos veículos (Yoder e Witczak, 1975). A falha estrutural, abordada neste trabalho, está relacionada ao colapso da estrutura ou à falha de um ou mais componentes do pavimento, que o tornam incapaz de suportar as solicitações impostas (Huang, 2004).

Cada método de dimensionamento utiliza como critério de ruptura os mecanismos de deterioração do pavimento, que se apresentam sob diversas formas, com destaque para a deformação permanente da estrutura (controlada pela deformação vertical de compressão no topo do subleito) e as trincas por fadiga dos materiais asfálticos e cimentados (Tabela 1).

A seguir, são abordados em detalhe exemplos de modelos de previsão de desempenho à fadiga e à deformação permanente que relacionem o número de solicitações admissíveis com a deformação sofrida pela estrutura do pavimento quando solicitada pelo tráfego. 
Tabela 1. Critérios de ruptura de métodos de dimensionamento de pavimentos asfálticos (adaptado de Monismith e Brown, 1999)

\begin{tabular}{|c|c|}
\hline Método & Critérios de ruptura \\
\hline $\begin{array}{l}\text { Shell International } \\
\text { Petroleum }\end{array}$ & $\begin{array}{l}\text { Fadiga em camadas asfálticas ou estabilizadas com cimento } \\
\text { Deformação limite no topo do subleito }\end{array}$ \\
\hline Instituto do Asfalto (MS-1) & $\begin{array}{l}\text { Fadiga em camadas asfálticas } \\
\text { Deformação limite no topo do subleito }\end{array}$ \\
\hline Austroads & $\begin{array}{l}\text { Fadiga em camadas estabilizadas com cimento ou asfálticas } \\
\text { Deformação limite no topo do subleito }\end{array}$ \\
\hline $\begin{array}{l}\text { Laboratoire Central de } \\
\text { Ponts et Chaussées (LCPC) }\end{array}$ & $\begin{array}{l}\text { Fadiga em camadas estabilizadas com cimento ou asfálticas } \\
\text { Deformação permanente na camada asfáltica }\end{array}$ \\
\hline $\begin{array}{l}\text { Federal Aviation } \\
\text { Administration (LEDFAA) }\end{array}$ & $\begin{array}{l}\text { Fadiga em camadas estabilizadas com cimento ou asfálticas } \\
\text { Deformação limite no topo do subleito }\end{array}$ \\
\hline
\end{tabular}

\subsubsection{Deformação no topo do subleito}

As várias equações que associam o valor limite da deformação permanente com o número de repetições admissível da solicitação padrão $\left(N_{\text {def }}\right)$ consideram a deformação vertical de compressão do topo do subleito $\left(\varepsilon_{v}\right)$ e, em sua representação mais simples, é expressa da seguinte forma (Fernandes Jr., 1994):

$$
N_{d e f}=a \varepsilon_{v}^{b}
$$

O método da SHELL (1987), com base em dados de retroanálise do AASHO Road Test, obteve os valores de 0,028 e 0,25 para os parâmetros a e $b$, respectivamente. Em sua segunda versão, em 1987, apresentou uma proposta em que a deformação vertical de compressão no topo do subleito continuava a ser o limitante da deformação permanente e os parâmetros a e $b$ foram associados à diferentes níveis de confiança (Fernandes Jr., 1994), conforme apresentado na Tabela 2: 
Tabela 2. Parâmetros $a$ e $b$ da expressão de previsão de desempenho da deformação permanente (Monismith e Brown, 1999)

\begin{tabular}{ccc}
\hline Nível de confiança & a & b \\
\hline $\mathbf{5 0 \%}$ & 0,028 & $-0,25$ \\
$\mathbf{8 5 \%}$ & 0,021 & $-0,25$ \\
$\mathbf{9 5 \%}$ & 0,019 & $-0,21$ \\
\hline
\end{tabular}

\subsubsection{Fadiga das camadas asfálticas e cimentadas}

Segundo Huang (2004), a maior diferença entre os métodos de dimensionamento é a função de transferência da deformação de tração na camada asfáltica para o número admissível de solicitações. Essas funções de transferência são comumente baseadas em duas formas de equação geral. A primeira (Equação 2), descreve o número de solicitações admissíveis à fadiga $\left(N_{f a d}\right)$ em função apenas da deformação horizontal de tração na camada asfáltica ou cimentada $\left(\varepsilon_{h}\right)$.

$$
N_{f a d}=a \varepsilon_{h}^{b}
$$

A empresa de consultoria Austin Research Engineers (A.R.E., 1975) desenvolveu uma equação de ruptura à fadiga (Equação 3) com base nos resultados do AASHO Road Test, baseada na forma geral apresentada acima.

$$
N_{\text {fad }}=9,73 * 10^{-15} \varepsilon_{h}^{-5,16}
$$

Outros pesquisadores desenvolveram funções de transferência que consideram também o módulo de rigidez da camada $(E)$, cuja forma geral está representada na Equação 4.

$$
N_{f a d}=\mathrm{a} \varepsilon_{h}{ }^{\mathrm{b}} E^{c}
$$

Em que $a, b$ e $c$ são coeficientes determinados experimentalmente. O método de dimensionamento da SHELL (SHELL, 1998) utilizou dados obtidos de ensaios de flexão repetida de vigotas com deformação controlada para a calibração desses coeficientes. $\mathrm{O}$ resultado do modelo geral calibrado para as condições do método de dimensionamento da SHELL está apresentado na Equação 5:

$$
N_{\text {fad }}=0,0685 \varepsilon_{h}{ }^{-5,671} E^{-2,363}
$$




\subsection{Interface entre as camadas}

A maioria das avaliações estruturais de pavimentos assume que suas camadas adjacentes estão perfeitamente ligadas e que não há deslocamento entre elas. Essa condição de ligação entre as camadas é fundamental para que trabalhem como uma estrutura monolítica.

Em campo, para se aproximar dessa condição, a técnica mais comum utilizada é a aplicação, entre as camadas, de uma pintura de ligação, geralmente com emulsão asfáltica (Mohammad, 2009), cuja eficiência depende de diversos fatores, como as propriedades do material asfáltico e sua taxa de aplicação (Tashman et al., 2006; Kruntcheva et al., 2006; Raab et al., 2016; Nguyen, 2016). Todavia, mesmo com o auxílio dessas técnicas, uma conexão adequada nem sempre é alcançada e problemas relacionados diretamente à falha de aderência entre as camadas têm sido reportados em diversos estudos (Raab e Partl, 2004; Chamort et al., 2005; Sutanto, 2010; Asaduzzaman, 2014).

As trincas por deslizamento ou deformação horizontal na superfície do pavimento (corrugação) são as evidências mais comuns de defeitos associados à falha de aderência entre as camadas. Problemas de corrugação foram observados, em 2001 na Indonésia, em alguns locais de frenagem e conversão dos veículos (Sutanto, 2010). Raab e Partl (2004) relataram casos de trincas por deslizamento entre as camadas e corrugação relacionados a um fraco contato na interface inferior do revestimento. Trincas por deslizamento das camadas também foram observadas em um projeto de recapeamento de uma camada asfáltica (Figura 3), em que o defeito alcançou aproximadamente $40 \%$ da extensão do projeto pouco tempo depois da conclusão da obra (Charmot et al., 2005). 


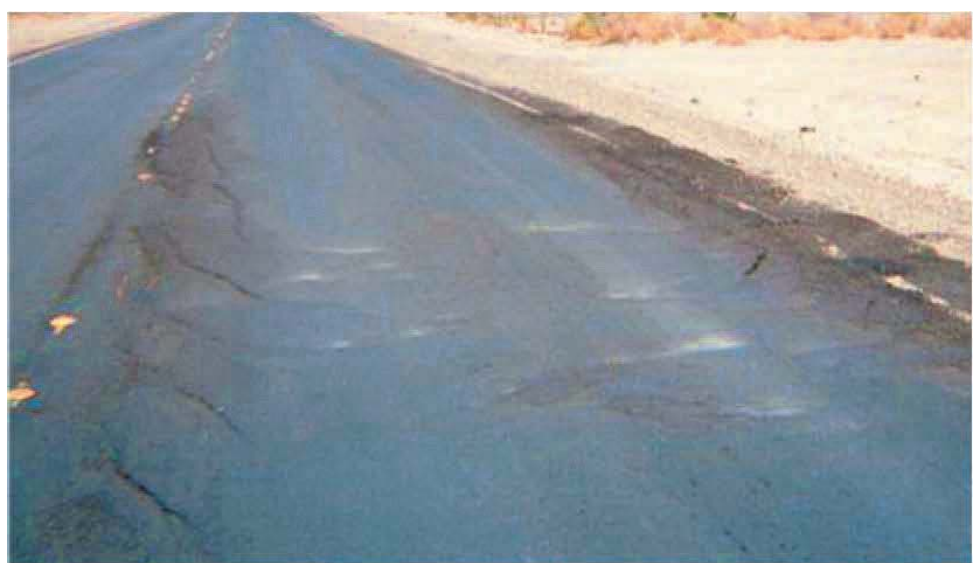

Figura 3. Trincas por deslizamento na interface inferior do revestimento asfáltico de uma rodovia em Nevada, USA (Chamort et al., 2005)

Sutanto (2010) aponta que as falhas de aderência na pavimentação podem ser categorizadas em três tipos de modo de separação entre as camadas: Cisalhamento (modo A), tração (modo B) e cisalhamento mais tração (modo C), ilustrados na Figura 4.

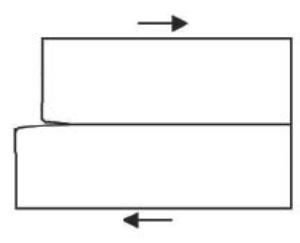

Modo A Cisalhamento

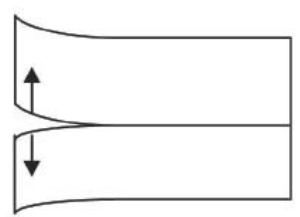

Modo B

Tração

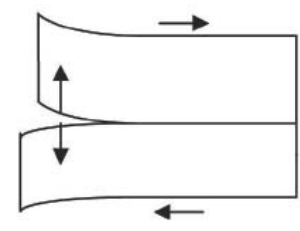

Modo C

Cisalhamento + Tração

Figura 4. Modos de separação entre camadas (adaptado de Sutanto, 2010)

A separação por cisalhamento (modo A) pode ocorrer devido à variação de temperatura ou ao tráfego. A contração e expansão da camada asfáltica, devido ao gradiente térmico, pode promover tensões de cisalhamento capazes de levar a interface à ruptura. Quanto ao tráfego, De Beer et al (1999) verificaram que o livre passar da roda sobre o pavimento pode promover altas tensões horizontais de contato que, em alguns casos, atingiram $20 \%$ das tensões verticais. Além disso, movimentos de frenagem, aceleração e conversão podem provocar esforços horizontais que contribuem para o aumento das tensões cisalhantes nas interfaces (Raab e Partl, 2004b).

A separação por tração (modo B) pode ocorrer como resultado o descolamento das camadas, no entanto esse tipo de fenômeno é raramente encontrado nos pavimentos. O modo C está ligado a camadas finas de revestimento e sua baixa capacidade de transferências de cargas horizontais, com concentração de tensões que provocam empenamento no revestimento, resultando no descolamento entre as camadas. Esse modo de separação também é raramente encontrado nas estruturas (Raab e Partl, 2004b). 
Além das falhas em pavimentos relacionadas diretamente ao descolamento das camadas, os mecanismos de falhas previstos no dimensionamento (trinca por fadiga e deformação permanente) também são afetados pela condição de interface, como descrito no item 2.2.2. Devido à dificuldade de alcançar em campo a condição ideal de aderência entre as camadas, estudos para investigar os efeitos dessa condição de contato no desempenho do pavimento ainda se fazem necessários.

\subsubsection{Modelagem da interface entre camadas}

Em função dos efeitos da condição de interface das camadas no desempenho do pavimento, a determinação de um modelo representativo dessas interfaces para caracterizar sua condição de aderência é essencial ao dimensionamento e avaliação dos pavimentos.

A solução de Burmister aborda apenas as duas condições extremas de interface: aderência total, que é desejável, e aderência nula, que é improvável devido à existência de atrito entre as camadas (Brown e Brunton, 1984). Devido a diferença dessas condições para a situação real de aderência entre as camadas, Uzan et al (1978) introduziram um método para a solução de um sistema elástico de camadas para uma condição de aderência parcial. Os autores adotaram o modelo constitutivo de Goodman apresentado em 1968, representado pela Equação 6, para representar a condição de interface:

$$
\tau=K_{S}(\Delta U)
$$

em que $\tau$ representa a tensão de cisalhamento da interface (MPa), $\Delta U$ é o deslocamento horizontal relativo na interface $(\mathrm{mm})$ e $K_{S}$ é o módulo de reação cisalhante da interface $(\mathrm{MPa} / \mathrm{mm})$. O módulo de reação cisalhante pode ser determinado em ensaios de cisalhamento direto na interface, sendo igual a inclinação da curva tensão cisalhante $x$ deslocamento.

Romanosh e Metcalf (2001a), ao analisar uma interface entre camadas asfálticas, dividiram a curva tensão cisalhante $x$ deslocamento em três estágios (Figura 5 (a)):

- Cisalhamento linear (0-1): a relação tensão-deslocamento cisalhante é definida por um comportamento linear e se estende até que a resistência máxima ao cisalhamento seja alcançada. 
- Pós-ruptura (1-2): a resistência cisalhante da interface é alcançada, contudo as camadas adjacentes ainda não estão completamente decoladas e apresentam alguma resistência ao cisalhamento.

- Estágio de fricção (2-3): as camadas adjacentes já não apresentam ligação o deslocamento é definido pelo atrito entre elas.

Devido a condição cíclica do carregamento na interface e a aparição única do estágio dois, o modelo constitutivo da interface entre as camadas apresentado por Romanoschi e Metcalf (2001a) classifica a relação tensão-deslocamento em dois estágios (Figura 5 (b)). No primeiro estágio, o deslocamento é proporcional à tensão cisalhante na interface e se estende até que esta alcance a tensão cisalhante resistida pela interface. No segundo estágio, o deslizamento entre as camadas é definido unicamente pelo coeficiente de atrito entre elas.

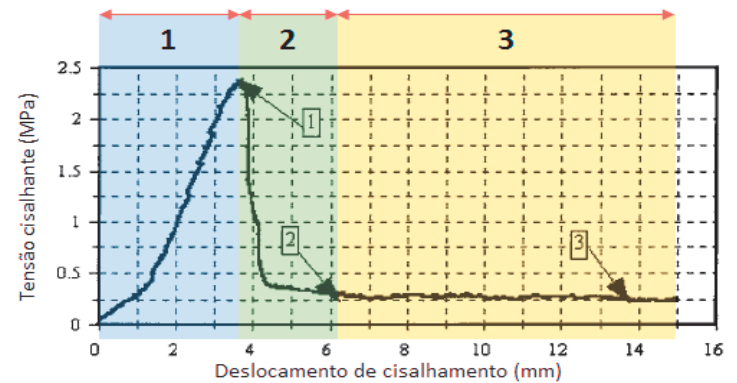

(a)

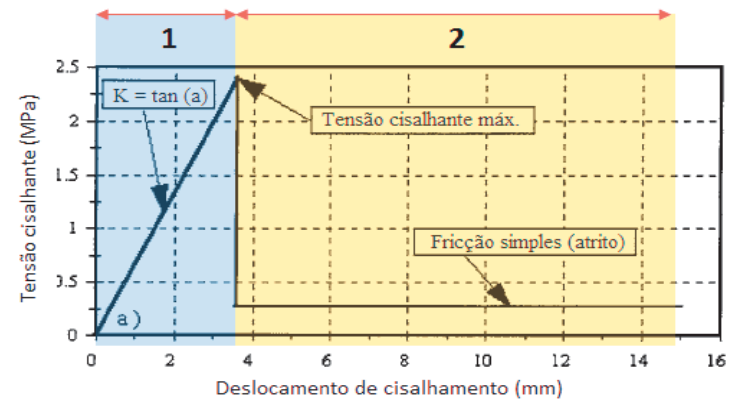

(b)

Figura 5. (a) Curva tensão x deslocamento típica, (b) modelo constitutivo de dois estágios (adaptado de Romanoschi e Metcalf, 2001a)

O parâmetro da elasticidade de cisalhamento horizontal (AK), representado pela Equação 7, foi introduzido ao software BISAR (SHELL, 1998) como o principal parâmetro de deslocamento relativo entre as camadas do pavimento.

$$
A K=\frac{\text { Deslocamento horizontal relativo }}{\text { Tensão cisalhante na interface }}\left[\mathrm{m}^{3} /_{N}\right]
$$


Tal parâmetro é o inverso do módulo de reação cisalhante. Essa variável associa-se matematicamente ás características dos materiais através do parâmetro de atrito $\alpha(0 \leq \alpha \leq 1)$, definido por meio da Equação 8 (Sutanto, 2010):

$$
\alpha=\frac{A K}{A K+\frac{1+v}{E} \cdot a}
$$

Em que $a$ é o raio de aplicação de carga em metros, $E$ e $v$ são o módulo de resiliência (Pa) e o coeficiente de Poisson da camada acima da interface, respectivamente.

\subsubsection{Os efeitos da aderência entre camadas no desempenho dos pavimentos}

A premissa de uma aderência perfeita entre as camadas permite estimar o comportamento estrutural de um pavimento sob a condição de total transmissão de esforços de uma camada para a outra, como um sistema único. No entanto, a falta de aderência nas interfaces implica em uma mudança na distribuição dos esforços atuantes no pavimento, agora analisado por camadas, como mostra Tschegg (1995) por meio de uma analogia com vigas bi apoiadas (Figura 6).
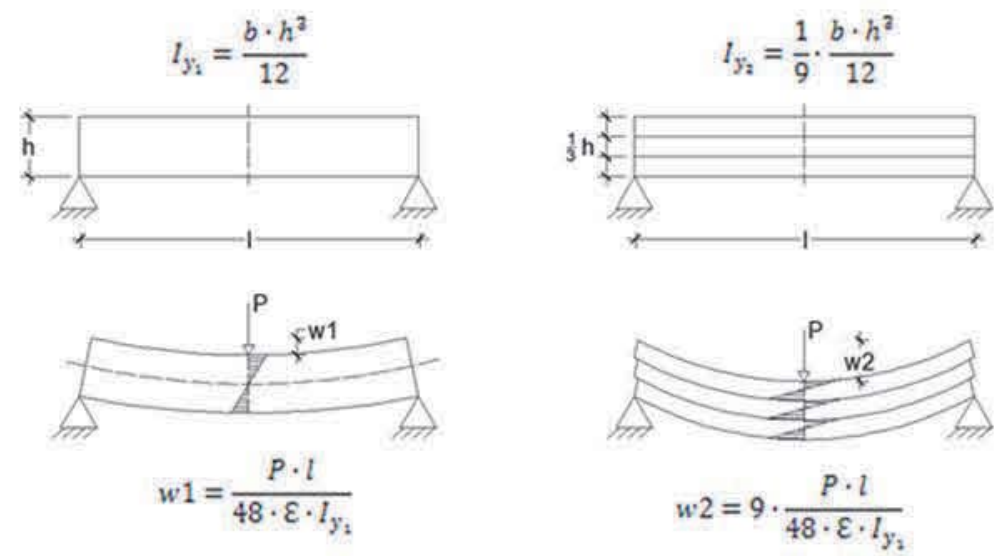

Figura 6. Analogia de um sistema de camadas com vigas bi apoiadas sob diferentes condições de aderência (adaptado de Tschegg, 1995)

Os efeitos da variação da condição de interface entre camadas no estado de tensões e deformações do pavimento e, consequentemente, na sua capacidade de suportar as solicitações do tráfego têm sido estudados por diversos pesquisadores (Uzan et al., 1978; Kruntcheva et al., 2005; Romanoschi, 1999; Ziari e Khabiri, 2007; Sutanto, 2010; Sun, 2011 e Wu, 2017).

Uzan et al (1978) analisaram um pavimento composto por 4 camadas e verificaram a influência da condição de contato entre a camada superficial (asfáltica) e a camada de binder. Os autores simularam, com o programa BISAR, a resposta mecânica sob diferentes condições de aderência 
entre as duas camadas (aderência total e livre deslizamento). Os resultados obtidos mostraram que a tensão horizontal de tração no fundo da camada superficial sofreu um aumento considerável mediante a perda de aderência entre a camada superficial e a camada asfáltica inferior (binder).

O mesmo foi verificado por Hu e Walubita (2010) que, por meio de um programa de elementos finitos ANSYS, também verificaram os efeitos da aderência entre a camada superficial e a camada de binder. Os autores analisaram duas estruturas diferentes quanto as propriedades mecânicas (modulo de resiliência e coeficiente de Poisson) e no caso extremo, a perda de aderência entre as duas camadas resultou em uma deformação horizontal no fundo da camada superficial aproximadamente onze vezes maior. A variação, em magnitude, da deformação horizontal de tração na camada superficial também foi verificada por Hariyadi et al. (2013), no entanto os autores indicam que a condição de interface pouco influencia na localização da deformação crítica ao longo da camada.

Problemas relacionados ao estado de colagem na interface não ocorrem apenas entre duas camadas asfálticas, a camada de revestimento e a camada de ligação ou binder (Raab e Partl, 2004a). Ziari e Khabiri (2007) conduziram um estudo que consistiu na modelagem, utilizando o programa KENLAYER, de um pavimento composto por uma camada asfáltica superficial e uma intermediária (binder) assentadas em uma base granular. O programa utilizado permitiu aos autores considerarem as duas condições extremas de aderência nas interfaces (aderência total e aderência nula), aplicadas as duas interfaces (interfaces revestimento-binder e binderbase). A combinação das condições de contato aplicada às duas interfaces resultou em quatro casos analisados (Tabela 3).

Tabela 3. Casos de condições de aderência (adaptado de Ziari e Khabiri, 2007)

\begin{tabular}{ccc} 
CASOS & $\begin{array}{c}\text { Interface } \\
\text { Revestimento/binder }\end{array}$ & $\begin{array}{c}\text { Interface } \\
\text { binder/base }\end{array}$ \\
\hline A & 1 & 1 \\
B & 1 & 0 \\
C & 0 & 1 \\
D & 0 & 0 \\
\hline
\end{tabular}

Em que 1 representa a condição de completa aderência e 0 a condição de livre deslizamento. $\mathrm{O}$ estudo mostrou que a condição de interface afetou significativamente o estado de deformação de toda a estrutura do pavimento, com a perda de aderência na primeira interface resultando em 
um aumento das deformações horizontais de tração na fibra inferior da camada asfáltica. No entanto, a perda de aderência da interface inferior (binder-base) foi responsável pelo maior aumento dessas deformações. Efeito semelhante também foi verificado pelos autores quanto à deformação vertical de compressão no topo do subleito, que apresentou seu valor mínimo sob condição de total aderência e seu valor máximo quando apenas a interface binder-base permitia o livre deslizamento entre as camadas.

Kruntcheva et al. (2005) desenvolveram um estudo teórico sobre os efeitos da condição de interface no comportamento mecânico de um pavimento com estrutura semelhante à estudada por Ziari e Khabiri (2007). Os autores consideraram além das condições extremas de aderência, uma condição parcial de contato entre as camadas. Por meio do programa BISAR, a condição parcial de aderência foi definida pelo módulo de reação ao cisalhamento horizontal (K). Os resultados indicaram que a variação da aderência entre a camada de binder e base chegou a reduzir a vida do pavimento em aproximadamente $80 \%$.

Romanosch e Metcalf (2001b) simularam os efeitos da aderência no estado de tensões de um pavimento com uma camada de base, por meio do programa de elementos finitos ABAQUS. Além das duas condições extremas de aderência na interface, os autores modelaram uma condição parcial, definida indiretamente pelo parâmetro $\mathrm{K}$, obtido por meio do ensaio de cisalhamento direto na interface. A camada de rolamento sofreu predominantemente deformações de compressão quando as camadas asfálticas estavam perfeitamente aderidas e de tração para as outras condições de interface analisadas. Os resultados ainda mostraram que a camada de binder sofreu a máxima deformação de tração quando apenas a segunda interface não apresentou ligação entre as camadas. A deformação vertical de compressão no topo do subleito também foi afetada pela interação das camadas e apresentou o máximo valor sob a condição de contato perfeito nas duas interfaces e foi mais afetada pela interação na interface binder-base, assim como verificado por Ziari e Khabiri (2007).

Wu et al. (2017) utilizaram o parâmetro de elasticidade do cisalhamento horizontal ( $A K$ ) para simular a condição de aderência entre uma camada asfáltica e uma base tratada com cimento. Os autores modelaram três condições de contato na interface (aderência total, parcial e nula) e analisaram a deflexão, a tensão de tração por flexão na fibra inferior da camada asfáltica e a tensão de cisalhamento no topo da camada de base, determinando a sensibilidade dessas respostas estruturais à rigidez e espessura das camadas, sob as diferentes condições de interface. Foi verificado que perda da aderência entre as camadas chegou a alterar as tensões da camada 
asfáltica do estado de compressão para tração. Os resultados ainda indicaram que, sob as condições de aderência total e parcial, a deflexão é mais sensível à espessura da base que aos outros fatores, já para a condição de aderência nula, a maior sensibilidade foi ao módulo de resiliência da camada de base.

\subsubsection{Interface no ABAQUS}

O programa computacional ABAQUS, que utiliza o método dos elementos finitos, foi lançado inicialmente para aplicações não lineares e gradualmente foi capacitado para abordagens lineares.

As interfaces entre superfícies podem ser modeladas por meio dos recursos de interação de interface existentes no ABAQUS que, são comumente utilizados para modelar o contato entre dois corpos, rígidos ou elásticos (Tsai e Mall, 2000; Jackson e Green, 2005; Yoo et al., 2006).

Nesses recursos, as duas superfícies em contato precisam ser classificadas como master e slave. Para alcançar uma melhor simulação de interface, a superfície slave deve ser a face com a malha mais refinada e nos casos em que as densidades das malhas são similares, a face associada ao material menos rígido. A superfície slave desliza ao longo da master, sofrendo ou não deformação quando esta última é definida como flexível ou rígida, respectivamente. Em cada passo da análise, o programa identifica a menor distância entre os nós de ambas as superfícies e o movimento relativo entre eles (ABAQUS, 2014a).

A superfície slave pode acompanhar, penetrar ou se separar da face master em função da relação entre a pressão e o espaço entre os elementos em contato. No caso dos pavimentos, cujas camadas estão sempre em contato, a relação entre a tensão e o deslocamento na interface podem ser modeladas no ABAQUS com os algoritmos de contato já definidos no programa ou podese implementar uma sub-rotina definida pelo usuário (Romanosch, 1999).

O programa permite, através da opção de contato Tie Constraint, condicionar o movimento de cada nó de uma superfície ao movimento do nó mais próximo pertencente a outra superfície com a qual faz contato (ABAQUS, 2014b), ou seja, não há movimento relativo entre os nós. Para analises estruturais, isso implica na restrição dos graus de liberdade de translação e rotação do elemento. A utilização dessa ferramenta representaria a condição de perfeita aderência entre as superfícies estudadas. 
O comportamento da interface entre as duas camadas dos pavimentos também pode ser modelado no ABAQUS com o modelo de Coulomb. O conceito básico desse modelo é relacionar a tensão de cisalhamento máxima permitida na interface com a pressão de contato entre as camadas.

Na forma básica do modelo de Coulomb, duas superfícies em contato podem transmitir tensões de cisalhamento até uma certa magnitude $\left(\tau_{\text {crit }}\right)$ antes de começarem a se deslocar entre si, como pode ser visto na Figura 7, onde as linhas sólida e pontilhada mostram o comportamento da interface antes e depois que tensão cisalhante atinge a tensão crítica, respectivamente.

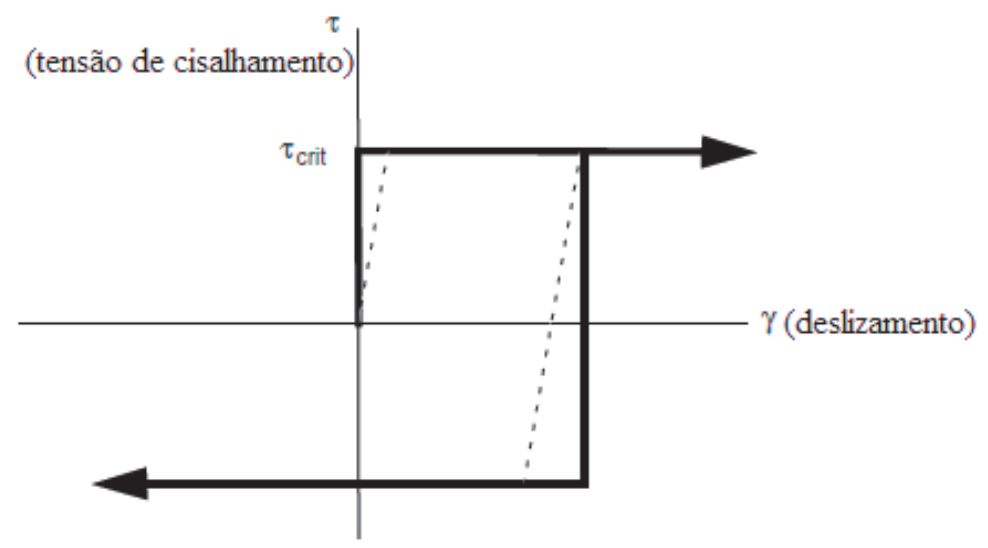

Figura 7. Tensão de cisalhamento na interface $\mathrm{x}$ deslizamento entre as superfícies no modo Friction (ABAQUS, 2014a)

O modelo de Coulomb define a tensão crítica de cisalhamento, como uma fração da pressão de contato entre as superfícies ( $p$ ), como representado na Equação 9.

$$
\tau_{c r i t}=\mu p
$$

em que o $\mu$ é o coeficiente de atrito, normalmente associados a valores entre 0 e 1 , e considerado o mesmo em todas as direções (coeficiente isotrópico).

A modelagem da interface entre camadas ainda pode assumir que há um deslocamento elástico relativo, proporcional à tensão tangencial, enquanto a tensão crítica $\left(\tau_{\text {crit }}\right)$ não for alcançada. Nesse caso, a relação tensão-deslocamento seria definida pelo módulo de reação cisalhante $(K)$, que não depende da tensão normal à superfície, ou pelo deslocamento elástico máximo $\left(d_{\text {max }}\right)$ e tensão cisalhante crítica, uma vez que $k=\tau_{\text {crit }} / d_{\max }$. Quando a $\tau_{\text {crit }}$ é alcançada, a interface passa a ser definida pela condição de atrito descrita acima. 
Essa representação da interface foi chamada de "stick condition" por Romanoschi (1999) que utilizou o ABAQUS para simular uma interface entre camadas com aplicação de pintura asfáltica de ligação. A modelagem utilizou dados obtidos com o ensaio de cisalhamento direto na interface e os resultados de tensões e deformações se apresentaram significativamente similar aos resultados encontrados por meio da modelagem com o modelo de cisalhamento de Coulomb. A aproximação entre os resultados aponta a possibilidade de representar a interface entre as camadas por meio do parâmetro $K$, bem como pelo modelo de Coulomb, como feito neste trabalho. 


\section{MÉTODO}

As estruturas dos pavimentos abordadas neste trabalho foram modeladas com uso do Método dos Elementos Finitos por meio do software ABAQUS/CAE 6.14, o qual permitiu a estimativa do comportamento mecânico das estruturas sob diferentes condições de aderência entre as camadas.

A modelagem dos pavimentos sob carregamento do tráfego foi feita a partir das características gerais do problema como a geometria da estrutura, as características de carregamento e as condições de contorno.

\subsection{Estruturas dos pavimentos}

O estudo foi realizado com três configurações diferentes de pavimentos. A Estrutura I é formada por quatro camadas, contendo apenas uma camada asfáltica assentada sobre as camadas de base, sub-base e subleito (Figura 8). A Estrutura II, derivada da Estrutura I, substitui a camada asfáltica única por duas camadas asfálticas de mesmo material e espessuras equivalentes (Figura 9).

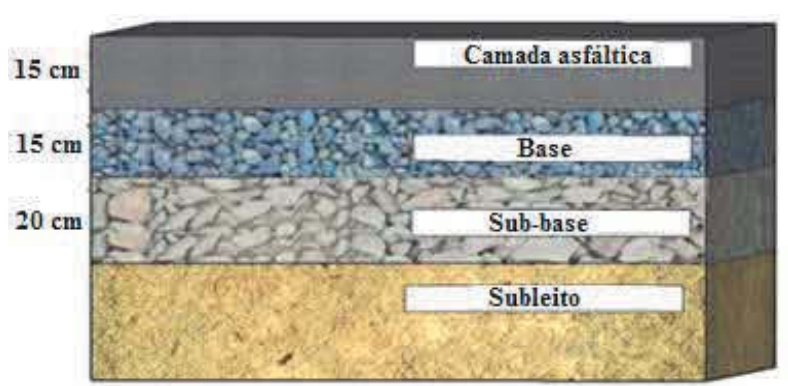

Figura 8. Estrutura I (adaptado de PACHECO, 2014)

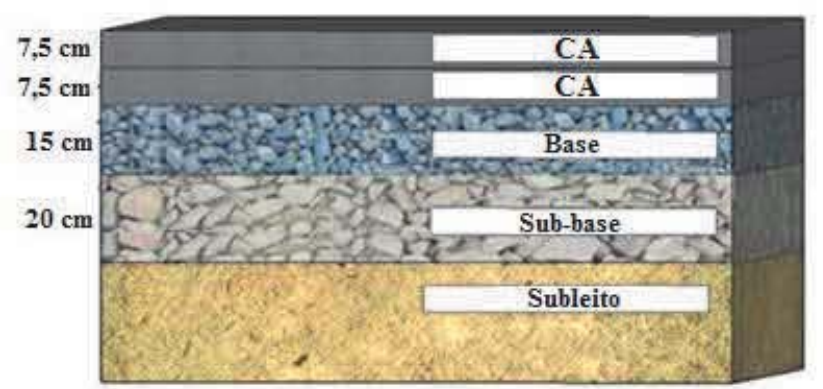

Figura 9. Estrutura II (adaptado de PACHECO, 2014) 
A Estrutura III consiste em um pavimento com duas camadas de material asfáltico sobrepostas às camadas de base, sub-base e subleito, no entanto, toma a camada asfáltica inferior como uma camada de binder, com propriedades distintas da camada superior (Figura 10).

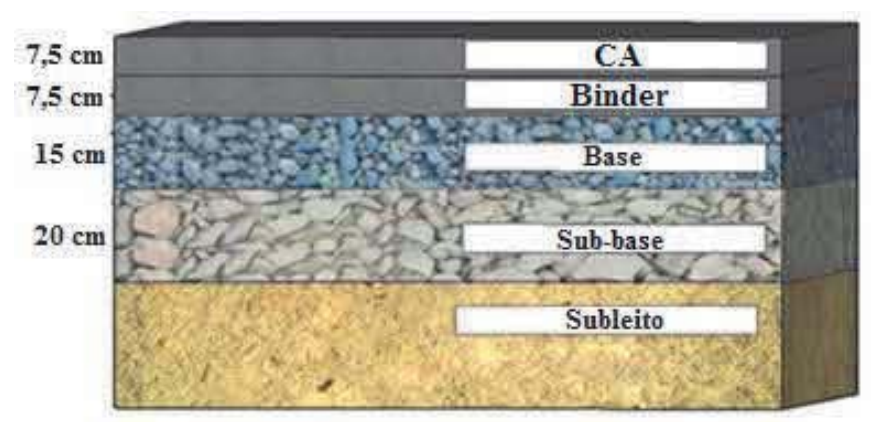

Figura 10. Estrutura III (adaptado de PACHECO, 2014)

Para todas as estruturas apresentadas, três diferentes módulos de resiliência (MR) foram atribuídos às camadas de concreto asfáltico, ou seja, estruturas com concreto asfáltico de baixo, médio e elevado módulo de resiliência. Para a camada de base, foram considerados dois materiais diferentes, uma brita graduada simples (BGS) e uma brita graduada tratada com cimento (BGTC). A sub-base é composta por macadame seco e o subleito é um solo arenoso. A configuração geral dos pavimentos analisados e os valores de módulo de resiliência e coeficiente de Poisson $(\boldsymbol{\mu})$ de cada camada são apresentados nas Tabelas 4, 5 e 6.

Tabela 4. Estrutura dos pavimentos com uma camada de revestimento

\begin{tabular}{|c|c|c|c|c|}
\hline \multicolumn{5}{|c|}{ Estrutura I } \\
\hline Camada & Material & Espessura (cm) & MR (Mpa) & $v$ \\
\hline Camada Asfáltica & $\mathrm{CA}$ & 15 & $3000 / 7000 / 11000$ & 0,3 \\
\hline Base & BGS/BGTC & 15 & $300 / 6000$ & $0,4 / 0,35$ \\
\hline Sub-base & Macadame Seco & 20 & 200 & 0,4 \\
\hline Subleito & Solo arenoso & $\infty$ & 100 & 0,45 \\
\hline
\end{tabular}

Tabela 5. Estruturas dos pavimentos com duas camadas iguais de revestimento

\begin{tabular}{ccccc}
\hline \multicolumn{5}{c}{ Estrutura II } \\
\hline Camada & Material & Espessura (cm) & MR (Mpa) & v \\
\hline Camada Asfáltica 1 & CA & 7,5 & $3000 / 7000 / 11000$ & 0,3 \\
Camada Asfáltica 2 & CA & 7,5 & $3000 / 7000 / 11000$ & 0,3 \\
Base & BGS/BGTC & 15 & $300 / 6000$ & $0,4 / 0,35$ \\
Sub-base & Macadame Seco & 20 & 200 & 0,4 \\
Subleito & Solo arenoso & $\infty$ & 100 & 0,45 \\
\hline
\end{tabular}


Tabela 6. Estruturas dos pavimentos com duas camadas diferentes de revestimento

\begin{tabular}{ccccc}
\hline \multicolumn{5}{c}{ Estrutura III } \\
\hline Camada & Material & Espessura (cm) & MR (Mpa) & v \\
\hline Camada Asfáltica 1 & CA & 7,5 & $3000 / 7000 / 11000$ & 0,3 \\
Camada Asfáltica 2 & Binder & 7,5 & 1800 & 0,3 \\
Base & BGS/BGTC & 15 & $300 / 6000$ & $0,4 / 0,35$ \\
Sub-base & Macadame Seco & 20 & 200 & 0,4 \\
Subleito & Solo arenoso & $\infty$ & 100 & 0,45 \\
\hline
\end{tabular}

As interfaces entre a camada asfáltica e a camada de base, para todas as estruturas, e entre as duas camadas asfálticas, para as Estruturas II e III, foram modeladas sob três condições de aderência diferentes:

- Aderência completa (sem deslocamento relativo)

- Aderência parcial

- Aderência nula

Para avaliar a sensibilidade da resposta estrutural dos pavimentos às condições de interação entre as camadas, as três condições de aderência foram combinadas em nove casos diferentes, apresentados na Tabela 7. As interfaces não contidas na Tabela 4 foram admitidas com aderência total entre as partes (condição 1 de aderência) e o pavimento com a Estrutura I, por ter uma camada única camada asfáltica, foi modelado apenas nos casos A, D e G.

\begin{tabular}{ccc}
\multicolumn{3}{c}{ Tabela 7. Condições de aderência nas interfaces } \\
\hline \multicolumn{3}{c}{ Condições de aderência entre as camadas } \\
\hline \multirow{2}{*}{ Casos } & Camada asfáltica 1 & Camada asfáltica 2 \\
\cline { 2 - 3 } & Camada asfáltica 2 & Base \\
\hline A & 1 & 1 \\
B & 0,5 & 1 \\
C & 0 & 1 \\
D & 1 & 0,5 \\
E & 0,5 & 0,5 \\
F & 0 & 0,5 \\
G & 1 & 0 \\
H & 0,5 & 0 \\
I & 0 & 0 \\
\hline
\end{tabular}




\subsection{Modelagem}

Para a determinação das tensões, deformações e deslocamentos que ocorrem no pavimento, foi utilizado o Método de Elementos Finitos por meio de uma modelagem tridimensional das estruturas no programa ABAQUS.

\subsubsection{Estrutura e materiais}

A modelagem da geometria do problema baseia-se em um sistema cartesiano de referência no espaço, (Figura 11). O eixo X corresponde à direção de tráfego da rodovia, o eixo Y à direção transversal da rodovia e o eixo $\mathrm{Z}$ normal à superfície de rolamento.

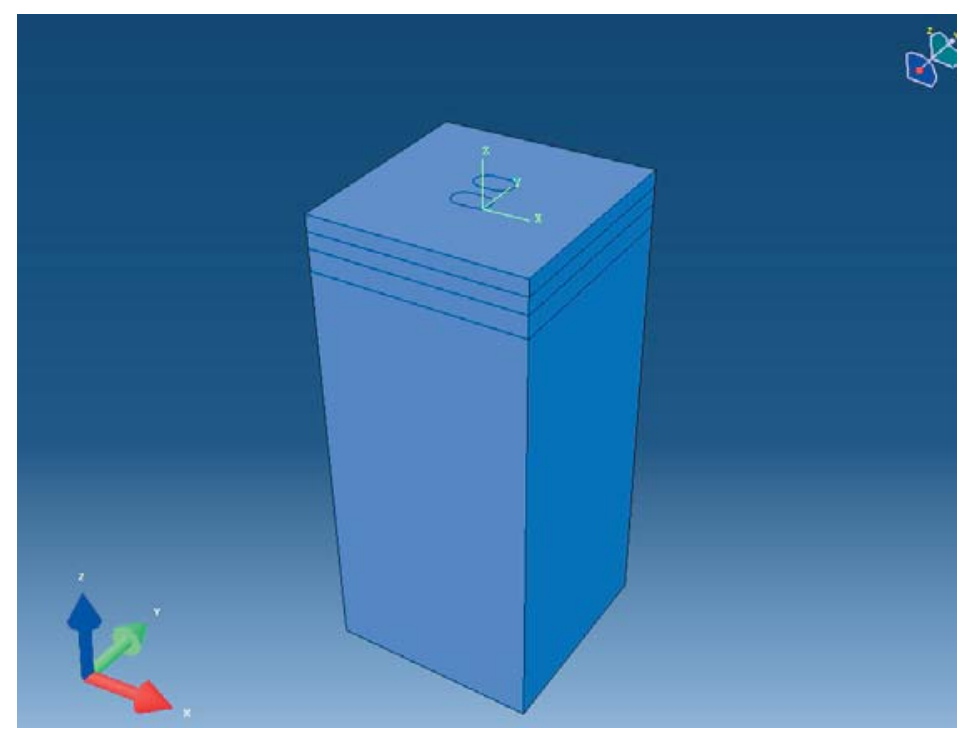

Figura 11. Disposição espacial da estrutura-orientação dos eixos

Cada camada do pavimento foi implementada separadamente como uma parte sólida. Devido aos tempos computacionais atrelados às simulações, foi considerada a simetria em $\mathrm{X}$ nos analisados. As dimensões do pavimento no plano XY foram fixadas em dois metros de largura e dois metros de comprimento. O subleito, considerado um espaço semi-infinito, pode ser modelado como elementos infinitos ou representado por uma camada suficientemente grande. Utilizou-se, neste trabalho, uma camada com espessura de 4 metros, como é adotado no programa FEPAVE2 (Medina e Motta, 2015).

Os materiais que compõe as camadas dos pavimentos foram admitidos como homogêneos, isotrópicos e com um comportamento elástico linear, o que faz do módulo de resiliência e o coeficiente de Poisson os principais parâmetros que descrevem o comportamento mecânico desses materiais. 


\subsubsection{Carregamento}

As cargas do tráfego foram modeladas com a configuração geométrica de um eixo simples de rodas duplas com magnitude da carga por roda e da pressão de inflação do pneu foram, respectivamente, 48,5 KN e a pressão de inflação de $720 \mathrm{KPa}$, como utilizado por De Beer et al. (1997).

A geometria da superfície de contato entre o pneu e o pavimento seguiu a recomendação de Huang (2004). O autor aponta uma elipse, modelada como a união entre um retângulo e duas semicircunferências, como a melhor forma geométrica de representar a área de aplicação das cargas do tráfego (Figura 12).
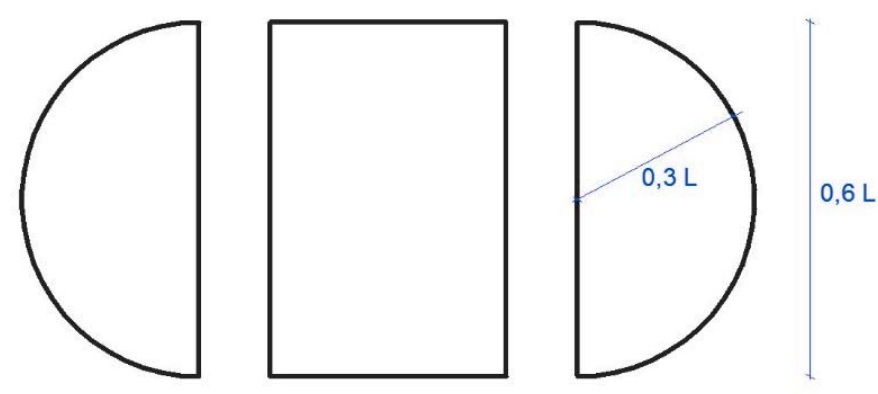

L

Figura 12. Área de contato pneu-pavimento (adaptado de HUANG, 2004)

A pressão de contato entre o pneu e o pavimento foi considerada uniforme e o carregamento implementado levou em consideração unicamente as componentes verticais das cargas do tráfego. Devido à simetria do problema, apenas o semieixo foi considerado nas simulações (Figura 13).

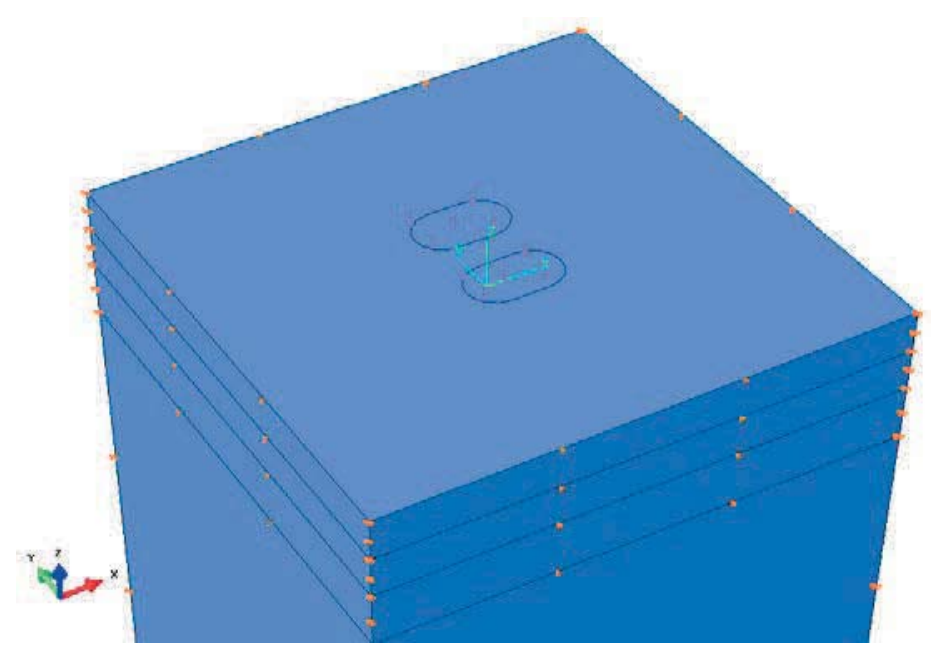

Figura 13. Carregamento empregado nas modelagens 


\subsubsection{Condições de contorno}

Três condições de contorno foram aplicadas na modelagem das estruturas de pavimentos analisadas neste trabalho. O fundo do subleito foi engastado, ou seja, impediu-se qualquer movimentação rotacional e de translação em todas as direções. As faces laterais no plano XZ das camadas foram impedidas de se movimentar no eixo $\mathrm{Y}$ e as faces laterais no plano $\mathrm{YZ}$, no eixo X (Figura 14).

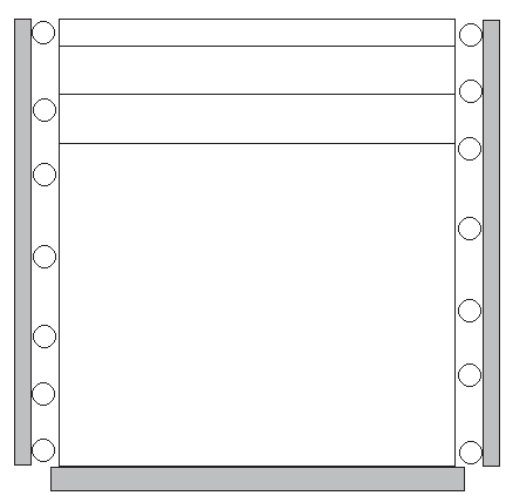

PLANO XZ

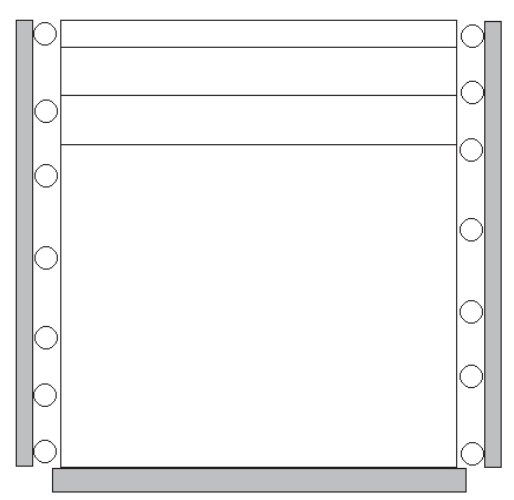

PLANO YZ

Figura 14. Condições de contorno das estruturas modeladas

\subsubsection{Malha de elementos finitos}

A modelagem das estruturas dos pavimentos utilizou uma malha não homogênea, com sua maior densidade de elementos concentrada nas camadas asfálticas. As dimensões dos elementos finitos aplicados a cada camada do pavimento podem ser vistas na Figura 15.

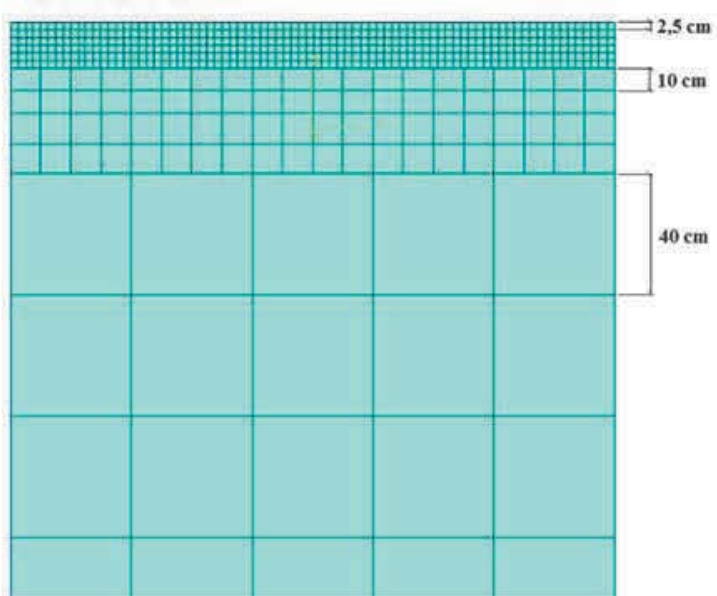

Figura 15. Tamanho dos elementos finitos por camada 
A malha empregada é composta por elementos denominados C3D8R. Essa nomenclatura representa elementos sólidos contínuos que possuem 8 nós e têm os dados de coordenadas fora dos nós obtidos por meio de uma interpolação linear.

\subsubsection{Interação entre as camadas}

A interação entre as camadas dos pavimentos foi modelada por meio dos instrumentos do ABAQUS que permitem definir as características de contato entre duas superfícies. Diante das diferentes ferramentas oferecidas pelo programa, fez-se uso da opção "tie constraint" para impedir o movimento relativo entre as camadas, o que representa a condição de completa aderência entre elas.

Nos casos em que a aderência entre as camadas é nula, foi estabelecido o contato entre as superfícies por meio do modo "Simple Friction", baseado no modelo de Coulomb, e se aplicou a condição de livre deslizamento entre as partes, ou seja, coeficiente de atrito $(\mu)$ igual a zero.

A condição de interação parcial também foi modelada com o modelo de Coulomb, em função da similaridade com o modelo stick condition, segundo os resultados obtidos por Romanosh (1999). A condição parcial se deu pela utilização de um coeficiente de atrito parcial, entre 0 e 1 , entre as camadas $(\mu=0,5)$.

\subsection{Dados de saída do ABAQUS}

Para uma análise mais completa do comportamento estrutural dos pavimentos, sob diferentes condições de aderência, foi obtida a disposição geral das tensões, deformações e deslocamentos ocorrentes nas estruturas dos pavimentos quando submetida ao carregamento do tráfego.

Por meio dos resultados obtidos nas simulações computacionais foram avaliadas as tensões, deformações e deslocamentos mais representativos quanto aos critérios de fadiga e deformação plástica do subleito, ou seja, o deslocamento vertical máximo no topo do revestimento $\left(\delta_{v}\right)$, a deformação horizontal de tração na face inferior das camadas asfálticas e cimentadas $\left(\varepsilon_{h}\right)$ e a deformação vertical por compressão no topo do subleito $\left(\varepsilon_{v}\right)$.

As respostas estruturais determinadas foram empregadas nos modelos de desempenho à fadiga e à deformação permanente. $\mathrm{O}$ cálculo das solicitações do tráfego admissíveis à fadiga $\left(N_{f a d}\right)$, para as camadas asfálticas e cimentadas, foi realizado por meio de equação desenvolvida pela empresa Austin Research Engineers (A.R.E., 1975). Uma vez que o módulo de rigidez não 
depende da condição de aderência entre as camadas, a escolha desse modelo se deu por estar em função apenas da deformação horizontal de tração.

$$
N_{\text {fad }}=9,73 * 10^{-15} \varepsilon_{h}^{-5,16}
$$

A vida do pavimento à deformação permanente $\left(N_{\text {def }}\right)$ foi calculada por meio do modelo do SHELL OIL (SHELL, 1998), baseados nos valores de $\varepsilon_{v}$. Os parâmetros $a$ e $b$ da função de transferência de deformação permanente foram relacionados à um nível de confiança de 50\%, comumente utilizado (Equação 10).

$$
N_{\text {def }}=\left(\frac{0,028}{\varepsilon_{v}}\right)^{4}
$$




\section{RESULTADOS: SIMULAÇÕES COMPUTACIONAIS}

A modelagem definida no Capítulo 3 foi utilizada para simular o comportamento do pavimento e estimar o campo de tensões e deformações da estrutura sob os nove casos de aderência entre camadas considerados. Os resultados apresentados nesse capítulo apontam a influência das condições de interface na distribuição das tensões e deformações na estrutura do pavimento flexível com base de BGS e BGTC.

As análises realizadas apresentaram simetria na distribuição das tensões, deformações e deslocamentos das estruturas, como pode ser visto na Figura 16, o que permitiu a exposição unilateral dos resultados.

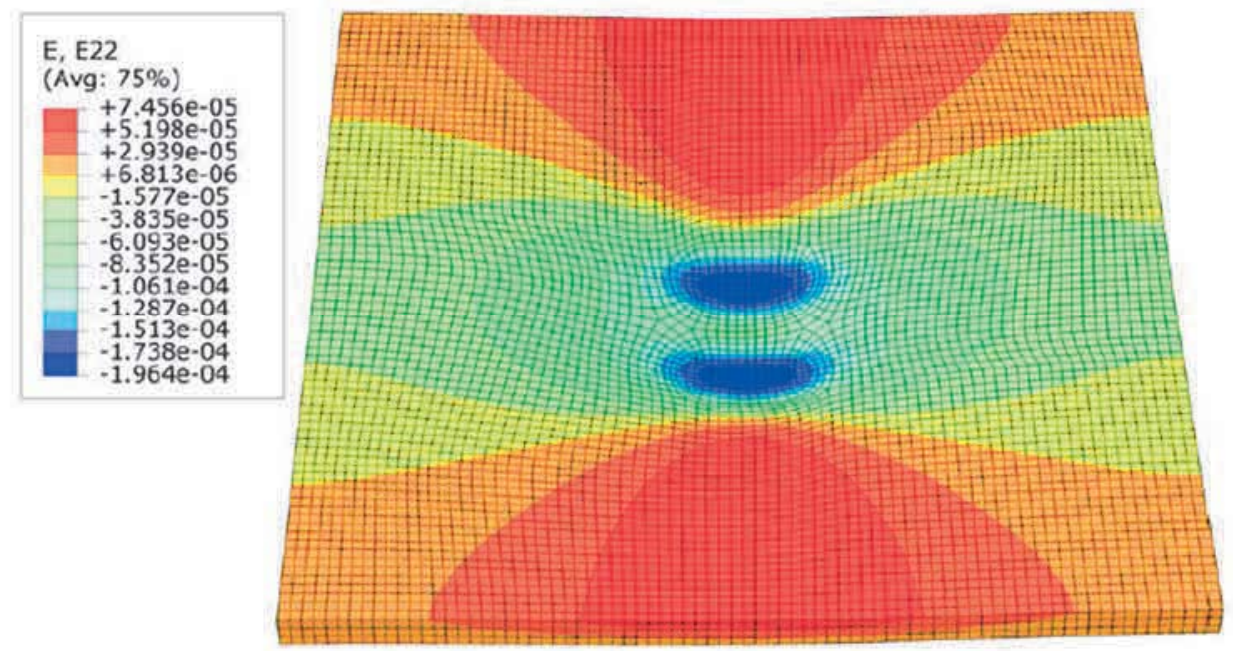

Figura 16. Simetria do quadro de deformações

As deformações, quando no plano horizontal, foram calculadas transversal e longitudinalmente. No entanto, apenas a maior deformação entre elas é apresentada neste capítulo.

\subsection{Respostas estruturais do pavimento com base granular simples}

\subsubsection{Estrutura I}

A influência da condição de aderência na deflexão da superfície do pavimento com base composta de BGS e BGTC, podem ser verificadas nas Figuras 17 e 18. Em ambas as situações, a condição de perfeita aderência entre a camada asfáltica e a base do pavimento resultou nas menores deflexões. A deflexão da superfície foi mais afetada no pavimento com base de BGTC e nesse, a perda, total ou parcial, da aderência nessa interface entre o revestimento e a base do pavimento implicou em um aumento da deflexão vertical de aproximadamente $40 \%$. 


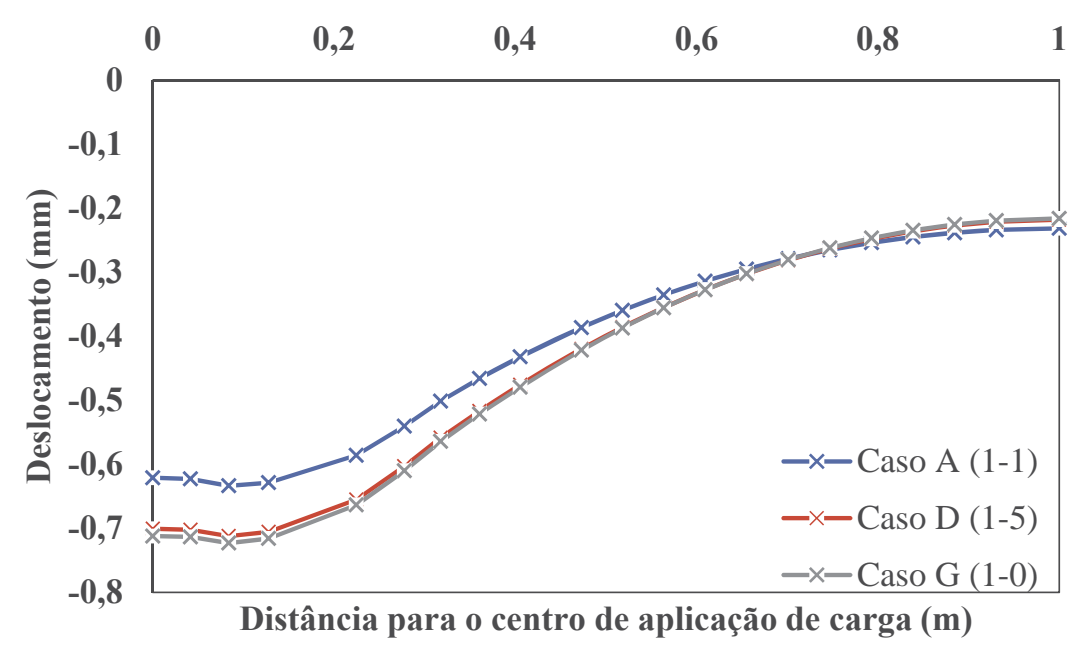

Figura 17. Curva de deflexão da estrutura com BGS

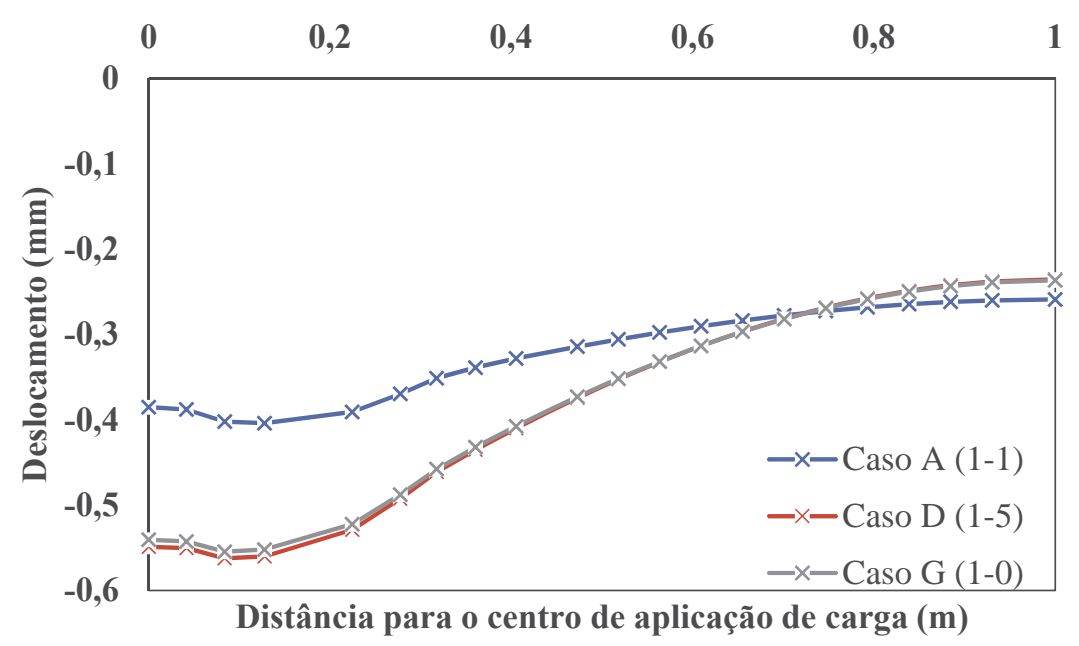

Figura 18. Curva de deflexão da estrutura com BGTC

Os valores máximos de deformação e o número de repetições de carregamento que levam à falha da estrutura, para os diferentes níveis de rigidez do material asfáltico e diferentes condições de aderência entre camadas, estão apresentados na Tabela 8. Os resultados mostram que, para os três níveis de rigidez do material asfáltico, a condição de perfeita aderência entre as camadas (Caso A) resulta em menor deformação horizontal na camada asfáltica e menor deformação vertical no topo do subleito. 
Tabela 8. Deformações máximas da Estrutura I com base de BGS (micro deformações)

\begin{tabular}{cccccc}
\hline \multirow{2}{*}{ CASO } & \multirow{2}{\text{MR}}{} & \multicolumn{2}{c}{$\varepsilon$ máx. } & \multicolumn{2}{c}{ Vida do pavimento } \\
\cline { 3 - 6 } & $(\mathbf{M P a})$ & Revestimento & Subleito & Nfad & Ndef \\
\hline $\mathrm{A}(1-1)$ & & $242,3^{*}$ & $-224,6$ & $4,41 \mathrm{E}+04$ & $2,42 \mathrm{E}+08$ \\
$\mathrm{D}(1-5)$ & \multirow{2}{*}{000} & $301,6^{*}$ & $-284,3$ & $1,43 \mathrm{E}+04$ & $9,41 \mathrm{E}+07$ \\
$\mathrm{G}(1-0)$ & & $318,3^{*}$ & $-291,2$ & $1,08 \mathrm{E}+04$ & $8,55 \mathrm{E}+07$ \\
\hline $\mathrm{A}(1-1)$ & & $161,4^{*}$ & $-188,4$ & $3,59 \mathrm{E}+05$ & $4,88 \mathrm{E}+08$ \\
$\mathrm{D}(1-5)$ & \multirow{2}{*}{7000} & $187^{*}$ & $-228,1$ & $1,68 \mathrm{E}+05$ & $2,27 \mathrm{E}+08$ \\
$\mathrm{G}(1-0)$ & & $201,7^{*}$ & -241 & $1,14 \mathrm{E}+05$ & $1,82 \mathrm{E}+08$ \\
\hline $\mathrm{A}(1-1)$ & & $122,7^{*}$ & -167 & $1,48 \mathrm{E}+06$ & $7,90 \mathrm{E}+08$ \\
$\mathrm{D}(1-5)$ & \multirow{2}{*}{11000} & $137,6^{*}$ & $-195,9$ & $8,18 \mathrm{E}+05$ & $4,17 \mathrm{E}+08$ \\
$\mathrm{G}(1-0)$ & & $144,6^{*}$ & $-204,3$ & $6,33 \mathrm{E}+05$ & $3,53 \mathrm{E}+08$ \\
\hline
\end{tabular}

* Localização crítica

Os resultados da Tabela 9, mostram que a estrutura com base de BGTC também apresentou os menores valores de deformação nos casos de aderência completa na interface. Quando a interface revestimento-base perdeu aderência, a deformação na camada asfáltica (MR $=3000$ Mpa) variou expressivamente, quando passou do estado de compressão para tração.

Tabela 9. Deformações máximas da Estrutura I com base de BGTC (micro deformações)

\begin{tabular}{|c|c|c|c|c|c|c|}
\hline \multirow{2}{*}{ CASO } & \multirow{2}{*}{$\begin{array}{c}\text { MR } \\
\text { (MPa) }\end{array}$} & \multicolumn{3}{|c|}{$\varepsilon$ máx. } & \multicolumn{2}{|c|}{ Vida do pavimento } \\
\hline & & Revestimento & Base & Subleito & Nfad & Ndef \\
\hline $\mathrm{A}(1-1)$ & & $-15,78$ & $72,74 *$ & $-137,3$ & $2,19 \mathrm{E}+07$ & $1,73 E+09$ \\
\hline $\mathrm{D}(1-5)$ & 3000 & $203,7 *$ & 95,12 & $-228,8$ & $1,08 \mathrm{E}+05$ & $2,24 \mathrm{E}+08$ \\
\hline $\mathrm{G}(1-0)$ & & $189,8^{*}$ & 92,29 & $-225,4$ & $1,56 \mathrm{E}+05$ & $2,38 \mathrm{E}+08$ \\
\hline $\mathrm{A}(1-1)$ & & 8,319 & $62,09 *$ & $-116,4$ & $4,97 \mathrm{E}+07$ & $3,35 \mathrm{E}+09$ \\
\hline $\mathrm{D}(1-5)$ & 7000 & $128,7^{*}$ & 69,56 & $-194,1$ & $1,16 \mathrm{E}+06$ & $4,33 \mathrm{E}+08$ \\
\hline $\mathrm{G}(1-0)$ & & $139,4 *$ & 73,23 & $-198,7$ & $7,65 \mathrm{E}+05$ & $3,94 \mathrm{E}+08$ \\
\hline $\mathrm{A}(1-1)$ & & 15,11 & $56,4^{*}$ & $-108,7$ & $8,16 \mathrm{E}+07$ & $4,40 \mathrm{E}+09$ \\
\hline $\mathrm{D}(1-5)$ & 11000 & $103 *$ & 57,16 & $-174,4$ & $3,65 \mathrm{E}+06$ & $6,64 \mathrm{E}+08$ \\
\hline $\mathrm{G}(1-0)$ & & $108,7^{*}$ & 59,03 & $-177,6$ & $2,76 \mathrm{E}+06$ & $6,18 \mathrm{E}+08$ \\
\hline
\end{tabular}

\subsubsection{Estrutura II}

A influência da condição de aderência na deflexão da superfície do pavimento com base de BGS e BGTC, podem ser verificadas nos Figuras 19 e 20. Verificou-se que a deflexão da superfície do pavimento foi mais sensível a interface entre as duas camadas asfálticas. O mesmo 
não aconteceu com a estrutura que apresenta uma base de BGTC, quando a interface com a base apresentou maiores variações de deflexão sob diferentes condições de aderência.

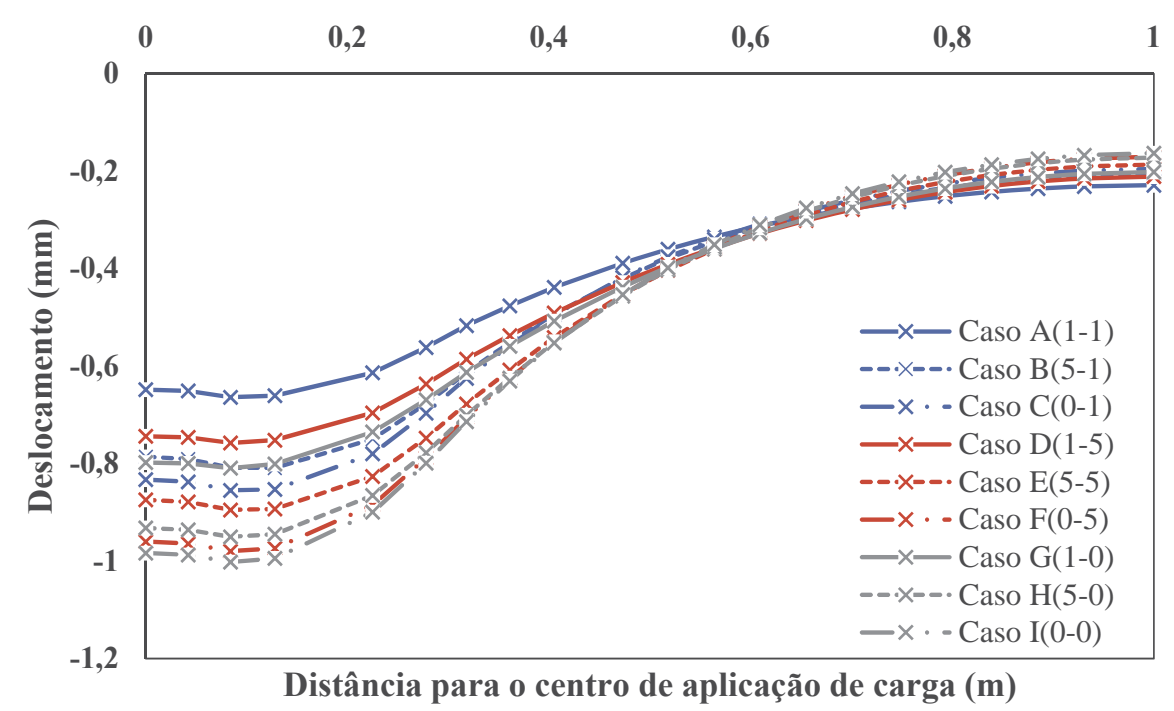

Figura 19. Curva de deflexão da Estrutura II com base de BGS

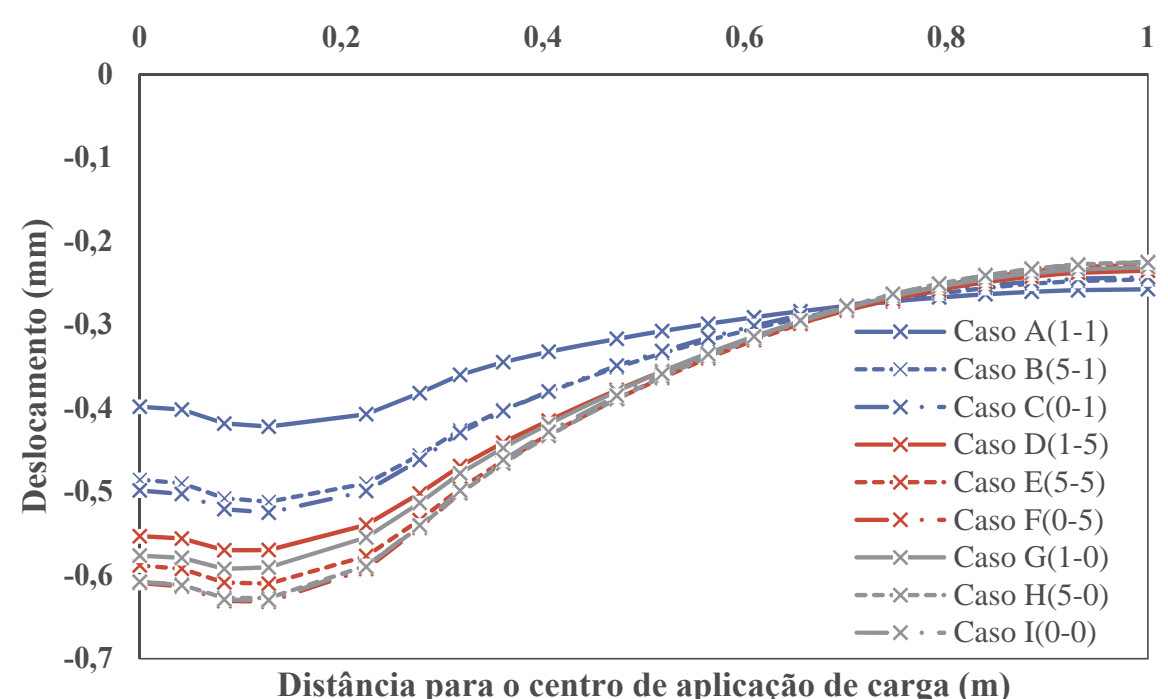

Figura 20. Curva de deflexão da Estrutura II com base de BGTC

Em ambos os casos, o afundamento da trilha de roda teve seu valor máximo com ambas as camadas não aderidas (caso I) e alcançou uma deflexão máxima aproximadamente $50 \%$ maior que o valor encontrado sob a condição de perfeita aderência em ambas as camadas (caso A).

Na Tabela 10, mostra-se os valores máximos de deformação e o número de repetições de carregamento que leva à falha da estrutura para diferentes níveis de rigidez do material asfáltico e diferentes condições de aderência entre camadas. Os resultados mostram que, a camada de revestimento (nos três níveis de rigidez) e subleito sofreram as menores deformações quando, 
em ambas as interfaces, as camadas estavam perfeitamente aderidas (Caso A) e as menores deformações no caso de perda total de aderência nas duas interfaces (Caso I), no entanto o mesmo não foi verificado na camada asfáltica inferior. De uma maneira geral, é possível observar uma tendência de decréscimo da vida útil do pavimento com a perda de aderência entre as camadas.

Tabela 10. Deformações máximas da Estrutura II com base de BGS (micro deformações)

\begin{tabular}{|c|c|c|c|c|c|c|}
\hline \multirow[b]{2}{*}{ CASO } & \multirow[b]{2}{*}{$\begin{array}{c}\text { MR } \\
\text { (MPa) }\end{array}$} & \multicolumn{3}{|c|}{$\varepsilon$ máx. } & \multicolumn{2}{|c|}{ Vida do pavimento } \\
\hline & & Revestimento & $\begin{array}{l}\text { C. A. } \\
\text { inferior }\end{array}$ & Subleito & Nfad & Ndef \\
\hline $\mathrm{A}(1-1)$ & & $-14,58$ & $242,6^{*}$ & $-225,1$ & $4,39 \mathrm{E}+04$ & $2,39 \mathrm{E}+08$ \\
\hline $\mathrm{B}(5-1)$ & & $207,8^{*}$ & 169,5 & $-286,2$ & $9,75 \mathrm{E}+04$ & $9,16 \mathrm{E}+07$ \\
\hline $\mathrm{C}(0-1)$ & & $274,2^{*}$ & 174,6 & $-294,9$ & $2,33 \mathrm{E}+04$ & $8,13 \mathrm{E}+07$ \\
\hline $\mathrm{D}(1-5)$ & & $-2,828$ & $302,2 *$ & $-284,6$ & $1,41 \mathrm{E}+04$ & $9,37 \mathrm{E}+07$ \\
\hline$E(5-5)$ & 3000 & 220,8 & $227,8^{*}$ & $-347,5$ & $6,07 \mathrm{E}+04$ & $4,22 \mathrm{E}+07$ \\
\hline $\mathrm{F}(0-5)$ & & $316,5^{*}$ & 289 & -372 & $1,11 \mathrm{E}+04$ & $3,21 \mathrm{E}+07$ \\
\hline $\mathrm{G}(1-0)$ & & 1,733 & $352^{*}$ & $-307,5$ & $6,43 \mathrm{E}+03$ & $6,87 \mathrm{E}+07$ \\
\hline $\mathrm{H}(5-0)$ & & 230,3 & $290,1^{*}$ & $-370,1$ & $1,74 \mathrm{E}+04$ & $3,28 \mathrm{E}+07$ \\
\hline $\mathrm{I}(0-0)$ & & $327,3 *$ & 311,8 & $-380,1$ & $9,35 \mathrm{E}+03$ & $2,94 \mathrm{E}+07$ \\
\hline $\mathrm{A}(1-1)$ & & $-11,33$ & $160 *$ & -189 & $3,76 \mathrm{E}+05$ & $4,82 \mathrm{E}+08$ \\
\hline $\mathrm{B}(5-1)$ & & $153,9 *$ & 144,4 & $-262,2$ & $4,59 \mathrm{E}+05$ & $1,30 \mathrm{E}+08$ \\
\hline $\mathrm{C}(0-1)$ & & $195^{*}$ & 141,84 & $-269,22$ & $1,35 \mathrm{E}+05$ & $1,17 \mathrm{E}+08$ \\
\hline $\mathrm{D}(1-5)$ & & $-8,405$ & $187,3^{*}$ & $-228,3$ & $1,67 \mathrm{E}+05$ & $2,26 \mathrm{E}+08$ \\
\hline $\mathrm{E}(5-5)$ & 7000 & $171,3 *$ & 165,6 & $-318,1$ & $2,64 \mathrm{E}+05$ & $6,00 \mathrm{E}+07$ \\
\hline$F(0-5)$ & & $206,9 *$ & 195,8 & $-338,1$ & $9,97 \mathrm{E}+04$ & $4,70 \mathrm{E}+07$ \\
\hline $\mathrm{G}(1-0)$ & & $-7,572$ & $201,8^{*}$ & -241 & $1,13 \mathrm{E}+05$ & $1,82 \mathrm{E}+08$ \\
\hline $\mathrm{H}(5-0)$ & & 183,3 & $189,7 *$ & $-336,8$ & $1,56 \mathrm{E}+05$ & $4,78 \mathrm{E}+07$ \\
\hline $\mathrm{I}(0-0)$ & & $346,1^{*}$ & 204,4 & $-344,7$ & $7,01 \mathrm{E}+03$ & $4,35 \mathrm{E}+07$ \\
\hline $\mathrm{A}(1-1)$ & & $-9,007$ & $121,3 *$ & $-167,7$ & $1,57 \mathrm{E}+06$ & $7,77 \mathrm{E}+08$ \\
\hline $\mathrm{B}(5-1)$ & & $128,9 *$ & 114 & $-247,9$ & $1,15 \mathrm{E}+06$ & $1,63 \mathrm{E}+08$ \\
\hline $\mathrm{C}(0-1)$ & & $142,2^{*}$ & 120 & $-252,1$ & $6,90 \mathrm{E}+05$ & $1,52 \mathrm{E}+08$ \\
\hline $\mathrm{D}(1-5)$ & & $-7,759$ & $137,8^{*}$ & -196 & $8,12 \mathrm{E}+05$ & $4,16 \mathrm{E}+08$ \\
\hline$E(5-5)$ & 11000 & $140^{*}$ & 134,6 & $-295,3$ & $7,48 \mathrm{E}+05$ & $8,08 \mathrm{E}+07$ \\
\hline$F(0-5)$ & & $160,3^{*}$ & 153,6 & $-311,9$ & $3,72 \mathrm{E}+05$ & $6,49 \mathrm{E}+07$ \\
\hline $\mathrm{G}(1-0)$ & & $-7,475$ & $144,6^{*}$ & $-204,3$ & $6,33 E+05$ & $3,53 E+08$ \\
\hline $\mathrm{H}(5-0)$ & & 147,6 & $148,4^{*}$ & -311 & $5,54 \mathrm{E}+05$ & $6,57 \mathrm{E}+07$ \\
\hline $\mathrm{I}(0-0)$ & & $163,1^{*}$ & 158,4 & $-317,2$ & $3,40 \mathrm{E}+05$ & $6,07 \mathrm{E}+07$ \\
\hline
\end{tabular}

* Localização crítica 
Quando a estrutura é composta por uma base mais rígida (Tabela 11), os resultados mostram que, para os três níveis de rigidez do material asfáltico, a condição de perfeita aderência entre as camadas (Caso A) resulta em um pavimento com a vida mais longa que os demais casos analisados, o que pode resultar em um pavimento superestimado quando essa condição de interface não é alcançada. Os resultados ainda mostram que a localização mais propícia ao surgimento de trincas também foi afetada pela condição de aderência entre as camadas.

Tabela 11. Deformações máximas da Estrutura II com base de BGTC (micro deformações)

\begin{tabular}{|c|c|c|c|c|c|c|c|}
\hline \multirow[b]{2}{*}{ CASO } & \multirow[b]{2}{*}{$\begin{array}{c}\text { MR } \\
\text { (MPa) }\end{array}$} & \multicolumn{4}{|c|}{$\varepsilon$ máx. } & \multicolumn{2}{|c|}{ Vida do pavimento } \\
\hline & & Revestimento & $\begin{array}{l}\text { C. A. } \\
\text { inferior }\end{array}$ & Base & Subleito & Nfad & Ndef \\
\hline $\mathrm{A}(1-1)$ & & $-50,47$ & $-23,42$ & $72,95^{*}$ & $-137,4$ & $2,16 \mathrm{E}+07$ & $1,72 \mathrm{E}+09$ \\
\hline $\mathrm{B}(5-1)$ & & $120,2^{*}$ & 94,56 & 92,65 & $-182,1$ & $1,64 \mathrm{E}+06$ & $5,59 \mathrm{E}+08$ \\
\hline $\mathrm{C}(0-1)$ & & $142,9 *$ & $-106,2$ & 99,6 & $-185,5$ & $6,73 E+05$ & $5,19 \mathrm{E}+08$ \\
\hline $\mathrm{D}(1-5)$ & & 19 & $181,1^{*}$ & 89,07 & $-223,5$ & $1,98 \mathrm{E}+05$ & $2,46 \mathrm{E}+08$ \\
\hline $\mathrm{E}(5-5)$ & 3000 & $142,4^{*}$ & 112,5 & 107,7 & $-249,6$ & $6,85 \mathrm{E}+05$ & $1,58 \mathrm{E}+08$ \\
\hline $\mathrm{F}(0-5)$ & & $169,7^{*}$ & 131,7 & 120,3 & $-256,2$ & $2,77 \mathrm{E}+05$ & $1,43 \mathrm{E}+08$ \\
\hline $\mathrm{G}(1-0)$ & & 26,61 & $208,5^{*}$ & 97,12 & $-230,5$ & $9,58 \mathrm{E}+04$ & $2,18 \mathrm{E}+08$ \\
\hline $\mathrm{H}(5-0)$ & & $145,9^{*}$ & 139,3 & 117,3 & $-255,3$ & $6,05 E+05$ & $1,45 \mathrm{E}+08$ \\
\hline $\mathrm{I}(0-0)$ & & $171,2 *$ & 138,7 & 123,2 & $-257,7$ & $2,65 \mathrm{E}+05$ & $1,39 \mathrm{E}+08$ \\
\hline $\mathrm{A}(1-1)$ & & $-27,95$ & 20,26 & $62,34^{*}$ & $-116,6$ & $4,87 \mathrm{E}+07$ & $3,33 \mathrm{E}+09$ \\
\hline $\mathrm{B}(5-1)$ & & 65,55 & $-38,8$ & $85,26^{*}$ & $-154,6$ & $9,67 \mathrm{E}+06$ & $1,08 \mathrm{E}+09$ \\
\hline $\mathrm{C}(0-1)$ & & 74,89 & $-41,63$ & $89,71^{*}$ & $-156,5$ & $7,44 \mathrm{E}+06$ & $1,02 \mathrm{E}+09$ \\
\hline $\mathrm{D}(1-5)$ & & 1,274 & $12,89 *$ & 69,61 & $-194,2$ & $1,23 \mathrm{E}+06$ & $4,32 \mathrm{E}+08$ \\
\hline$E(5-5)$ & 7000 & 92,41 & 86,38 & $98,82^{*}$ & $-238,2$ & $4,52 \mathrm{E}+06$ & $1,91 \mathrm{E}+08$ \\
\hline $\mathrm{F}(0-5)$ & & 105,2 & 98,41 & $108,7^{*}$ & $-244,2$ & $2,76 \mathrm{E}+06$ & $1,73 \mathrm{E}+08$ \\
\hline $\mathrm{G}(1-0)$ & & 3,066 & $139,4^{*}$ & 73,2 & $-198,7$ & $7,65 \mathrm{E}+05$ & $3,94 \mathrm{E}+08$ \\
\hline $\mathrm{H}(5-0)$ & & 97,8 & 98 & $105,8^{*}$ & $-243,1$ & $3,18 \mathrm{E}+06$ & $1,76 \mathrm{E}+08$ \\
\hline $\mathrm{I}(0-0)$ & & 105,8 & 99,93 & $110^{*}$ & $-245,2$ & $2,60 \mathrm{E}+06$ & $1,70 \mathrm{E}+08$ \\
\hline $\mathrm{A}(1-1)$ & & $-19,52$ & 23,24 & $56,66^{*}$ & $-108,8$ & $7,97 \mathrm{E}+07$ & $4,39 \mathrm{E}+09$ \\
\hline $\mathrm{B}(5-1)$ & & 50,29 & -107200 & $81,82^{*}$ & $-142,9$ & $1,20 \mathrm{E}+07$ & $1,47 \mathrm{E}+09$ \\
\hline $\mathrm{C}(0-1)$ & & 54,56 & 37,66 & $84,44^{*}$ & $-143,9$ & $1,02 \mathrm{E}+07$ & $1,43 \mathrm{E}+09$ \\
\hline $\mathrm{D}(1-5)$ & & -10 & $103,1^{*}$ & 57,16 & $-272,7$ & $3,63 \mathrm{E}+06$ & $6,64 \mathrm{E}+08$ \\
\hline$E(5-5)$ & 11000 & 80,16 & 75,08 & $91,39 *$ & $-228,3$ & $6,76 \mathrm{E}+06$ & $2,26 \mathrm{E}+08$ \\
\hline $\mathrm{F}(0-5)$ & & 89,11 & 84,69 & $99,22 *$ & $-233,7$ & $4,42 \mathrm{E}+06$ & $2,06 \mathrm{E}+08$ \\
\hline $\mathrm{G}(1-0)$ & & $-9,854$ & $108,8^{*}$ & 58,97 & $-177,6$ & $2,75 \mathrm{E}+06$ & $6,18 \mathrm{E}+08$ \\
\hline $\mathrm{H}(5-0)$ & & 84,34 & 82,91 & $96,64^{*}$ & $-232,6$ & $5,07 \mathrm{E}+06$ & $2,10 \mathrm{E}+08$ \\
\hline $\mathrm{I}(0-0)$ & & 90,25 & 86,43 & $100,8^{*}$ & $-234,9$ & $4,08 \mathrm{E}+06$ & $2,02 \mathrm{E}+08$ \\
\hline
\end{tabular}

* Localização crítica 


\subsubsection{Estrutura III}

A influência da condição de aderência na deflexão da superfície do pavimento com base de BGS e BGTC, podem ser verificadas nos Figuras 21 e 22. Para a estrutura com BGS, a perda de aderência na interface entre as camadas asfálticas resultou em um aumento da deflexão maior que o provocado pela interface inferior. Efeito contrário foi verificado na estrutura com uma base de BGTC, quando a deflexão foi mais afetada pela interação binder com a base do pavimento. Assim como o encontrado na Estrutura II, o afundamento da trilha de roda foi máximo com ambas as interfaces não aderidas (caso I). A perda total de aderência nas duas interfaces resultou em um aumento na deflexão superior a 50\% para a estrutura com os dois tipos de base adotados.

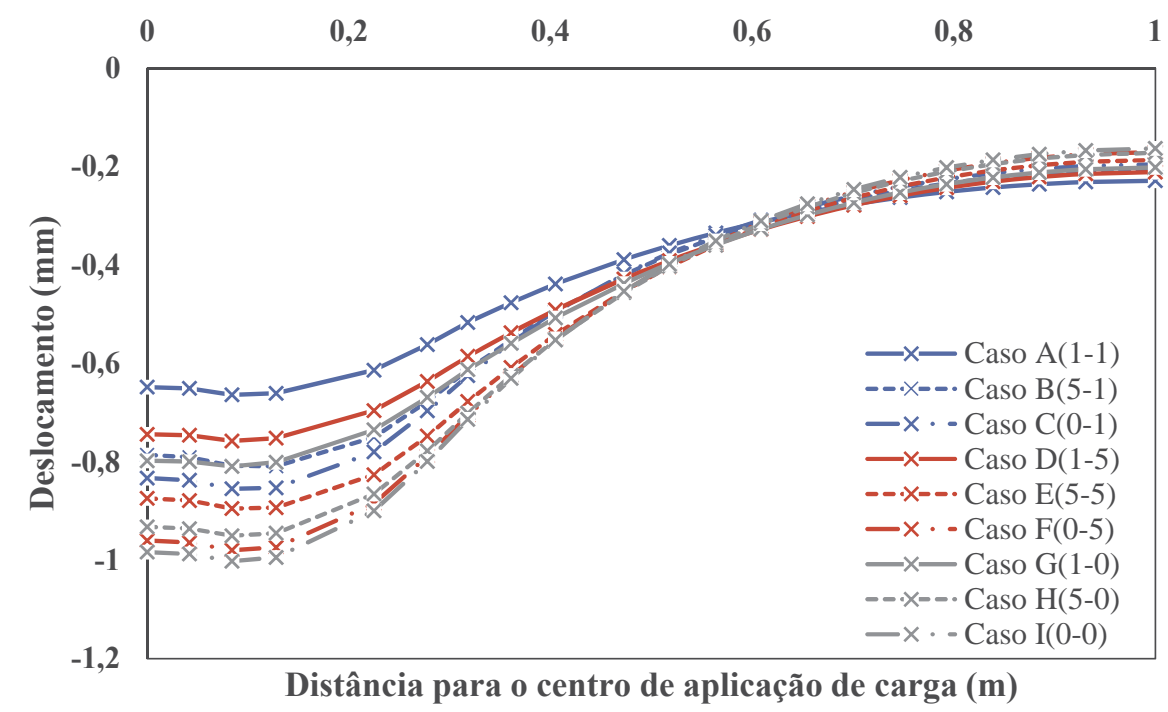

Figura 21. Curva de deflexão da Estrutura III com base de BGS

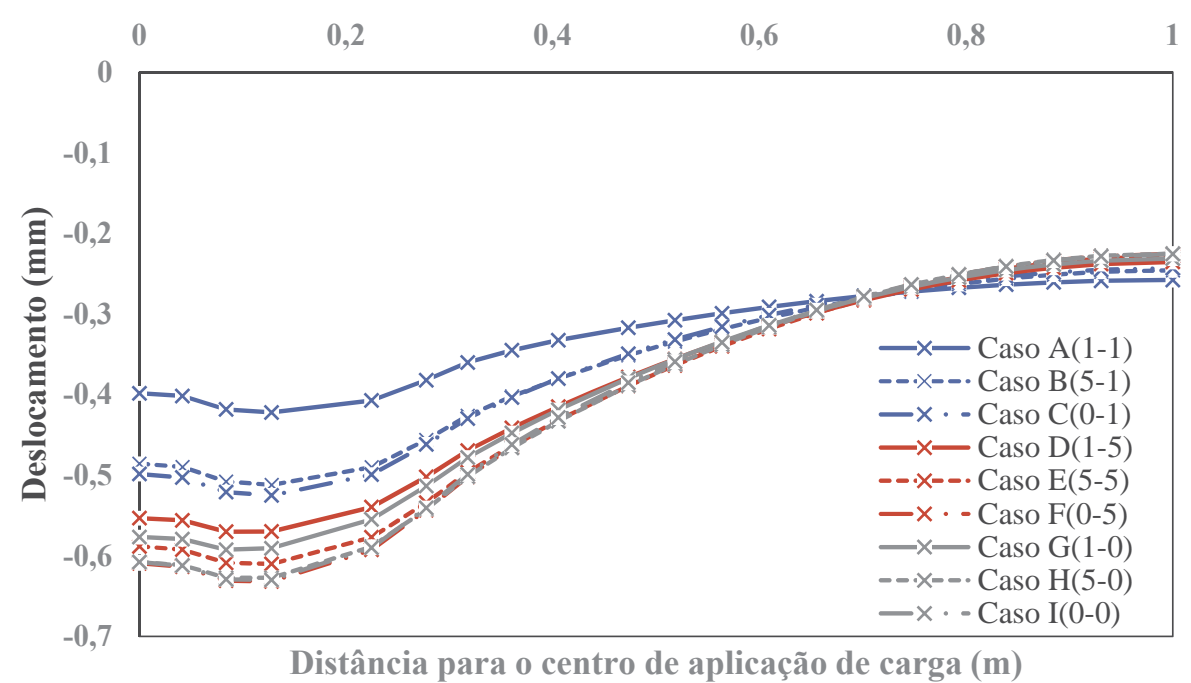

Figura 22. Curva de deflexão da Estrutura III com base de BGTC 
A Tabela 12 contém, para diferentes níveis de rigidez do material asfáltico e diferentes condições de aderência entre camadas, os valores máximos de deformação e o número de repetições de carregamento que levam a estrutura ao colapso. Observa-se que, com uma camada asfáltica inferior menos rígida, o pavimento teve uma vida mais longa na condição de completa aderência na primeira interface e aderência parcial na segunda interface (Caso B)

Tabela 12. Deformações máximas da Estrutura III com base de BGS (micro deformações)

\begin{tabular}{|c|c|c|c|c|c|c|}
\hline \multirow{2}{*}{ CASO } & \multirow{2}{*}{$\begin{array}{c}\text { MR } \\
\text { (MPa) }\end{array}$} & \multicolumn{3}{|c|}{$\varepsilon$ máx. } & \multicolumn{2}{|c|}{ Vida do pavimento } \\
\hline & & Revestimento & Binder & Subleito & Nfad & Ndef \\
\hline $\mathrm{A}(1-1)$ & & 21,66 & $299,1 *$ & $-230,3$ & $1,49 \mathrm{E}+04$ & $2,19 \mathrm{E}+08$ \\
\hline $\mathrm{B}(5-1)$ & & $225,7 *$ & 171,8 & $-293,3$ & $6,37 \mathrm{E}+04$ & $8,31 \mathrm{E}+07$ \\
\hline $\mathrm{C}(0-1)$ & & $295^{*}$ & 161,1 & $-304,2$ & $1,58 \mathrm{E}+04$ & $7,18 \mathrm{E}+07$ \\
\hline $\mathrm{D}(1-5)$ & & 41,93 & $383,2 *$ & $-268,5$ & $4,15 E+03$ & $1,18 \mathrm{E}+08$ \\
\hline $\mathrm{E}(5-5)$ & 3000 & 240,7 & $253,3^{*}$ & $-352,5$ & $3,51 \mathrm{E}+04$ & $3,98 \mathrm{E}+07$ \\
\hline $\mathrm{F}(0-5)$ & & $341,2^{*}$ & 322,2 & $-377,8$ & $7,55 \mathrm{E}+03$ & $3,02 \mathrm{E}+07$ \\
\hline $\mathrm{G}(1-0)$ & & 53,34 & $470,1 *$ & $-326,9$ & $1,44 \mathrm{E}+03$ & $5,38 \mathrm{E}+07$ \\
\hline $\mathrm{H}(5-0)$ & & 252,7 & $349,6^{*}$ & $-376,1$ & $6,66 \mathrm{E}+03$ & $3,07 \mathrm{E}+07$ \\
\hline $\mathrm{I}(0-0)$ & & 354,3 & $356,5^{*}$ & $-386,3$ & $6,02 \mathrm{E}+03$ & $2,76 \mathrm{E}+07$ \\
\hline $\mathrm{A}(1-1)$ & & 57,52 & $293,3 *$ & $-211,3$ & $1,65 \mathrm{E}+04$ & $3,08 \mathrm{E}+08$ \\
\hline $\mathrm{B}(5-1)$ & & $182,2^{*}$ & 139,6 & $-282,1$ & $1,92 \mathrm{E}+05$ & $9,71 \mathrm{E}+07$ \\
\hline $\mathrm{C}(0-1)$ & & $221,9 *$ & 121 & $-292,4$ & $6,95 \mathrm{E}+04$ & $8,41 \mathrm{E}+07$ \\
\hline $\mathrm{D}(1-5)$ & & 73,66 & $368,7 *$ & $-277,4$ & $5,06 \mathrm{E}+03$ & $1,04 \mathrm{E}+08$ \\
\hline $\mathrm{E}(5-5)$ & 7000 & 201,1 & $214,5^{*}$ & $-335,2$ & $8,28 \mathrm{E}+04$ & $4,87 \mathrm{E}+07$ \\
\hline $\mathrm{F}(0-5)$ & & 253,8 & $255,7 *$ & $-358,6$ & $3,34 \mathrm{E}+04$ & $3,72 \mathrm{E}+07$ \\
\hline $\mathrm{G}(1-0)$ & & 87,19 & $439,1^{*}$ & $-304,1$ & $2,05 \mathrm{E}+03$ & $7,19 \mathrm{E}+07$ \\
\hline $\mathrm{H}(5-0)$ & & 221 & $288,5^{*}$ & -357 & $1,79 \mathrm{E}+04$ & $3,78 \mathrm{E}+07$ \\
\hline $\mathrm{I}(0-0)$ & & 261,6 & $281 *$ & $-366,2$ & $2,05 \mathrm{E}+04$ & $3,42 \mathrm{E}+07$ \\
\hline $\mathrm{A}(1-1)$ & & 65,17 & $278,7 *$ & $-202,3$ & $2,14 \mathrm{E}+04$ & $3,67 \mathrm{E}+08$ \\
\hline $\mathrm{B}(5-1)$ & & $160,5^{*}$ & 118,8 & $-272,5$ & $3,70 \mathrm{E}+05$ & $1,11 \mathrm{E}+08$ \\
\hline $\mathrm{C}(0-1)$ & & $185,4^{*}$ & 98,1 & $-282,1$ & $1,76 \mathrm{E}+05$ & $9,71 \mathrm{E}+07$ \\
\hline $\mathrm{D}(1-5)$ & & 84,73 & $347,2 *$ & $-265,3$ & $6,90 \mathrm{E}+03$ & $1,24 \mathrm{E}+08$ \\
\hline $\mathrm{E}(5-5)$ & 11000 & 176,3 & $187,8^{*}$ & $-320,9$ & $1,64 \mathrm{E}+05$ & $5,80 \mathrm{E}+07$ \\
\hline $\mathrm{F}(0-5)$ & & 210 & $215,9 *$ & -342 & $8,01 \mathrm{E}+04$ & $4,49 E+07$ \\
\hline $\mathrm{G}(1-0)$ & & 96,76 & $407,2 *$ & $-290,3$ & $3,03 \mathrm{E}+03$ & $8,65 \mathrm{E}+07$ \\
\hline $\mathrm{H}(5-0)$ & & 335,4 & $249,1 *$ & $-340,8$ & $3,83 \mathrm{E}+04$ & $4,56 \mathrm{E}+07$ \\
\hline $\mathrm{I}(0-0)$ & & 215,4 & $236,5^{*}$ & $-348,8$ & $5,00 \mathrm{E}+04$ & $4,15 \mathrm{E}+07$ \\
\hline
\end{tabular}

* Localização crítica

Os resultados das deformações máximas mostram que quando a condição de perfeita aderência entre as camadas não foi alcançada, a distribuição de deformações ao longo da estrutura muda 
de forma expressiva. A condição de interface também resulta na variação da localização da deformação horizontal crítica. Quando houve uma perda total de aderência nas interfaces, a máxima deformação horizontal ocorreu na camada de revestimento e não mais na camada de binder como aconteceu no Caso A. Assim, as trincas por fadiga iniciariam em pontos diferentes da estrutura em função da condição de interface. $\mathrm{O}$ mesmo pode ser observado para pavimentos com base de BGTC (Tabela 13), contudo, o pavimento com a vida mais longa está associado a condição de completa aderência entre as camadas (Caso A).

Tabela 13. Deformações máximas da Estrutura III com base de BGTC (micro deformações)

\begin{tabular}{|c|c|c|c|c|c|c|c|}
\hline \multirow{2}{*}{ CASO } & \multirow{2}{*}{$\begin{array}{c}\text { MR } \\
(\mathrm{MPa})\end{array}$} & \multicolumn{4}{|c|}{$\varepsilon$ máx. } & \multicolumn{2}{|c|}{ Vida do pavimento } \\
\hline & & Revestimento & Binder & Base & Subleito & Nfad & Ndef \\
\hline $\mathrm{A}(1-1)$ & & 21,66 & 299,1 & $308,1^{*}$ & $-230,3$ & $1,83 \mathrm{E}+07$ & $1,47 \mathrm{E}+09$ \\
\hline $\mathrm{B}(5-1)$ & & $135^{*}$ & $-132,1$ & 95,12 & $-198,4$ & $9,03 \mathrm{E}+05$ & $3,97 \mathrm{E}+08$ \\
\hline $\mathrm{C}(0-1)$ & & $163,8^{*}$ & 154,8 & 103,9 & $-203,1$ & $3,33 \mathrm{E}+05$ & $3,61 \mathrm{E}+08$ \\
\hline $\mathrm{D}(1-5)$ & & 50,28 & $223,1^{*}$ & 93,61 & $-230,3$ & $6,60 \mathrm{E}+04$ & $2,19 \mathrm{E}+08$ \\
\hline $\mathrm{E}(5-5)$ & 3000 & $156,6^{*}$ & 132,7 & 109 & $-251,4$ & $4,20 \mathrm{E}+05$ & $1,54 \mathrm{E}+08$ \\
\hline $\mathrm{F}(0-5)$ & & $188^{*}$ & 160,6 & 121,6 & $-258,1$ & $1,63 \mathrm{E}+05$ & $1,39 \mathrm{E}+08$ \\
\hline $\mathrm{G}(1-0)$ & & 63,78 & $271,3^{*}$ & 103,9 & $-238,8$ & $2,46 \mathrm{E}+04$ & $1,89 \mathrm{E}+08$ \\
\hline $\mathrm{H}(5-0)$ & & 161,5 & $177,6^{*}$ & 119,3 & $-257,4$ & $2,19 \mathrm{E}+05$ & $1,40 \mathrm{E}+08$ \\
\hline $\mathrm{I}(0-0)$ & & $188,4 *$ & 170,2 & 123,9 & $-256,6$ & $1,62 \mathrm{E}+05$ & $1,42 \mathrm{E}+08$ \\
\hline $\mathrm{A}(1-1)$ & & 3,066 & 30,37 & $68,73^{*}$ & $-127,3$ & $2,94 \mathrm{E}+07$ & $2,34 \mathrm{E}+09$ \\
\hline $\mathrm{B}(5-1)$ & & $92,94 *$ & $-125,9$ & 91,41 & $-195,2$ & $6,20 \mathrm{E}+06$ & $4,23 \mathrm{E}+08$ \\
\hline $\mathrm{C}(0-1)$ & & $107 *$ & $-149,4$ & 99,48 & $-199,9$ & $3,00 \mathrm{E}+06$ & $3,85 \mathrm{E}+08$ \\
\hline $\mathrm{D}(1-5)$ & & 62,18 & $224,2^{*}$ & 86,67 & $-221,2$ & $6,74 \mathrm{E}+04$ & $2,57 \mathrm{E}+08$ \\
\hline$E(5-5)$ & 7000 & 110,5 & $122,7 *$ & 103,4 & $-245,1$ & $1,48 \mathrm{E}+06$ & $1,70 \mathrm{E}+08$ \\
\hline $\mathrm{F}(0-5)$ & & 126,5 & $149,9^{*}$ & 113,7 & $-251,6$ & $5,26 \mathrm{E}+05$ & $1,53 \mathrm{E}+08$ \\
\hline $\mathrm{G}(1-0)$ & & 68,84 & $270,3^{*}$ & 95,72 & $-229,9$ & $2,51 \mathrm{E}+04$ & $2,20 \mathrm{E}+08$ \\
\hline $\mathrm{H}(5-0)$ & & 180,1 & $163,6^{*}$ & 111,8 & $-250,9$ & $3,35 \mathrm{E}+05$ & $1,55 \mathrm{E}+08$ \\
\hline $\mathrm{I}(0-0)$ & & 127,7 & $158,8^{*}$ & 116,2 & -253 & $3,91 \mathrm{E}+05$ & $1,50 \mathrm{E}+08$ \\
\hline $\mathrm{A}(1-1)$ & & 9,334 & 34,74 & $65,47^{*}$ & $-121,2$ & $3,78 \mathrm{E}+07$ & $2,85 \mathrm{E}+09$ \\
\hline $\mathrm{B}(5-1)$ & & 76,38 & 98,34 & $88,12^{*}$ & $-192,3$ & $8,16 \mathrm{E}+06$ & $4,49 \mathrm{E}+08$ \\
\hline $\mathrm{C}(0-1)$ & & 86 & $-144,2$ & $95,5^{*}$ & $-196,9$ & $5,39 \mathrm{E}+06$ & $4,09 \mathrm{E}+08$ \\
\hline $\mathrm{D}(1-5)$ & & -10 & $103,1^{*}$ & 57,16 & $-174,4$ & $7,58 \mathrm{E}+04$ & $2,86 \mathrm{E}+08$ \\
\hline$E(5-5)$ & 11000 & 96,6 & $115^{*}$ & 98,32 & $-239,4$ & $2,06 \mathrm{E}+06$ & $1,87 \mathrm{E}+08$ \\
\hline$F(0-5)$ & & 102,9 & $139,7^{*}$ & 107,1 & $-245,5$ & $7,57 \mathrm{E}+05$ & $1,69 E+08$ \\
\hline $\mathrm{G}(1-0)$ & & 68,78 & $261,3^{*}$ & 90,05 & $-223,9$ & $2,99 \mathrm{E}+04$ & $2,45 \mathrm{E}+08$ \\
\hline $\mathrm{H}(5-0)$ & & 103,4 & $152,5^{*}$ & 105,4 & $-244,8$ & $4,81 \mathrm{E}+05$ & $1,71 E+08$ \\
\hline $\mathrm{I}(0-0)$ & & 111,3 & $147,2^{*}$ & 109,1 & $-246,9$ & $5,78 \mathrm{E}+05$ & $1,65 \mathrm{E}+08$ \\
\hline
\end{tabular}

* Localização crítica 


\section{ANÁLISE ESTATÍSTICA}

A presente análise estatística tem como objeto de estudo os resultados de deformação obtidos nas simulações computacionais, apresentados no Capítulo 4, e foi realizada com o auxílio do programa de análise estatística Minitab 17. As variáveis independentes são representadas pelas respostas estruturais dos pavimentos avaliados e foram analisadas separadamente, por estarem associados a diferentes mecanismos de deterioração estrutural. Dentro deste experimento, os fatores e seus níveis correspondentes são dados por:

- Fator A: módulo de elasticidade do concreto asfáltico (MR)

o Nível $A_{0}=3000 \mathrm{Mpa}$

o Nível $A_{1}=7000 \mathrm{Mpa}$

o Nível $A_{2}=11000 \mathrm{Mpa}$

- Fator B: Condição de aderência na interface entre camadas asfálticas $\left(i_{1}\right)$

o Nível $B_{0}=$ aderência total (1)

o Nível $B_{1}=$ aderência parcial $(0,5)$

o Nível $B_{2}=$ aderência nula (0)

- Fator C: Condição de aderência na interface entre a camada asfáltica e a base $\left.\left(i_{2}\right)\right)$

o Nível $C_{0}=$ aderência total (1)

o Nível $C_{1}=$ aderência parcial $(0,5)$

o Nível $C_{2}=$ aderência nula (0)

\subsection{Análise de Significância}

As variações nos resultados obtidos das simulações computacionais podem ocorrer devido aos fatores estudados ou em função do acaso, ou seja, uma variação aleatória. Dessa forma, foi realizada uma análise de significância para aceitar ou não um determinado fator como responsável pelas variações encontradas nos resultados da pesquisa

Neste trabalho, o nível de significância dos fatores foi determinado por meio do P-valor, associado a um nível de confiança de 95\%. Ou seja, um fator considerado significante ( $\mathrm{P}<$ $0,05)$ tem $95 \%$ de probabilidade de ser um dos responsáveis pelas diferenças verificadas nas respostas estruturais do pavimento. Os valores de $\mathrm{P}$ calculados para cada tipo de estrutura estão dispostos nas Tabelas 14, 15 e 16. 
Tabela 14. P-Valor dos fatores-Estrutura I

\begin{tabular}{lcccc}
\hline \multirow{2}{*}{ Modelo } & \multicolumn{2}{c}{ Base de BGS } & \multicolumn{2}{c}{ Base de BGTC } \\
\cline { 2 - 5 } & MR & $\boldsymbol{i}_{\mathbf{2}}$ & MR & $\boldsymbol{i}_{\mathbf{2}}$ \\
\hline ch,revest & 0,001 & 0,042 & 0,335 & 0,014 \\
ch,base & - & - & 0,009 & 0,14 \\
\multirow{2}{*}{ cv,subleito } & 0,001 & 0,004 & 0,004 & 0 \\
\hline
\end{tabular}

Tabela 15. P-Valor dos fatores-Estrutura II

\begin{tabular}{|c|c|c|c|c|c|c|}
\hline \multirow{2}{*}{ Modelo } & \multicolumn{3}{|c|}{ Base de BGS } & \multicolumn{3}{|c|}{ Base de BGTC } \\
\hline & MR & $i_{1}$ & $i_{2}$ & MR & $i_{1}$ & $i_{2}$ \\
\hline ch,revest & 0,001 & 0,00 & 0,165 & 0,00 & 0,00 & 0,001 \\
\hline En, CAinterior & 0,00 & 0,063 & 0,00 & 0,385 & 0,385 & 0,379 \\
\hline En,base & - & - & - & 0,00 & 0,00 & 0,00 \\
\hline Ev, SuOtertu & 0,00 & 0,00 & 0,00 & 0,023 & 0,001 & 0,00 \\
\hline
\end{tabular}

Tabela 16. P-Valor dos fatores-Estrutura III

\begin{tabular}{lcccccc}
\hline \multirow{2}{*}{ Modelo } & \multicolumn{3}{c}{ Base de BGS } & \multicolumn{3}{c}{ Base de BGTC } \\
\cline { 2 - 7 } & MR & $\boldsymbol{i}_{\mathbf{1}}$ & $\boldsymbol{i}_{\mathbf{2}}$ & MR & $\boldsymbol{i}_{\mathbf{1}}$ & $\boldsymbol{i}_{\mathbf{2}}$ \\
\hline ch,revest & 0,226 & 0,00 & 0,061 & 0,00 & 0,00 & 0,001 \\
Eh,binder & 0,00 & 0,00 & 0,00 & 0,199 & 0,019 & 0,00 \\
ch,base & - & - & - & 0,153 & 0,933 & 0,797 \\
Ev,subleito & 0,00 & 0,00 & 0,00 & 0,022 & 0,001 & 0,00 \\
\hline
\end{tabular}

Com base nas tabelas apresentadas, é possível verificar que as alterações das respostas estruturais calculadas têm, na maioria dos casos, uma parcela explicada pela condição de aderência entre as camadas do pavimento que, para algumas das respostas estruturais, teve um $\mathrm{P}$-valor menor que o correspondente à rigidez do material asfáltico. A condição de aderência na interface entre as camadas asfálticas e na interface entre a camada asfáltica e a base foram significativas em, respectivamente, 74 e $79 \%$ das respostas estruturais avaliadas.

\subsection{Análise de Regressão}

No experimento fatorial, ainda foi realizada uma análise de regressão para tentar relacionar quantitativamente as variáveis independentes (Fatores A, B e C) com as respostas estruturais 
dos pavimentos, através do desenvolvimentos de modelos de regressão linear múltipla. Abaixo, são dispostas as equações de regressão das respostas estruturais e os valores médios dos coeficientes associado a cada fator.

- Modelos lineares de regressão da Estrutura I com base de BGS

$$
\begin{aligned}
& \varepsilon_{\text {h,revest }}(M R, i 1, i 2) \\
& =201,91+85,49 \mathrm{~A}_{0}-18,54 \mathrm{~A}_{1}-66,94 \mathrm{~A}_{2}+19,62 C_{0}+6,82 C_{1} \\
& -26,44 C_{2} \\
& \begin{aligned}
& \varepsilon_{v, \text { subleito }}(M R, i 1, i 2) \\
&=-224,98-41,72 \mathrm{~A}_{0}+5,81 \mathrm{~A}_{1}+35,911 \mathrm{~A}_{2}-20,52 C_{0} \\
&-11,12 C_{1}+31,64 C_{2}
\end{aligned}
\end{aligned}
$$

— Modelos lineares de regressão da Estrutura I com base de BGTC

$$
\begin{aligned}
& \varepsilon_{h, \text { revest }}(M R, i 1, i 2) \\
& \qquad=97,9+28 \mathrm{~A}_{0}-5,7 \mathrm{~A}_{1}-22,3 \mathrm{~A}_{2}+48,1 C_{0}+47,3 C_{1}-95,3 C_{2} \\
& \varepsilon_{h, \text { base }}(M R, i 1, i 2) \\
& =70,85+15,87 \mathrm{~A}_{0}-2,55 \mathrm{~A}_{1}-13,32 \mathrm{~A}_{2}+4 C_{0}+3,1 C_{1}-7,1 C_{2} \\
& \begin{aligned}
\varepsilon_{v, \text { subleito }}(M R, i 1, i 2) \\
=
\end{aligned} \\
& -25,61 C_{1}+52,69 C_{2}
\end{aligned}
$$

— Modelos lineares de regressão da Estrutura II com base de BGS

$$
\begin{aligned}
& \varepsilon_{\text {h,revest }}(M R, i 1, i 2) \\
& \qquad \begin{aligned}
& 135,12+38,3 \mathrm{~A}_{0}+1,5 \mathrm{~A}_{1}-39,8 \mathrm{~A}_{2}+101,7 \mathrm{~B}_{0}+40,9 \mathrm{~B}_{1} \\
& -142,6 \mathrm{~B}_{2}+18,7 C_{0}-2,1 C_{1}-16,6 C_{2}
\end{aligned} \\
& \begin{aligned}
\varepsilon_{h, \text { CA inferior }}(M R, i 1, i 2) \\
=191,97+70,21 \mathrm{~A}_{0}-15,21 \mathrm{~A}_{1}-55 \mathrm{~A}_{2}+2,41 \mathrm{~B}_{0}-15,96 B_{1} \\
+13,54 \mathrm{~B}_{2}+30,39 C_{0}+7,33 C_{1}-37,72 C_{2}
\end{aligned}
\end{aligned}
$$




$$
\begin{aligned}
& \varepsilon_{v, \text { subleito }}(M R, i 1, i 2) \\
& \qquad \begin{aligned}
& -285,14-33,53 \mathrm{~A}_{0}+4,32 \mathrm{~A}_{1}+29,21 \mathrm{~A}_{2}-34,88 \mathrm{~B}_{0} \\
& -23,2 B_{1}+58,09 \mathrm{~B}_{2}-27,38 C_{0}-13,95 C_{1}+41,33 C_{2}
\end{aligned}
\end{aligned}
$$

- Modelos lineares de regressão da Estrutura II com base de BGTC $\varepsilon_{h, \text { revest }}(M R, i 1, i 2)$

$$
\begin{aligned}
& =67,22+31,39 \mathrm{~A}_{0}-9,66 \mathrm{~A}_{1}-21,73 \mathrm{~A}_{2}+44,3 \mathrm{~B}_{0}+30,46 B_{1} \\
& -74,75 \mathrm{~B}_{2}+12,24 C_{0}+9,37 C_{1}-21,61 C_{2}
\end{aligned}
$$

$\varepsilon_{h, \text { binder }}(M R, i 1, i 2)$

$$
\begin{aligned}
& =-3898+3995 \mathrm{~A}_{0}+3951 \mathrm{~A}_{1}-7946 \mathrm{~A}_{2}+3957 \mathrm{~B}_{0}-7941 B_{1} \\
& +3984 \mathrm{~B}_{2}+4020 C_{0}+3996 C_{1}-8017 C_{2}
\end{aligned}
$$

$\varepsilon_{h, \text { base }}(M R, i 1, i 2)$

$$
\begin{aligned}
& =90,757+11,45 \mathrm{~A}_{0}-1,49 \mathrm{~A}_{1}-9,97 \mathrm{~A}_{2}+13,24 \mathrm{~B}_{0}+6,73 B_{1} \\
& -19,97 \mathrm{~B}_{2}+7,36 C_{0}+2,8 C_{1}-10,15 C_{2}
\end{aligned}
$$

$\varepsilon_{v, \text { subleito }}(M R, i 1, i 2)$

$$
\begin{aligned}
& =-205,35-14,4 \mathrm{~A}_{0}+6,32 \mathrm{~A}_{1}+8,09 \mathrm{~A}_{2}-12,18 \mathrm{~B}_{0}-8,73 B_{1} \\
& +20,91 \mathrm{~B}_{2}-25,27 C_{0}-32,49 C_{1}+57,76 C_{2}
\end{aligned}
$$

— Modelos lineares de regressão da Estrutura III com base de BGS

$\varepsilon_{h, \text { revest }}(M R, i 1, i 2)$

$$
\begin{aligned}
& =182,08+20,9 \mathrm{~A}_{0}-8,8 \mathrm{~A}_{1}-12,1 \mathrm{~A}_{2}+77,8 \mathrm{~B}_{0}+39,7 B_{1} \\
& -117,4 \mathrm{~B}_{2}+26,6 C_{0}-1,7 C_{1}-24,9 C_{2}
\end{aligned}
$$

$\varepsilon_{h, \text { binder }}(M R, i 1, i 2)$

$$
\begin{aligned}
& =270,65+38,78 \mathrm{~A}_{0}-3,83 \mathrm{~A}_{1}-32,95 \mathrm{~A}_{2}-43,1 \mathrm{~B}_{0}-51,43 B_{1} \\
& +94,535 \mathrm{~B}_{2}+71,3 C_{0}+12,51 C_{1}-83,82 C_{2}
\end{aligned}
$$

$\varepsilon_{v, \text { subleito }}(M R, i 1, i 2)$

$$
\begin{aligned}
& =-309,82-14,17 \mathrm{~A}_{0}+0,46 \mathrm{~A}_{1}+13,71 \mathrm{~A}_{2}-30 \mathrm{~B}_{0}-15,78 B_{1} \\
& +45,78 \mathrm{~B}_{2}-34,23 C_{0}-12,2 C_{1}+46,43 C_{2}
\end{aligned}
$$


- Modelos lineares de regressão da Estrutura III com base de BGTC

$$
\begin{aligned}
& \varepsilon_{h, \text { revest }}(M R, i 1, i 2) \\
& \qquad \begin{aligned}
& 98,24+27,20 \mathrm{~A}_{0}-0,59 \mathrm{~A}_{1}-26,61 \mathrm{~A}_{2}+35,27 \mathrm{~B}_{0} \\
& +25,43 B_{1}-60,70 \mathrm{~B}_{2}+21,07 C_{0}-0,07 C_{1}-21 C_{2}
\end{aligned} \\
& \varepsilon_{\text {h,binder }}(M R, i 1, i 2) \\
& =118,9+43 \mathrm{~A}_{0}-25 \mathrm{~A}_{1}-18 \mathrm{~A}_{2}-31,4 \mathrm{~B}_{0}-40,6 B_{1}+72 \mathrm{~B}_{2} \\
& +78,1 C_{0}+33,5 C_{1}-111,6 C_{2} \\
& \varepsilon_{h, \text { base }}(M R, i 1, i 2) \\
& =106,73+24,2 \mathrm{~A}_{0}-8,2 \mathrm{~A}_{1}-16 \mathrm{~A}_{2}+3,3 \mathrm{~B}_{0}-4,3 B_{1}+\mathrm{B}_{2} \\
& +1,6 C_{0}-7,81 C_{1}+6,1 C_{2} \\
& \varepsilon_{v, \text { subleito }}(M R, i 1, i 2) \\
& =-221,62-14,42 \mathrm{~A}_{0}+2,28 \mathrm{~A}_{1}+12,14 \mathrm{~A}_{2}-13 \mathrm{~B}_{0}-8,92 B_{1} \\
& +21,92 \mathrm{~B}_{2}-23,07 C_{0}-13,6 C_{1}+36,67 C_{2}
\end{aligned}
$$

Nas Tabelas 17, 18 e 19, são apresentados os valores médios dos coeficientes associado a cada fator dos modelos de regressão das Estruturas I, II e III, respectivamente.

Tabela 17. Valor médio dos coeficientes de cada fator-Estrutura I

\begin{tabular}{lcccc}
\hline \multirow{2}{*}{ Modelos } & \multicolumn{2}{c}{ Base de BGS } & \multicolumn{2}{c}{ Base de BGTC } \\
\cline { 2 - 5 } & Fator A & Fator C & Fator A & Fator C \\
\hline ch,revest & 56,99 & 17,63 & 18,67 & 63,57 \\
ch,base & - & - & 10,57 & 4,73 \\
Ev,subleito & & & 15,79 & 35,13 \\
\hline
\end{tabular}

Tabela 18. Valor médio dos coeficientes de cada fator-Estrutura II

\begin{tabular}{lcccccc}
\hline \multirow{2}{*}{ Modelos } & \multicolumn{3}{c}{ Base de BGS } & \multicolumn{3}{c}{ Base de BGTC } \\
\cline { 2 - 7 } & Fator A & Fator B & Fator C & Fator A & Fator B & Fator C \\
\hline ch,revest & 26,53 & 95,07 & 12,47 & 20,93 & 49,84 & 14,41 \\
ch,CA inferior & 46,81 & 10,64 & 25,15 & 5297,33 & 5294,00 & 5344,33 \\
ch,base & - & - & - & 7,64 & 13,31 & 6,77 \\
Ev,subleito & 22,35 & 38,72 & 27,55 & 9,60 & 13,94 & 38,51 \\
\hline
\end{tabular}


Tabela 19. Valor médio dos coeficientes de cada fator-Estrutura III

\begin{tabular}{lcccccc}
\hline \multirow{2}{*}{ Modelos } & \multicolumn{3}{c}{ Base de BGS } & \multicolumn{3}{c}{ Base de BGTC } \\
\cline { 2 - 7 } & Fator A & Fator B & Fator C & Fator A & Fator B & Fator C \\
\hline ch,revest & 13,93 & 78,30 & 17,73 & 54,40 & 121,40 & 42,14 \\
ch,binder & 25,19 & 63,02 & 55,88 & 86,00 & 144,00 & 123,20 \\
ch,base & - & - & - & 48,40 & 8,60 & 15,51 \\
Ev,subleito & 9,45 & 30,52 & 30,95 & 28,84 & 43,84 & 73,34 \\
\hline
\end{tabular}

Para as equações de regressão apresentadas, foi realizado o cálculo do coeficiente de determinação $\left(R^{2}\right)$ de cada modelo dos três tipos de estrutura abordados na análise. As Tabelas 20, 21 e 22 apresentam os coeficientes de determinação dos modelos referentes as estruturas I, II e III, respectivamente.

Tabela 20. Coeficientes de determinação dos modelos de regressão da Estrutura I

\begin{tabular}{lcc}
\hline \multicolumn{1}{c}{ Modelo } & Base de BGS & Base de BGTC \\
\hline$\varepsilon$ h,revest & 97,84 & 89,23 \\
$\varepsilon h$,base & - & 91,82 \\
$\varepsilon v$, subleito & 97,79 & 98,8 \\
\hline
\end{tabular}

Tabela 21. Coeficientes de determinação dos modelos de regressão da Estrutura II

\begin{tabular}{lcc}
\hline \multicolumn{1}{c}{ Modelo } & Base de BGS & Base de BGTC \\
\hline ch,revest & 91,89 & 93,84 \\
ch,CA inferior & 88,77 & 23,2 \\
ch,base & - & 95,7 \\
$\varepsilon v$, subleito & 97,29 & 89,85 \\
\hline
\end{tabular}

Tabela 22. Coeficientes de determinação dos modelos de regressão da Estrutura III

\begin{tabular}{lcc}
\hline \multicolumn{1}{c}{ Modelo } & Base de BGS & Base de BGTC \\
\hline ch,revest & 85,04 & 89,21 \\
$\varepsilon$ h,binder & 96,59 & 65,39 \\
$\varepsilon$ h,base & - & 19,14 \\
$\varepsilon v$, subleito & 97,96 & 80,29 \\
\hline
\end{tabular}


A partir dos resultados dos coeficientes de determinação observou-se que os erros associados aos fatores A, B e C dos modelos referentes a Estrutura I são inferiores a 11\%, valor semelhante aos encontrados para os modelos da Estrutura II, com exceção da deformação horizontal de tração na camada de binder quando a estrutura foi composta por uma base de BGTC. A Estrutura III, por sua vez, apresentou modelos de regressão com maior sensibilidade as condições de interface e rigidez do concreto asfáltico para a determinação das deformações horizontais na camada de binder e na base do pavimento.

\subsection{Comparação entre as condições de interface}

As respostas estruturais foram calculadas por meio dos modelos de regressão e são representadas em função da rigidez do material asfáltico. Os resultados encontrados são apresentados em forma de gráfico, para melhor compreensão e praticidade em identificar os efeitos da condição de contato entre as camadas no comportamento estrutural dos pavimentos.

\subsubsection{Estrutura I}

Nas Figuras 23 a 27, são comparados os comportamentos estruturais do pavimento com apenas uma camada asfáltica, sob cada caso de aderência considerado na pesquisa. As Figuras 23 e 24 mostram os valores de deformação horizontal na camada de revestimento e vertical no subleito, respectivamente, do pavimento com base de BGS. Observa-se que a deformação horizontal no revestimento foi afetada pela condição de contato com a camada de base, de maneira proporcional à rigidez do revestimento. A condição de total aderência com a base resultou em uma deformação horizontal no revestimento aproximadamente 15, 23 e 30\% menor, para o módulo de resiliência de 3000, 7000 e $11000 \mathrm{MPa}$, respectivamente.

A aderência entre o revestimento e a base também afetou as camadas inferiores do pavimento. Assim como no revestimento, a menor deformação no subleito apareceu quando as duas camadas estavam perfeitamente ligadas e a menor deformação, quando a aderência entre as partes foi completamente perdida. A perda de aderência entre o revestimento e a base resultou em um aumento de aproximadamente $33 \%$ da deformação vertical de compressão no topo do subleito. 


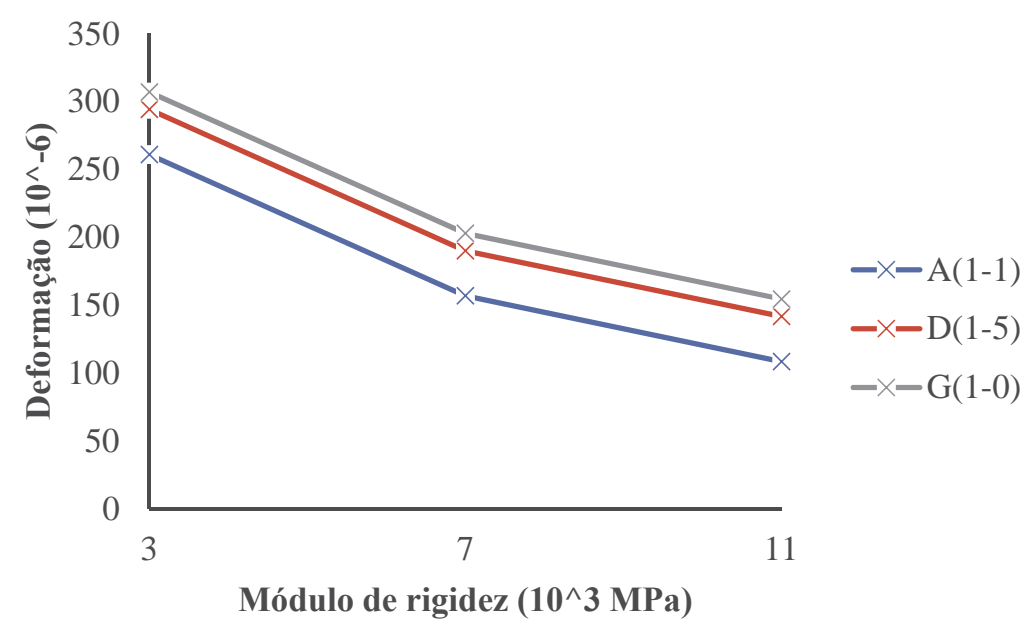

Figura 23. Deformação horizontal no revestimento do pavimento com base de BGS

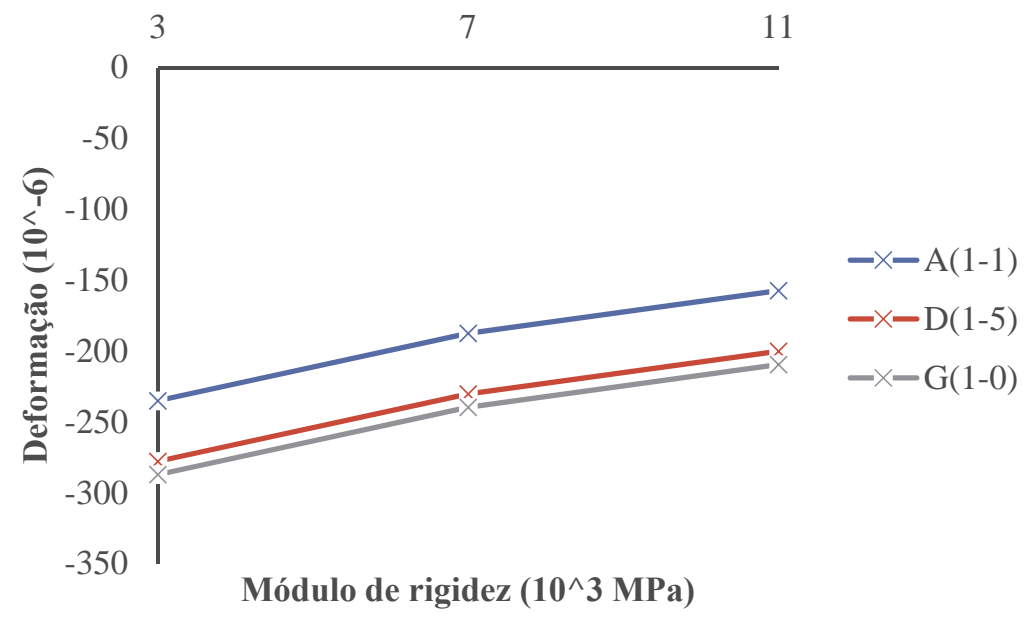

Figura 24. Deformação vertical no subleito do pavimento com base de BGS

As Figuras 25 a 27 mostram as respostas estruturais do pavimento com base composta por BGTC. A utilização de uma base mais rígida não alterou de forma expressiva o efeito da condição de interface revestimento-base, que foi maior em todas camadas do pavimento com o revestimento mais rígido. Quando perfeitamente ligado à base de BGTC, o revestimento apresentou uma deformação horizontal de compressão que, passou para o estado de tração com a perda parcial e total de aderência.

A base da estrutura sofreu as maiores deformações horizontais quando não havia resistência ao movimento entre elas (Caso G), efeito semelhante ao que se observou no subleito do pavimento. Na camada de base e no subleito a perda de ligação na interface analisada implicou em deformações 22 e $79 \%$ maiores, respectivamente. 


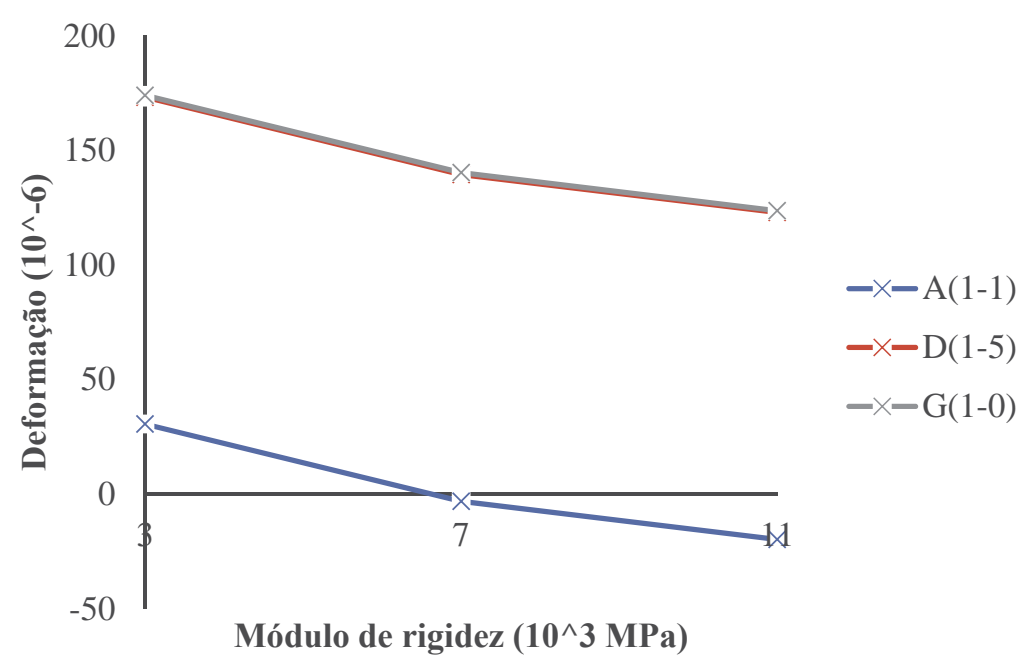

Figura 25. Deformação horizontal no revestimento do pavimento com base de BGTC

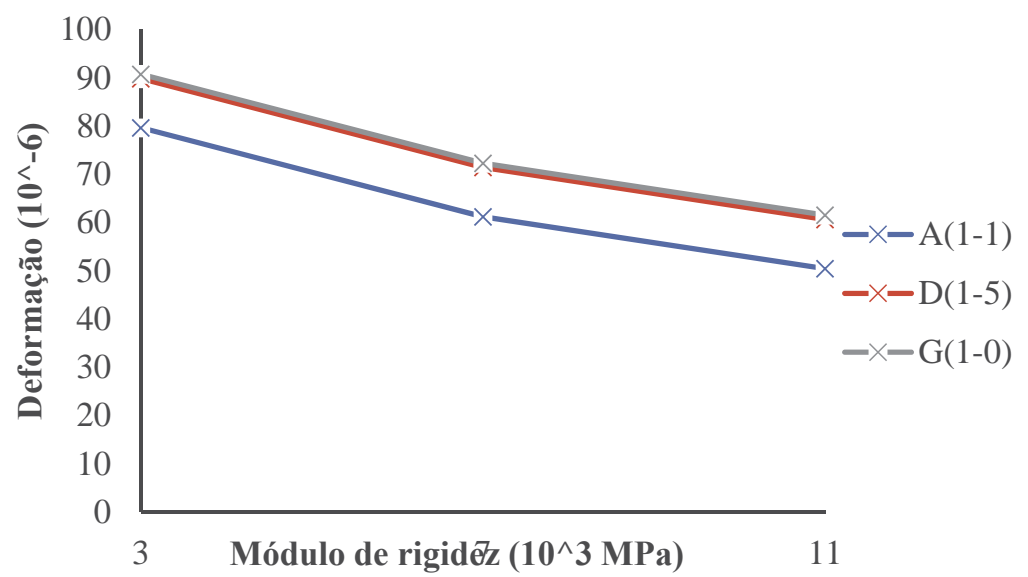

Figura 26. Deformação horizontal na base do pavimento com base de BGTC

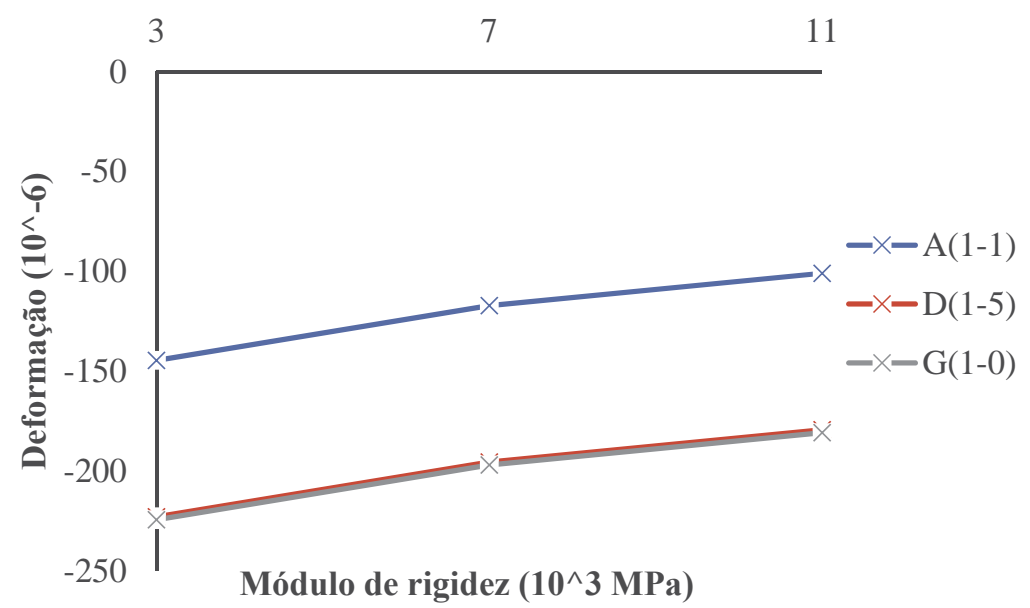

Figura 27. Deformação vertical no subleito do pavimento com base de BGTC 
De maneira geral, observou-se que a condição de contato entre as camadas de revestimento e base, influenciou o comportamento estrutural não só da camada superficial do pavimento como também das camadas inferiores. No pavimento, com ambos os tipos de base, o revestimento foi a camada mais sensível a interação na interface revestimento-base.

\subsubsection{Estrutura II}

Nas Figuras 28 a 35, são comparados os comportamentos estruturais do pavimento com duas camadas asfálticas iguais, para cada caso de aderência considerado na pesquisa. As Figuras 28 a 31 mostram as respostas estruturais do pavimento com base de BGS.

Os resultados na Figura 28 indicam que a deformação horizontal no revestimento foi mais sensível à condição da interface entre as camadas asfálticas do que entre a camada asfáltica e a base do pavimento. A deformação horizontal na camada superficial se apresentou no estado de compressão quando ambas as interfaces estavam perfeitamente aderidas (Caso A). A perda de aderência nas duas interfaces (Caso I), por sua vez, resultou em maiores deformações em alguns casos, quando levou a deformação horizontal no revestimento ao estado de tração.

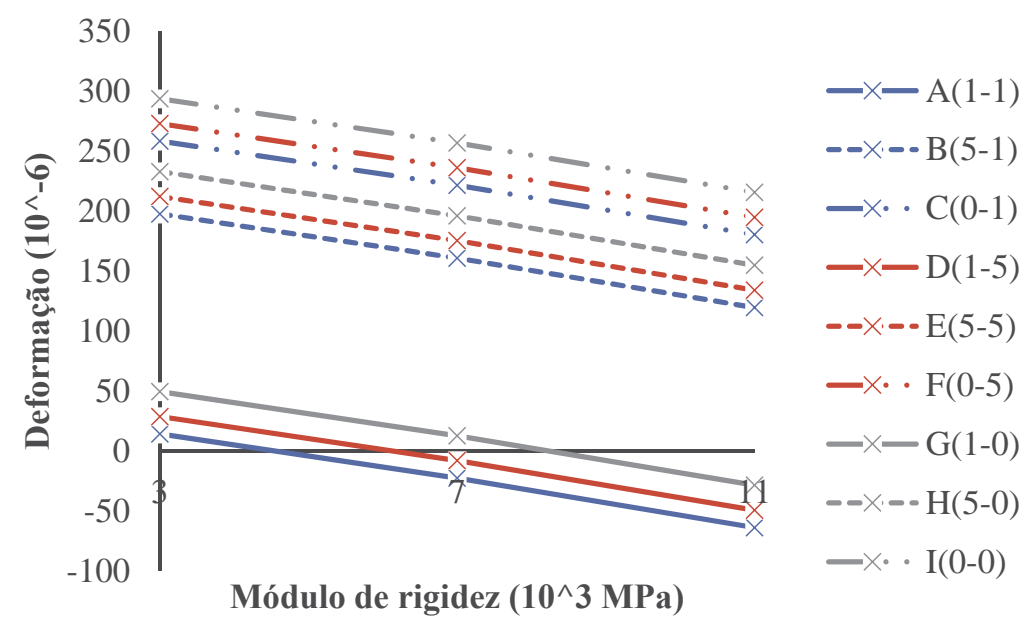

Figura 28. Deformação horizontal no revestimento do pavimento com base de BGS 


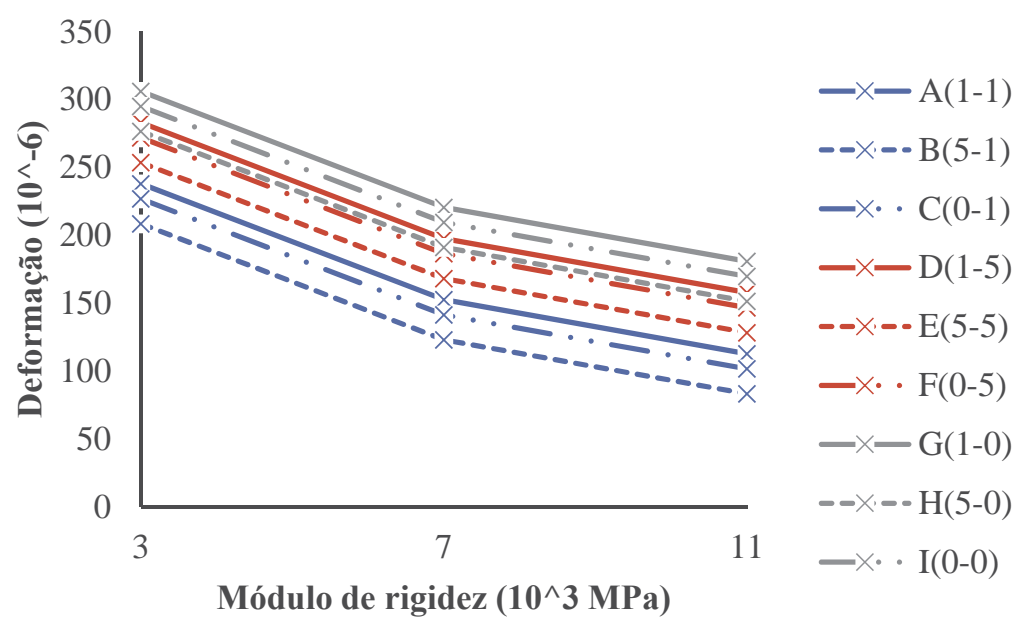

Figura 29. Deformação horizontal na camada asfáltica inferior do pavimento com base de BGS

As camadas de revestimento e subleito apresentaram as menores deformações quando havia uma perfeita aderência em ambas as interfaces. No entanto, isso não foi notado na camada asfáltica inferior (Figura 29), o que pode ter ocorrido em função da alteração na distribuição de tensões ao longo da espessura da camada, provocada pela variação da condição de interface. Na Figura 30, é apresentado o quadro de tensões quando variada a condição da interface entre as camadas asfálticas, e nela, observa-se que a perda de aderência levou a tensão horizontal, que tendia ao estado de tração ao longo da espessura, a voltar ao estado de compressão no topo da camada inferior, o que resultou em menores tensões máximas nesta camada.

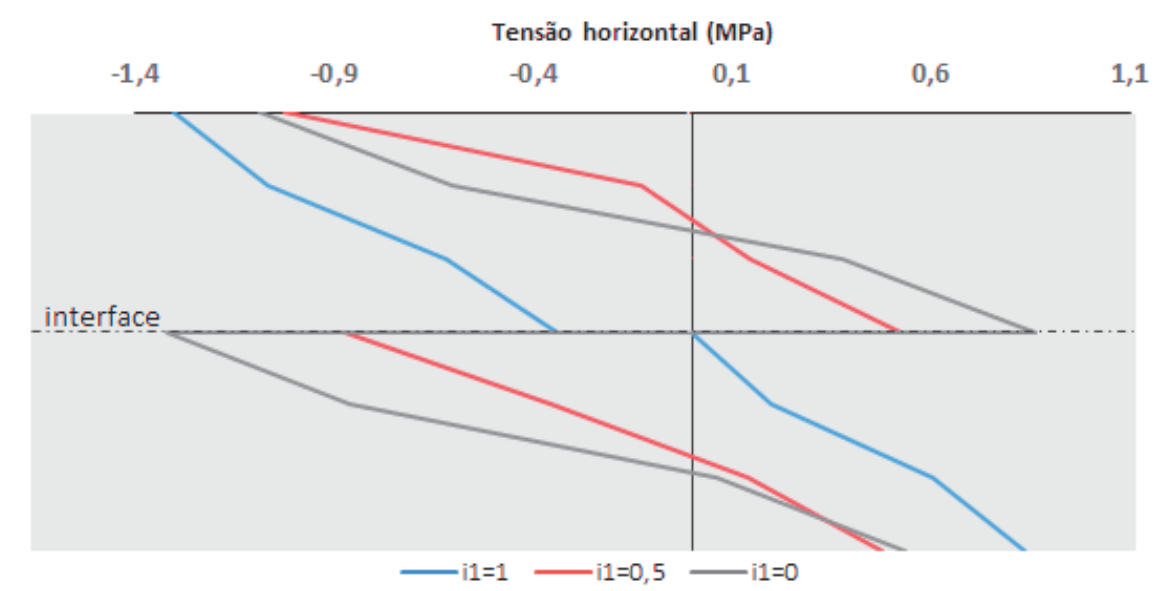

Figura 30. Distribuição de tensões ao longo da espessura das camadas asfálticas

Os resultados na Figura 31 indicam que a deformação vertical de compressão no topo do subleito foi mais sensível à condição da interface entre as camadas asfálticas do que entre a camada asfáltica e a base do pavimento. Nessa camada, a perda total de aderência acarretou em 
deformação vertical de compressão aproximadamente duas vezes maior que a deformação encontrada no Caso A (aderência completas nas duas interfaces).

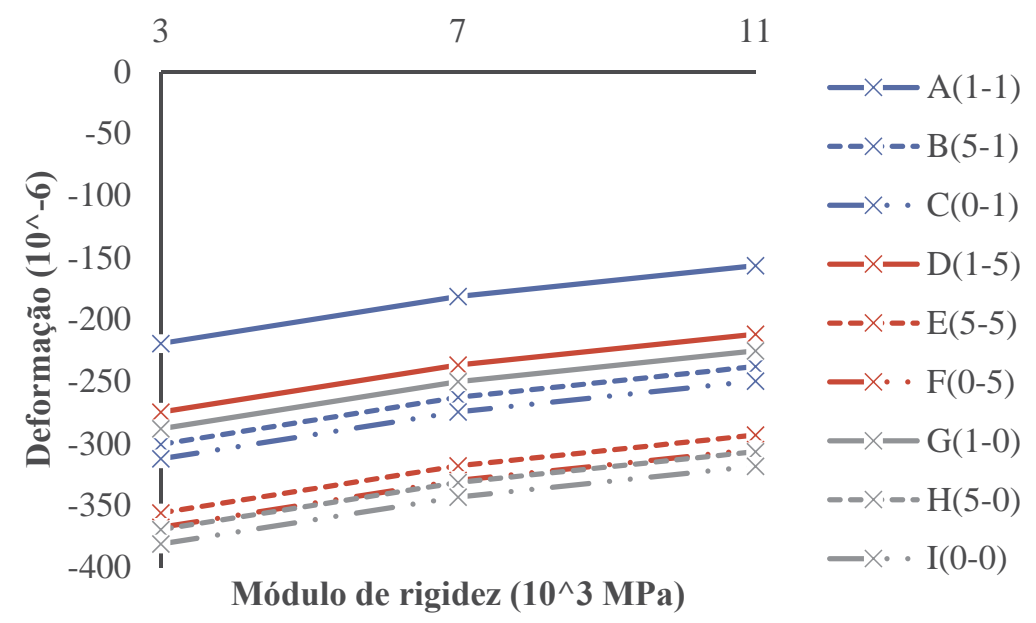

Figura 31. Deformação vertical no subleito do pavimento com base de BGS

As Figuras 32 a 35 mostram as respostas estruturais do pavimento com base de BGTC. Segundo os resultados da Figura 32, a deformação horizontal no revestimento, do pavimento com base de BGTC, também foi mais sensível à condição da interface entre as camadas asfálticas do que entre a camada asfáltica e a base do pavimento. A deformação horizontal na camada superficial apresentou uma deformação de tração, quando o módulo de rigidez foi igual a 3000 MPa e uma deformação de compressão para camadas mais rígidas. A menor deformação ocorreu quando ambas as interfaces estavam perfeitamente aderidas (Caso A).

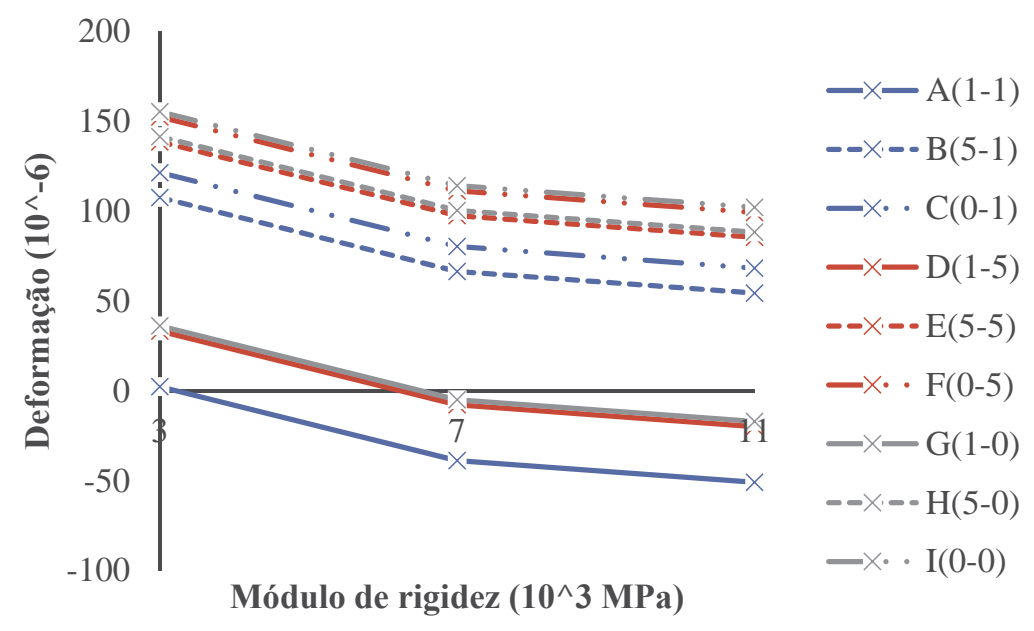

Figura 32. Deformação horizontal no revestimento do pavimento com base de BGTC 


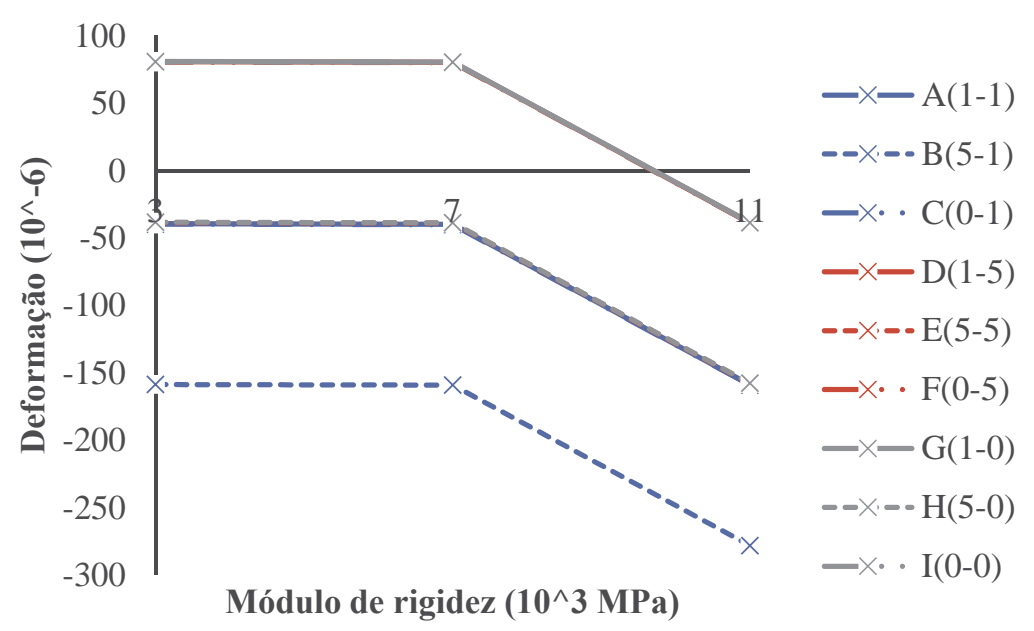

Figura 33. Deformação horizontal na camada asfáltica inferior do pavimento com base de BGTC

A base da estrutura, composta por BGTC, sofreu as menores deformações horizontais no caso de perfeita aderência nas duas interfaces, mesmo efeito que se observou no subleito do pavimento, quanto a deformação vertical de compressão. Em ambas as camadas, a perda total de aderência nas interfaces levou a deformações aproximadamente 2 vezes superior.

As duas interfaces analisadas tiveram efeito sobre as deformações na base e no subleito do pavimento. No entanto, a deformação horizontal máxima da camada de base foi mais sensível à condição de contato entre a camada asfáltica e a base. O subleito por sua vez, foi mais afetado pela interação entre as camadas asfálticas.

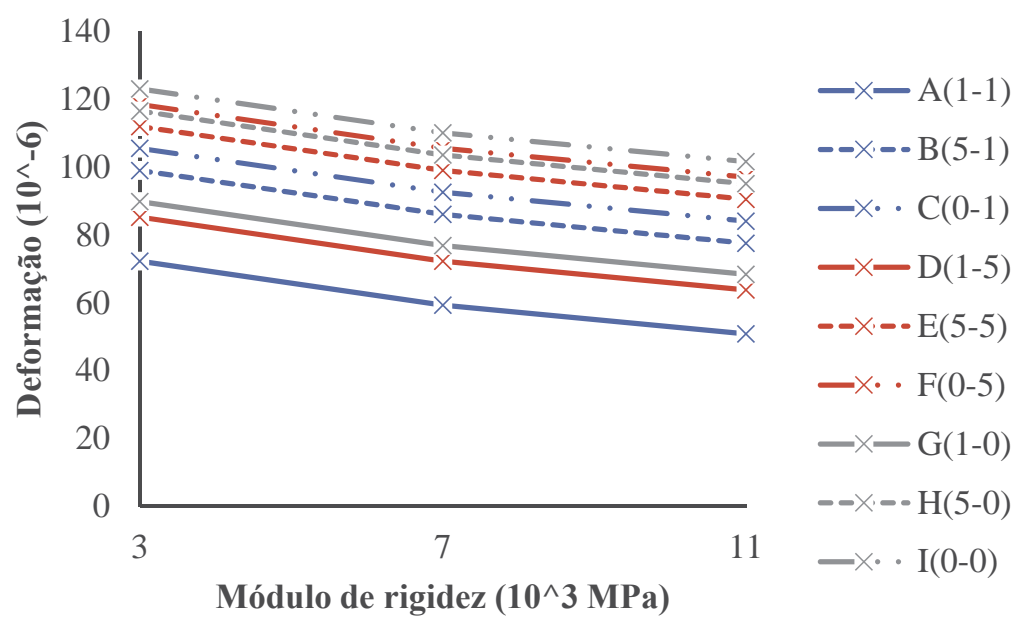

Figura 34. Deformação horizontal na base do pavimento com base de BGTC 


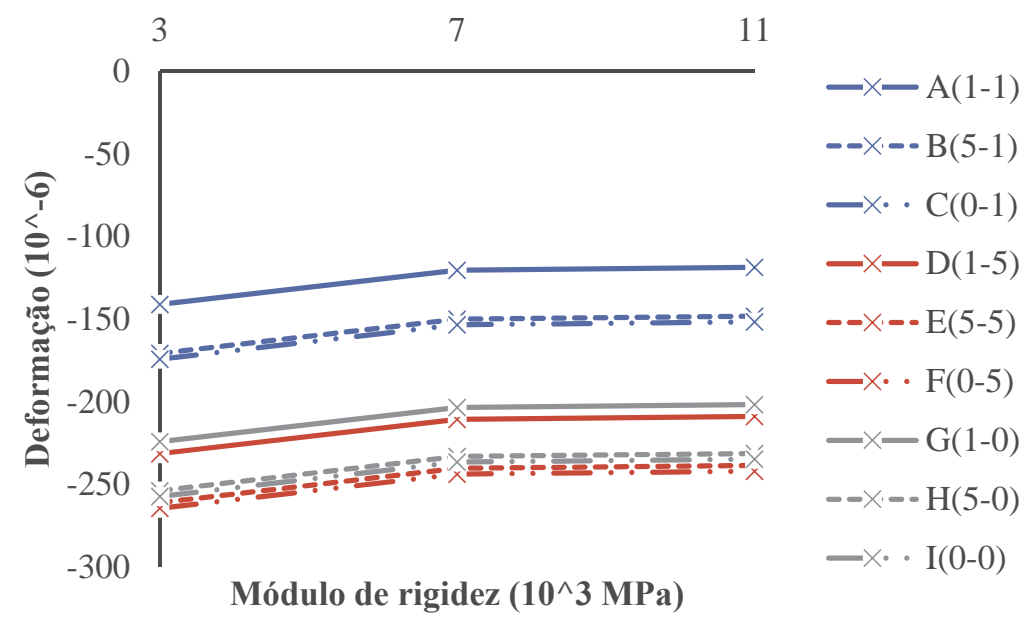

Figura 35. Deformação vertical no subleito do pavimento com base de BGTC

\subsubsection{Estrutura III}

Nas Figuras 36 a 42, são comparados os comportamentos estruturais do pavimento com a camada de revestimento assentada na camada de binder. As Figuras 36 a 38 mostram as respostas estruturais do pavimento com base de BGS. Os resultados da Figura 36 sinalizam que a deformação horizontal no revestimento foi mais sensível à condição da interface entre as camadas asfálticas do que entre a camada de binder e a base do pavimento. Considerar uma perfeita aderência entre as camadas resultou em uma deformação horizontal máxima no revestimento aproximadamente $90 \%$ menor que a deformação calculada quando não havia aderência nas interfaces (Caso I).

Na Figura 37, verifica-se que a máxima deformação horizontal de tração no binder ocorreu sob a condição de livre deslizamento nas duas interfaces (Caso I). No entanto, as maiores deformações não apareceram quando havia um perfeito contato entre as partes. Quando a camada de binder esteve ligada parcial ou totalmente à base, a perda de aderência com o revestimento gerou um aumento na sua deformação horizontal.

O perfeito contato entre as camadas, nas duas interfaces estudadas, provocou na camada de subleito as menores deformações verticais de compressão (Figura 38), cerca de $43 \%$ menor que a deformação encontrada quando não havia aderência entre as camadas (Caso I). Para essa resposta estrutural, não se notou grandes diferenças entre os efeitos causados pela interface entre camadas asfálticas e a interface binder-base. 


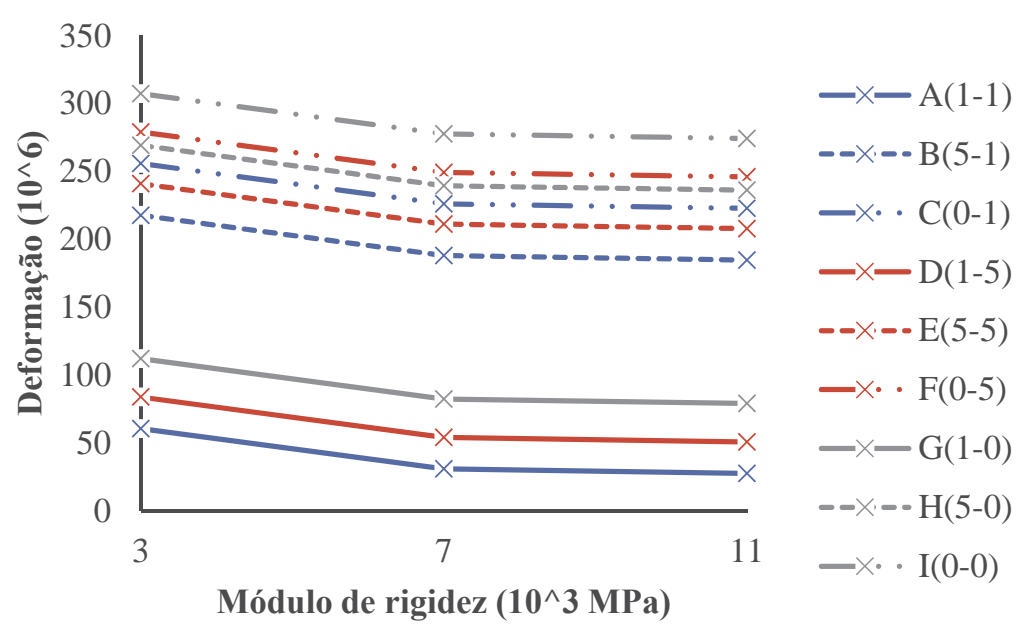

Figura 36. Deformação horizontal no revestimento do pavimento com base de BGS

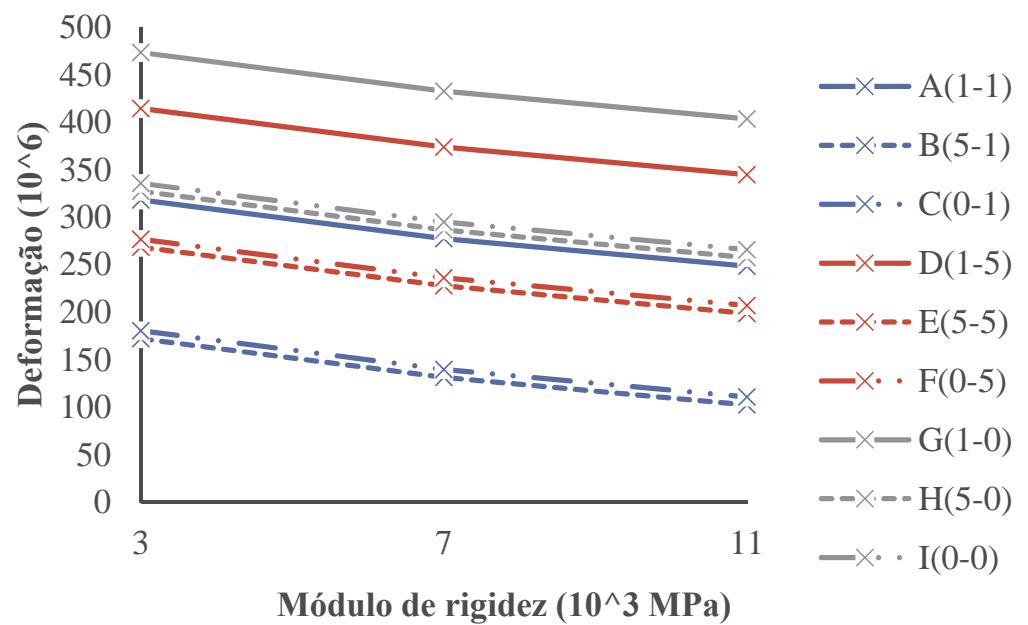

Figura 37. Deformação horizontal no binder do pavimento com base de BGS

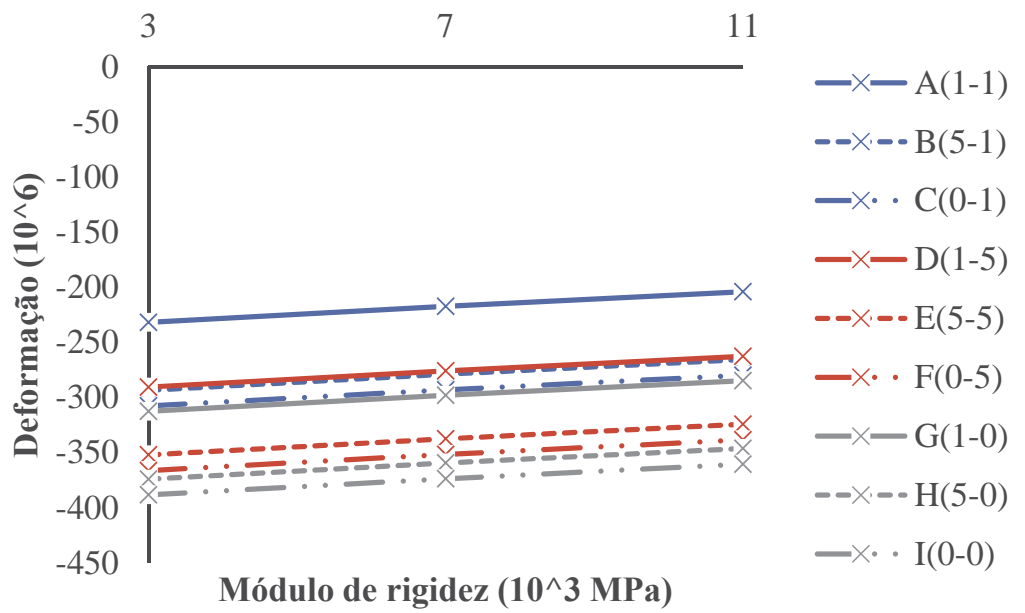

Figura 38. Deformação vertical no subleito do pavimento com base de BGS

As Figuras 39 a 42 mostram as respostas estruturais do pavimento com base de BGTC. De acordo com os resultados da Figura 39, a deformação horizontal no revestimento foi mais 
sensível à condição da interface entre as camadas asfálticas do que entre a camada de binder e a base do pavimento. Nessa camada, a menor deformação horizontal foi verificada quando ambas as interfaces estavam perfeitamente aderidas (Caso A) e a maior, com a perda de aderência nas duas interfaces (Caso I). Também pode-se observar que quanto mais rígida a camada de revestimento, maior o efeito da condição de interface sobre a deformação horizontal máxima.

Na Figura 40, pode-se observar que a perda de aderência apenas na primeira interface (Casos B e C) provocou uma redução nas deformações sofridas pela camada de binder. Em todos os outros casos considerados, a falta de ligação, total ou parcial, implicou no aumento dessas deformações.

A camada de base (Figura 41), composta por BGTC, foi a menos afetada pela interação entre as camadas. Com o revestimento mais rígido, a máxima deformação horizontal nessa camada, entre os nove casos estudados, foi aproximadamente $27 \%$ superior a menor deformação máxima.

Os resultados na Figura 42 apontam que a deformação vertical de compressão no topo do subleito foi mais sensível à condição da interface entre o binder e a base do pavimento do que entre as camadas asfálticas. Nessa camada, a perda total de aderência acarretou em um aumento de aproximadamente $63 \%$ da deformação vertical de compressão.

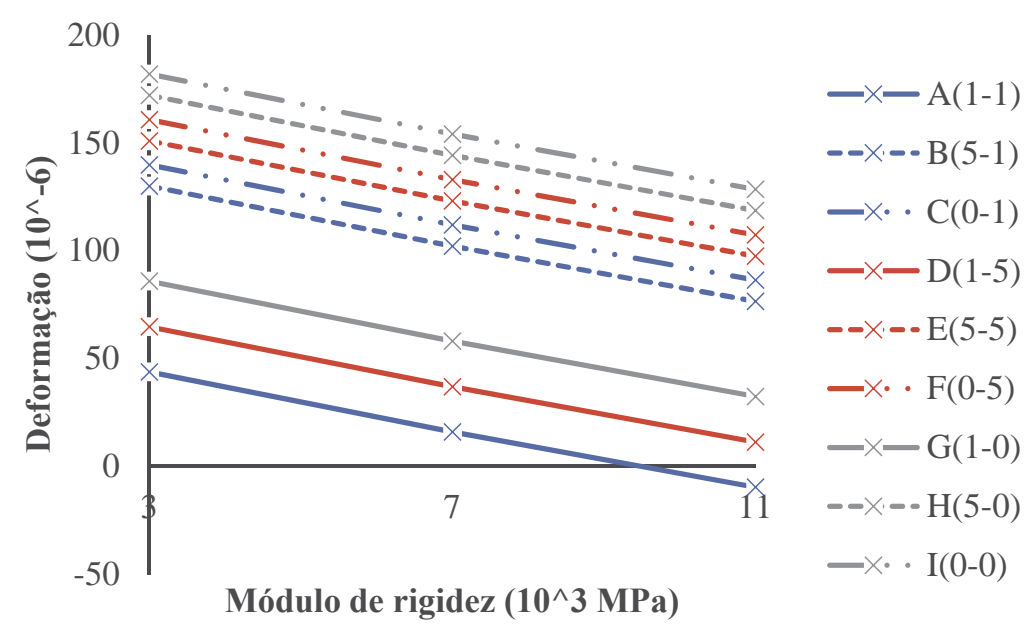

Figura 39. Deformação horizontal no revestimento do pavimento com base de BGTC 


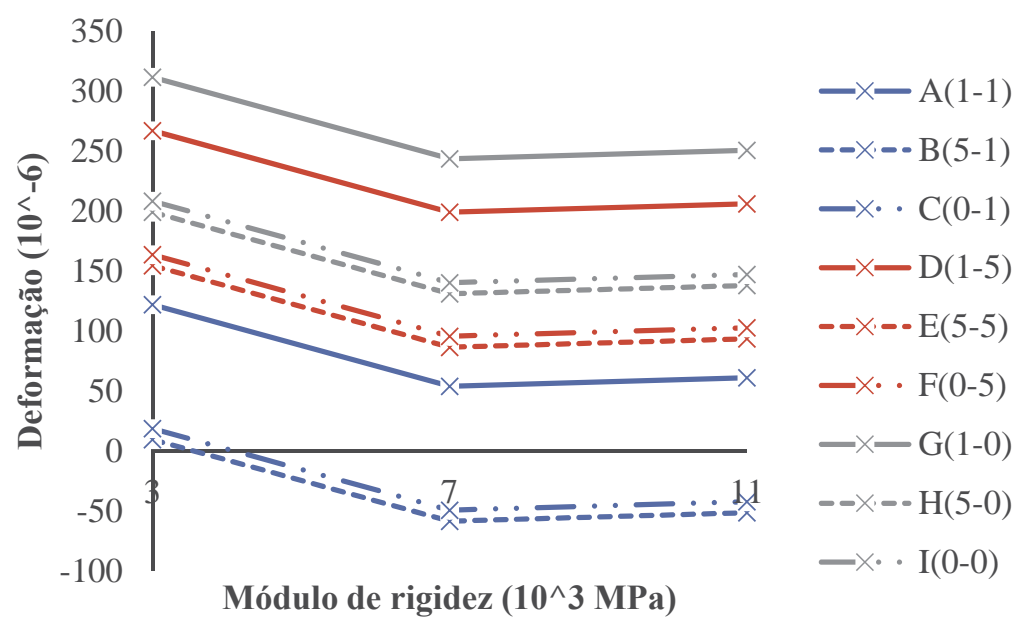

Figura 40. Deformação horizontal no binder do pavimento com base de BGTC

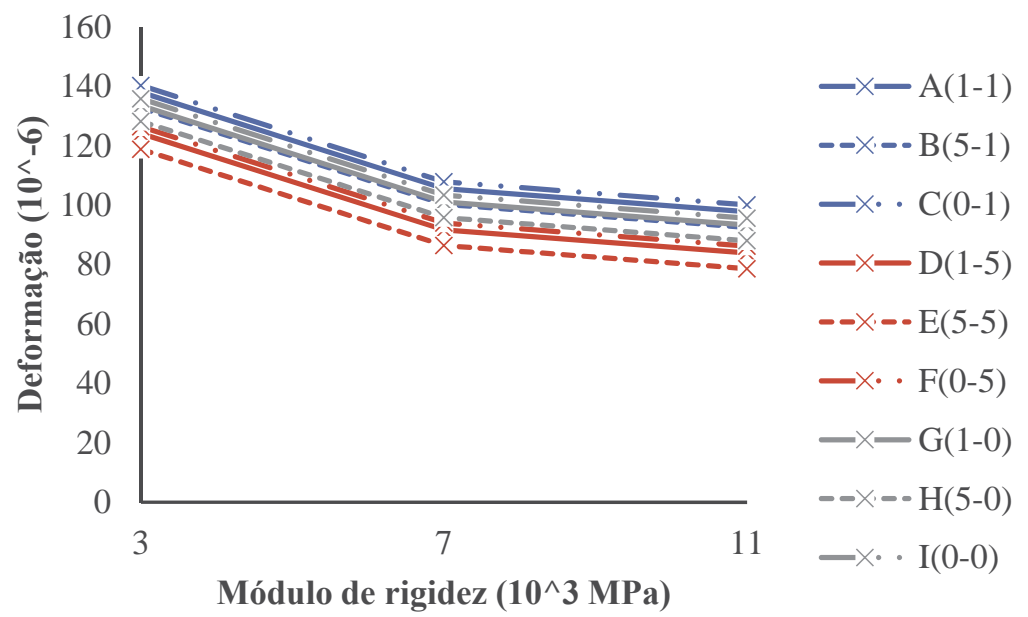

Figura 41. Deformação horizontal na base do pavimento com base de BGTC

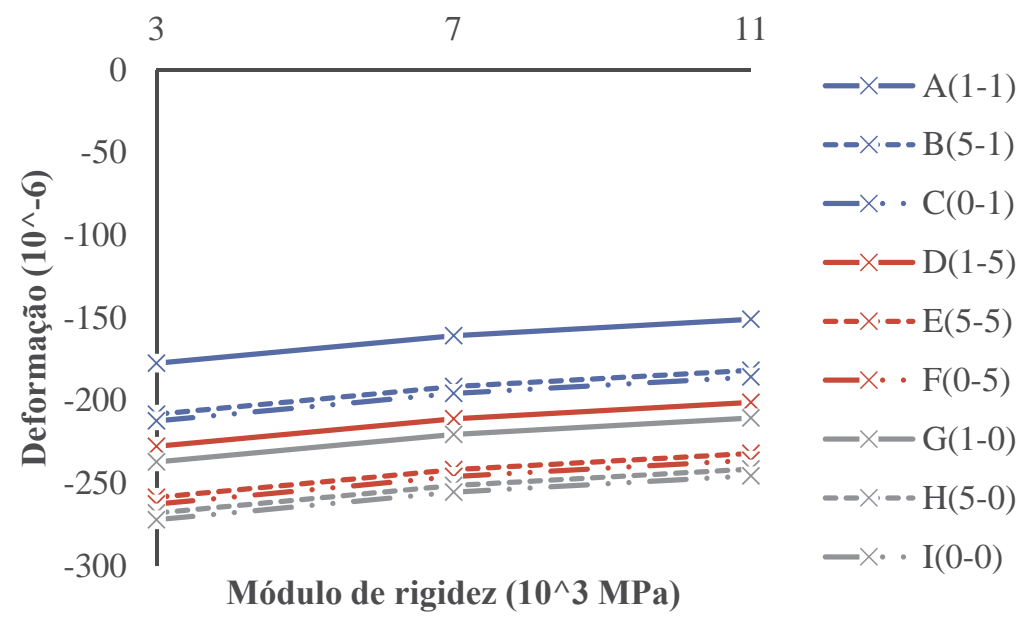

Figura 42. Deformação vertical no subleito do pavimento com base de BGTC 


\subsection{Efeito da condição de interface na vida do pavimento}

As respostas estruturais calculadas com os modelos de regressão foram associadas ao número de solicitações admissíveis à fadiga e à deformação permanente, por meio dos modelos de previsão de desempenho. Os valores de deformação apresentados no item anterior indicam que quando a condição de perfeita aderência entre as camadas não é alcançada, a distribuição de tensões e deformações muda expressivamente, o que afeta também a previsão de desempenho do pavimento, como pode ser visto nas Tabelas 23 a 27, onde são apresentadas as deformações máximas e os locais críticos relacionados ao número de solicitações admissíveis. Nas Tabelas 23 e 24 são apresentados os resultados de deformação da Estrutura I.

Tabela 23. Deformações máximas da Estrutura I com base de BGS (micro deformações)

\begin{tabular}{|c|c|c|c|c|c|}
\hline \multirow{2}{*}{ CASO } & \multirow{2}{*}{$\begin{array}{c}\text { MR } \\
\text { (MPa) }\end{array}$} & \multicolumn{2}{|c|}{$\varepsilon$ máx. } & \multicolumn{2}{|c|}{ Vida do pavimento } \\
\hline & & Revestimento & Subleito & Nfad & Ndef \\
\hline $\mathrm{A}(1-1)$ & & $260,96 *$ & $-235,06$ & $3,01 \mathrm{E}+04$ & $2,01 \mathrm{E}+08$ \\
\hline $\mathrm{D}(1-5)$ & 3000 & $294,22 *$ & $-277,82$ & $1,62 \mathrm{E}+04$ & $1,03 \mathrm{E}+08$ \\
\hline $\mathrm{G}(1-0)$ & & $307,02 *$ & $-287,22$ & $1,30 \mathrm{E}+04$ & $9,03 \mathrm{E}+07$ \\
\hline $\mathrm{A}(1-1)$ & & $156,93^{*}$ & $-187,53$ & $4,15 \mathrm{E}+05$ & $4,97 \mathrm{E}+08$ \\
\hline $\mathrm{D}(1-5)$ & 7000 & $190,19 *$ & $-230,29$ & $1,54 \mathrm{E}+05$ & $2,19 \mathrm{E}+08$ \\
\hline $\mathrm{G}(1-0)$ & & $202,99 *$ & $-239,69$ & $1,10 \mathrm{E}+05$ & $1,86 \mathrm{E}+08$ \\
\hline $\mathrm{A}(1-1)$ & & $108,53 *$ & $-157,43$ & $2,78 \mathrm{E}+06$ & $1,00 \mathrm{E}+09$ \\
\hline $\mathrm{D}(1-5)$ & 11000 & $141,79^{*}$ & $-200,19$ & $7,01 \mathrm{E}+05$ & $3,83 \mathrm{E}+08$ \\
\hline $\mathrm{G}(1-0)$ & & $154,59^{*}$ & $-209,59$ & $4,49 \mathrm{E}+05$ & $3,19 \mathrm{E}+08$ \\
\hline
\end{tabular}

* Localização crítica

Tabela 24. Deformações máximas da Estrutura I com base de BGTC (micro deformações)

\begin{tabular}{ccccccc}
\hline \multirow{2}{*}{ CASO } & \multirow{2}{*}{$\begin{array}{c}\text { MR } \\
\text { MPa) }\end{array}$} & \multicolumn{3}{c}{$\varepsilon$ máx. } & \multicolumn{3}{c}{ Vida do pavimento } \\
\cline { 3 - 7 } & & Revestimento & Base & Subleito & Nfad & Ndef \\
\hline $\mathrm{A}(1-1)$ & & 30,6 & $79,62^{*}$ & $-144,48$ & $1,38 \mathrm{E}+07$ & $1,41 \mathrm{E}+09$ \\
$\mathrm{D}(1-5)$ & \multirow{2}{*}{000} & $173,2^{*}$ & 89,82 & $-222,78$ & $2,50 \mathrm{E}+05$ & $2,50 \mathrm{E}+08$ \\
$\mathrm{G}(1-0)$ & & $174^{*}$ & 90,72 & $-224,25$ & $2,44 \mathrm{E}+05$ & $2,43 \mathrm{E}+08$ \\
\hline $\mathrm{A}(1-1)$ & & $-3,1$ & $61,2^{*}$ & $-117,04$ & $5,35 \mathrm{E}+07$ & $3,28 \mathrm{E}+09$ \\
$\mathrm{D}(1-5)$ & \multirow{2}{*}{7000} & $139,5^{*}$ & 71,4 & $-195,34$ & $7,62 \mathrm{E}+05$ & $4,22 \mathrm{E}+08$ \\
$\mathrm{G}(1-0)$ & & $140,3^{*}$ & 72,3 & $-196,81$ & $7,40 \mathrm{E}+05$ & $4,10 \mathrm{E}+08$ \\
\hline $\mathrm{A}(1-1)$ & & $-19,7$ & $50,43^{*}$ & $-100,88$ & $1,45 \mathrm{E}+08$ & $5,93 \mathrm{E}+09$ \\
$\mathrm{D}(1-5)$ & \multirow{2}{*}{11000} & $122,9^{*}$ & 60,63 & $-179,18$ & $1,47 \mathrm{E}+06$ & $5,96 \mathrm{E}+08$ \\
$\mathrm{G}(1-0)$ & & $123,7^{*}$ & 61,53 & $-180,65$ & $1,42 \mathrm{E}+06$ & $5,77 \mathrm{E}+08$ \\
\hline
\end{tabular}

* Localização crítica 
Nas Tabelas 25 e 26 são apresentados os resultados de deformação da Estrutura II, obtidos com as equações de regressão.

Tabela 25. Deformações máximas da Estrutura II com base de BGS (micro deformações)

\begin{tabular}{|c|c|c|c|c|c|c|}
\hline \multirow[b]{2}{*}{ CASO } & \multirow[b]{2}{*}{$\begin{array}{c}\text { MR } \\
\text { (MPa) }\end{array}$} & \multicolumn{3}{|c|}{$\varepsilon$ máx. } & \multicolumn{2}{|c|}{ Vida do pavimento } \\
\hline & & Revestimento & $\begin{array}{c}\text { C. A. } \\
\text { inferior }\end{array}$ & Subleito & Nfad & Ndef \\
\hline $\mathrm{A}(1-1)$ & & 14,22 & $238 *$ & $-219,25$ & $4,84 \mathrm{E}+04$ & $2,66 \mathrm{E}+08$ \\
\hline $\mathrm{B}(5-1)$ & & 197,72 & $208,5^{*}$ & $-300,54$ & $9,58 \mathrm{E}+04$ & $7,53 \mathrm{E}+07$ \\
\hline $\mathrm{C}(0-1)$ & & $258,52 *$ & 226,87 & $-312,22$ & $3,16 \mathrm{E}+04$ & $6,47 \mathrm{E}+07$ \\
\hline $\mathrm{D}(1-5)$ & & 28,72 & $283,05^{*}$ & $-274,53$ & $1,98 \mathrm{E}+04$ & $1,08 \mathrm{E}+08$ \\
\hline $\mathrm{E}(5-5)$ & 3000 & 212,22 & $253,55^{*}$ & $-355,82$ & $3,49 \mathrm{E}+04$ & $3,83 \mathrm{E}+07$ \\
\hline $\mathrm{F}(0-5)$ & & $273,02 *$ & 271,92 & $-367,5$ & $2,38 \mathrm{E}+04$ & $3,37 \mathrm{E}+07$ \\
\hline $\mathrm{G}(1-0)$ & & 49,52 & $306,11 *$ & $-287,96$ & $1,32 \mathrm{E}+04$ & $8,94 \mathrm{E}+07$ \\
\hline $\mathrm{H}(5-0)$ & & 233,02 & $276,61 *$ & $-369,25$ & $2,23 \mathrm{E}+04$ & $3,31 \mathrm{E}+07$ \\
\hline $\mathrm{I}(0-0)$ & & 293,82 & $294,98 *$ & $-380,93$ & $1,60 \mathrm{E}+04$ & $2,92 \mathrm{E}+07$ \\
\hline $\mathrm{A}(1-1)$ & & $-22,58$ & $152,58 *$ & $-181,4$ & $4,80 \mathrm{E}+05$ & $5,68 \mathrm{E}+08$ \\
\hline $\mathrm{B}(5-1)$ & & $160,92 *$ & 123,08 & $-262,69$ & $3,65 \mathrm{E}+05$ & $1,29 \mathrm{E}+08$ \\
\hline $\mathrm{C}(0-1)$ & & $221,72 *$ & 141,45 & $-274,37$ & $6,98 \mathrm{E}+04$ & $1,08 \mathrm{E}+08$ \\
\hline $\mathrm{D}(1-5)$ & & $-8,08$ & $197,63 *$ & $-236,68$ & $1,26 \mathrm{E}+05$ & $1,96 \mathrm{E}+08$ \\
\hline $\mathrm{E}(5-5)$ & 7000 & $175,42 *$ & 168,13 & $-317,97$ & $2,34 \mathrm{E}+05$ & $6,01 \mathrm{E}+07$ \\
\hline $\mathrm{F}(0-5)$ & & $236,22 *$ & 186,5 & $-329,65$ & $5,03 \mathrm{E}+04$ & $5,20 \mathrm{E}+07$ \\
\hline $\mathrm{G}(1-0)$ & & 12,72 & $220,69 *$ & $-250,11$ & $7,15 \mathrm{E}+04$ & $1,57 \mathrm{E}+08$ \\
\hline $\mathrm{H}(5-0)$ & & $196,22 *$ & 191,19 & $-331,4$ & $1,31 \mathrm{E}+05$ & $5,10 \mathrm{E}+07$ \\
\hline $\mathrm{I}(0-0)$ & & $257,02 *$ & 209,56 & $-343,08$ & $3,26 \mathrm{E}+04$ & $4,44 \mathrm{E}+07$ \\
\hline $\mathrm{A}(1-1)$ & & $-63,88$ & $112,79 *$ & $-156,51$ & $2,28 \mathrm{E}+06$ & $1,02 \mathrm{E}+09$ \\
\hline $\mathrm{B}(5-1)$ & & $119,62 *$ & 83,29 & $-237,8$ & $1,69 \mathrm{E}+06$ & $1,92 \mathrm{E}+08$ \\
\hline $\mathrm{C}(0-1)$ & & $180,42 *$ & 101,66 & $-249,48$ & $2,02 \mathrm{E}+05$ & $1,59 \mathrm{E}+08$ \\
\hline $\mathrm{D}(1-5)$ & & $-49,38$ & $157,84^{*}$ & $-211,79$ & $4,03 \mathrm{E}+05$ & $3,05 \mathrm{E}+08$ \\
\hline $\mathrm{E}(5-5)$ & 11000 & $134,12 *$ & 128,34 & $-293,08$ & $9,34 \mathrm{E}+05$ & $8,33 \mathrm{E}+07$ \\
\hline $\mathrm{F}(0-5)$ & & $194,92 *$ & 146,71 & $-304,76$ & $1,36 \mathrm{E}+05$ & $7,13 \mathrm{E}+07$ \\
\hline $\mathrm{G}(1-0)$ & & $-28,58$ & $180,9^{*}$ & $-225,22$ & $1,99 \mathrm{E}+05$ & $2,39 \mathrm{E}+08$ \\
\hline $\mathrm{H}(5-0)$ & & $154,92 *$ & 151,4 & $-306,51$ & $4,44 \mathrm{E}+05$ & $6,96 \mathrm{E}+07$ \\
\hline $\mathrm{I}(0-0)$ & & $215,72 *$ & 169,77 & $-318,19$ & $8,04 \mathrm{E}+04$ & $6,00 \mathrm{E}+07$ \\
\hline
\end{tabular}

* Localização crítica 
Tabela 26. Deformações máximas da Estrutura II com base de BGTC (micro deformações)

\begin{tabular}{|c|c|c|c|c|c|c|c|}
\hline \multirow[b]{2}{*}{ CASO } & \multirow[b]{2}{*}{$\begin{array}{c}\text { MR } \\
\text { (MPa) }\end{array}$} & \multicolumn{4}{|c|}{$\varepsilon$ máx. } & \multicolumn{2}{|c|}{ Vida do pavimento } \\
\hline & & Revestimento & $\begin{array}{l}\text { C. A. } \\
\text { inferior }\end{array}$ & Base & Subleito & Nfad & Ndef \\
\hline $\mathrm{A}(1-1)$ & & 2,25 & $-39,36$ & $72,287 *$ & $-141,08$ & $2,27 \mathrm{E}+07$ & $1,55 \mathrm{E}+09$ \\
\hline $\mathrm{B}(5-1)$ & & $107,46^{*}$ & $-158,61$ & 98,987 & $-170,72$ & $2,93 E+06$ & $7,24 \mathrm{E}+08$ \\
\hline $\mathrm{C}(0-1)$ & & $121,3^{*}$ & $-39,63$ & 105,497 & $-174,17$ & $1,57 \mathrm{E}+06$ & $6,68 \mathrm{E}+08$ \\
\hline $\mathrm{D}(1-5)$ & & 33,23 & 80,77 & $85,237^{*}$ & $-231,33$ & $9,68 \mathrm{E}+06$ & $2,15 \mathrm{E}+08$ \\
\hline $\mathrm{E}(5-5)$ & 3000 & $138,44 *$ & $-38,48$ & 111,937 & $-260,97$ & $7,93 \mathrm{E}+05$ & $1,33 \mathrm{E}+08$ \\
\hline $\mathrm{F}(0-5)$ & & $152,28 *$ & 80,5 & 118,447 & $-264,42$ & $4,85 \mathrm{E}+05$ & $1,26 \mathrm{E}+08$ \\
\hline $\mathrm{G}(1-0)$ & & 36,1 & 81,01 & $89,797 *$ & $-224,11$ & $7,40 \mathrm{E}+06$ & $2,44 \mathrm{E}+08$ \\
\hline $\mathrm{H}(5-0)$ & & $141,31^{*}$ & $-38,24$ & 116,497 & $-253,75$ & $7,13 \mathrm{E}+05$ & $1,48 \mathrm{E}+08$ \\
\hline $\mathrm{I}(0-0)$ & & $155,15^{*}$ & 80,74 & 123,007 & $-257,2$ & $4,40 \mathrm{E}+05$ & $1,40 \mathrm{E}+08$ \\
\hline $\mathrm{A}(1-1)$ & & $-38,8$ & $-39,8$ & $59,347 *$ & $-120,36$ & $6,27 \mathrm{E}+07$ & $2,93 \mathrm{E}+09$ \\
\hline $\mathrm{B}(5-1)$ & & 66,41 & $-159,05$ & $86,047^{*}$ & -150 & $9,22 \mathrm{E}+06$ & $1,21 \mathrm{E}+09$ \\
\hline $\mathrm{C}(0-1)$ & & 80,25 & $-40,07$ & $92,557 *$ & $-153,45$ & $6,33 \mathrm{E}+06$ & $1,11 \mathrm{E}+09$ \\
\hline $\mathrm{D}(1-5)$ & & $-7,82$ & $80,33^{*}$ & 72,297 & $-210,61$ & $1,32 \mathrm{E}+07$ & $3,12 \mathrm{E}+08$ \\
\hline $\mathrm{E}(5-5)$ & 7000 & 97,39 & $-38,92$ & $98,997 *$ & $-240,25$ & $4,47 \mathrm{E}+06$ & $1,84 \mathrm{E}+08$ \\
\hline $\mathrm{F}(0-5)$ & & $111,23^{*}$ & 80,06 & 105,507 & $-243,7$ & $2,45 \mathrm{E}+06$ & $1,74 \mathrm{E}+08$ \\
\hline $\mathrm{G}(1-0)$ & & $-4,95$ & $80,57^{*}$ & 76,857 & $-203,39$ & $1,29 \mathrm{E}+07$ & $3,59 \mathrm{E}+08$ \\
\hline $\mathrm{H}(5-0)$ & & 100,26 & $-38,68$ & $103,557^{*}$ & $-233,03$ & $3,55 \mathrm{E}+06$ & $2,08 \mathrm{E}+08$ \\
\hline $\mathrm{I}(0-0)$ & & $114,1^{*}$ & 80,3 & 110,067 & $-236,48$ & $2,15 \mathrm{E}+06$ & $1,97 \mathrm{E}+08$ \\
\hline $\mathrm{A}(1-1)$ & & $-50,87$ & $-158,77$ & $50,867 *$ & $-118,59$ & $1,39 \mathrm{E}+08$ & $3,11 \mathrm{E}+09$ \\
\hline $\mathrm{B}(5-1)$ & & 54,34 & $-278,02$ & $77,567 *$ & $-148,23$ & $1,58 \mathrm{E}+07$ & $1,27 \mathrm{E}+09$ \\
\hline $\mathrm{C}(0-1)$ & & 68,18 & $-159,04$ & $84,077 *$ & $-151,68$ & $1,04 \mathrm{E}+07$ & $1,16 \mathrm{E}+09$ \\
\hline $\mathrm{D}(1-5)$ & & $-19,89$ & $-38,64$ & $63,817^{*}$ & $-208,84$ & $4,31 \mathrm{E}+07$ & $3,23 \mathrm{E}+08$ \\
\hline$E(5-5)$ & 11000 & 85,32 & $-157,89$ & $90,517^{*}$ & $-238,48$ & $7,10 \mathrm{E}+06$ & $1,90 \mathrm{E}+08$ \\
\hline $\mathrm{F}(0-5)$ & & $99,16^{*}$ & $-38,91$ & 97,027 & $-241,93$ & $4,44 \mathrm{E}+06$ & $1,79 \mathrm{E}+08$ \\
\hline $\mathrm{G}(1-0)$ & & $-17,02$ & $-38,4$ & $68,377 *$ & $-201,62$ & $3,02 \mathrm{E}+07$ & $3,72 \mathrm{E}+08$ \\
\hline $\mathrm{H}(5-0)$ & & 88,19 & $-157,65$ & $95,077 *$ & $-231,26$ & $5,51 \mathrm{E}+06$ & $2,15 \mathrm{E}+08$ \\
\hline $\mathrm{I}(0-0)$ & & $102,03 *$ & $-38,67$ & 101,587 & $-234,71$ & $3,83 \mathrm{E}+06$ & $2,03 \mathrm{E}+08$ \\
\hline
\end{tabular}

* Localização crítica 
Tabela 27. Deformações máximas da Estrutura III com base de BGS (micro deformações)

\begin{tabular}{ccccccc}
\hline \multirow{2}{*}{ CASO } & MR & \multicolumn{3}{c}{$\boldsymbol{\varepsilon}$ máx. } & \multicolumn{2}{c}{ Vida do pavimento } \\
\cline { 3 - 6 } & MPa) & Revestimento & Binder & Subleito & Nfad & Ndef \\
\hline $\mathrm{A}(1-1)$ & & 60,68 & $318,14^{*}$ & $-231,78$ & $1,08 \mathrm{E}+04$ & $2,13 \mathrm{E}+08$ \\
$\mathrm{~B}(5-1)$ & $217,78^{*}$ & 172,18 & $-293,34$ & $7,65 \mathrm{E}+04$ & $8,30 \mathrm{E}+07$ \\
$\mathrm{C}(0-1)$ & & $255,88^{*}$ & 180,51 & $-307,56$ & $3,33 \mathrm{E}+04$ & $6,87 \mathrm{E}+07$ \\
$\mathrm{D}(1-5)$ & & 83,88 & $414,47^{*}$ & $-290,41$ & $2,77 \mathrm{E}+03$ & $8,64 \mathrm{E}+07$ \\
$\mathrm{E}(5-5)$ & 3000 & 240,98 & $268,51^{*}$ & $-351,97$ & $2,60 \mathrm{E}+04$ & $4,01 \mathrm{E}+07$ \\
$\mathrm{~F}(0-5)$ & & $279,08^{*}$ & 276,84 & $-366,19$ & $2,13 \mathrm{E}+04$ & $3,42 \mathrm{E}+07$ \\
$\mathrm{G}(1-0)$ & & 112,18 & $473,26^{*}$ & $-312,44$ & $1,40 \mathrm{E}+03$ & $6,45 \mathrm{E}+07$ \\
$\mathrm{H}(5-0)$ & & 269,28 & $327,3^{*}$ & -374 & $9,35 \mathrm{E}+03$ & $3,14 \mathrm{E}+07$ \\
$\mathrm{I}(0-0)$ & 307,38 & $335,63^{*}$ & $-388,22$ & $8,22 \mathrm{E}+03$ & $2,71 \mathrm{E}+07$ \\
\hline $\mathrm{A}(1-1)$ & 30,98 & $277,53^{*}$ & $-217,15$ & $2,19 \mathrm{E}+04$ & $2,76 \mathrm{E}+08$ \\
$\mathrm{~B}(5-1)$ & $188,08^{*}$ & 131,57 & $-278,71$ & $1,63 \mathrm{E}+05$ & $1,02 \mathrm{E}+08$ \\
$\mathrm{C}(0-1)$ & $226,18^{*}$ & 139,9 & $-292,93$ & $6,30 \mathrm{E}+04$ & $8,35 \mathrm{E}+07$ \\
$\mathrm{D}(1-5)$ & 54,18 & $373,86^{*}$ & $-275,78$ & $4,71 \mathrm{E}+03$ & $1,06 \mathrm{E}+08$ \\
$\mathrm{E}(5-5)$ & 7000 & 211,28 & $227,9^{*}$ & $-337,34$ & $6,06 \mathrm{E}+04$ & $4,75 \mathrm{E}+07$ \\
$\mathrm{~F}(0-5)$ & & $249,38^{*}$ & 236,23 & $-351,56$ & $3,80 \mathrm{E}+04$ & $4,02 \mathrm{E}+07$ \\
$\mathrm{G}(1-0)$ & 82,48 & $432,65^{*}$ & $-297,81$ & $2,22 \mathrm{E}+03$ & $7,81 \mathrm{E}+07$ \\
$\mathrm{H}(5-0)$ & & 239,58 & $286,69^{*}$ & $-359,37$ & $1,85 \mathrm{E}+04$ & $3,69 \mathrm{E}+07$ \\
$\mathrm{I}(0-0)$ & & 277,68 & $295,02^{*}$ & $-373,59$ & $1,60 \mathrm{E}+04$ & $3,16 \mathrm{E}+07$ \\
\hline $\mathrm{A}(1-1)$ & 27,68 & $248,41^{*}$ & $-203,9$ & $3,88 \mathrm{E}+04$ & $3,56 \mathrm{E}+08$ \\
$\mathrm{~B}(5-1)$ & & $184,78^{*}$ & 102,45 & $-265,46$ & $1,79 \mathrm{E}+05$ & $1,24 \mathrm{E}+08$ \\
$\mathrm{C}(0-1)$ & $222,88^{*}$ & 110,78 & $-279,68$ & $6,79 \mathrm{E}+04$ & $1,00 \mathrm{E}+08$ \\
$\mathrm{D}(1-5)$ & 50,88 & $344,74^{*}$ & $-262,53$ & $7,16 \mathrm{E}+03$ & $1,29 \mathrm{E}+08$ \\
$\mathrm{E}(5-5)$ & 11000 & $207,98^{*}$ & 198,78 & $-324,09$ & $9,71 \mathrm{E}+04$ & $5,57 \mathrm{E}+07$ \\
$\mathrm{~F}(0-5)$ & & $246,08^{*}$ & 207,11 & $-338,31$ & $4,08 \mathrm{E}+04$ & $4,69 \mathrm{E}+07$ \\
$\mathrm{G}(1-0)$ & 79,18 & $403,53^{*}$ & $-284,56$ & $3,18 \mathrm{E}+03$ & $9,37 \mathrm{E}+07$ \\
$\mathrm{H}(5-0)$ & 236,28 & $257,57^{*}$ & $-346,12$ & $3,22 \mathrm{E}+04$ & $4,28 \mathrm{E}+07$ \\
$\mathrm{I}(0-0)$ & & 265,9 & $-360,34$ & $2,32 \mathrm{E}+04$ & $3,65 \mathrm{E}+07$ \\
\hline & & & & & &
\end{tabular}

* Localização crítica 
Tabela 28. Deformações máximas da Estrutura III com base de BGTC (micro deformações)

\begin{tabular}{|c|c|c|c|c|c|c|c|}
\hline \multirow{2}{*}{ CASO } & \multirow{2}{*}{$\begin{array}{c}\text { MR } \\
\text { (MPa) }\end{array}$} & \multicolumn{4}{|c|}{$\varepsilon$ máx. } & \multicolumn{2}{|c|}{ Vida do pavimento } \\
\hline & & Revestimento & Binder & Base & Subleito & Nfad & Ndef \\
\hline $\mathrm{A}(1-1)$ & & 43,74 & 122,3 & $138,03 *$ & $-177,45$ & $8,05 \mathrm{E}+05$ & $6,20 \mathrm{E}+08$ \\
\hline $\mathrm{B}(5-1)$ & & 129,87 & 9,7 & $132,73^{*}$ & $-208,29$ & $9,85 \mathrm{E}+05$ & $3,27 \mathrm{E}+08$ \\
\hline $\mathrm{C}(0-1)$ & & 139,71 & 18,9 & $140,33 *$ & $-212,37$ & $7,39 \mathrm{E}+05$ & $3,02 \mathrm{E}+08$ \\
\hline $\mathrm{D}(1-5)$ & & 64,67 & $267,4^{*}$ & 124,13 & $-227,72$ & $2,65 \mathrm{E}+04$ & $2,29 \mathrm{E}+08$ \\
\hline $\mathrm{E}(5-5)$ & 3000 & 150,8 & $154,8^{*}$ & 118,83 & $-258,56$ & $4,46 \mathrm{E}+05$ & $1,38 \mathrm{E}+08$ \\
\hline $\mathrm{F}(0-5)$ & & 160,64 & $164 *$ & 126,43 & $-262,64$ & $3,31 \mathrm{E}+05$ & $1,29 \mathrm{E}+08$ \\
\hline $\mathrm{G}(1-0)$ & & 85,81 & $312 *$ & 133,53 & $-237,19$ & $1,20 \mathrm{E}+04$ & $1,94 \mathrm{E}+08$ \\
\hline $\mathrm{H}(5-0)$ & & 171,94 & $199,4 *$ & 128,23 & $-268,03$ & $1,21 \mathrm{E}+05$ & $1,19 \mathrm{E}+08$ \\
\hline $\mathrm{I}(0-0)$ & & 181,78 & $208,6^{*}$ & 135,83 & $-272,11$ & $9,56 \mathrm{E}+04$ & $1,12 \mathrm{E}+08$ \\
\hline $\mathrm{A}(1-1)$ & & 15,95 & 54,3 & $105,63 *$ & $-160,75$ & $3,20 \mathrm{E}+06$ & $9,21 \mathrm{E}+08$ \\
\hline $\mathrm{B}(5-1)$ & & $102,08^{*}$ & $-58,3$ & 100,33 & $-191,59$ & $3,82 \mathrm{E}+06$ & $4,56 \mathrm{E}+08$ \\
\hline $\mathrm{C}(0-1)$ & & $111,92 *$ & $-49,1$ & 107,93 & $-195,67$ & $2,38 \mathrm{E}+06$ & $4,19 \mathrm{E}+08$ \\
\hline $\mathrm{D}(1-5)$ & & 36,88 & 199,4 & $91,73^{*}$ & $-211,02$ & $1,21 \mathrm{E}+05$ & $3,10 \mathrm{E}+08$ \\
\hline $\mathrm{E}(5-5)$ & 7000 & $123,01 *$ & 86,8 & 86,43 & $-241,86$ & $1,46 \mathrm{E}+06$ & $1,80 \mathrm{E}+08$ \\
\hline $\mathrm{F}(0-5)$ & & $132,85^{*}$ & 96 & 94,03 & $-245,94$ & $9,81 \mathrm{E}+05$ & $1,68 \mathrm{E}+08$ \\
\hline $\mathrm{G}(1-0)$ & & 58,02 & 244 & $101,13 *$ & $-220,49$ & $4,26 \mathrm{E}+04$ & $2,60 \mathrm{E}+08$ \\
\hline $\mathrm{H}(5-0)$ & & $144,15^{*}$ & 131,4 & 95,83 & $-251,33$ & $6,44 \mathrm{E}+05$ & $1,54 \mathrm{E}+08$ \\
\hline $\mathrm{I}(0-0)$ & & $153,99^{*}$ & 140,6 & 103,43 & $-255,41$ & $4,58 \mathrm{E}+05$ & $1,44 \mathrm{E}+08$ \\
\hline $\mathrm{A}(1-1)$ & & $-9,67$ & 61,3 & $97,83^{*}$ & $-150,89$ & $4,76 \mathrm{E}+06$ & $1,19 \mathrm{E}+09$ \\
\hline $\mathrm{B}(5-1)$ & & 76,46 & $-51,3$ & $92,53^{*}$ & $-181,73$ & $6,34 \mathrm{E}+06$ & $5,64 \mathrm{E}+08$ \\
\hline $\mathrm{C}(0-1)$ & & 86,3 & $-42,1$ & $100,13 *$ & $-185,81$ & $4,22 \mathrm{E}+06$ & $5,16 \mathrm{E}+08$ \\
\hline $\mathrm{D}(1-5)$ & & 11,26 & $206,4 *$ & 83,93 & $-201,16$ & $1,01 \mathrm{E}+05$ & $3,75 \mathrm{E}+08$ \\
\hline $\mathrm{E}(5-5)$ & 11000 & $97,39^{*}$ & 93,8 & 78,63 & -232 & $4,87 \mathrm{E}+06$ & $2,12 \mathrm{E}+08$ \\
\hline $\mathrm{F}(0-5)$ & & $107,23 *$ & 103 & 86,23 & $-236,08$ & $2,96 \mathrm{E}+06$ & $1,98 \mathrm{E}+08$ \\
\hline $\mathrm{G}(1-0)$ & & 32,4 & $251^{*}$ & 93,33 & $-210,63$ & $3,68 \mathrm{E}+04$ & $3,12 \mathrm{E}+08$ \\
\hline $\mathrm{H}(5-0)$ & & 118,53 & $138,4^{*}$ & 88,03 & $-241,47$ & $7,94 \mathrm{E}+05$ & $1,81 \mathrm{E}+08$ \\
\hline $\mathrm{I}(0-0)$ & & 128,37 & $147,6^{*}$ & 95,63 & $-245,55$ & $5,70 \mathrm{E}+05$ & $1,69 \mathrm{E}+08$ \\
\hline
\end{tabular}

\subsubsection{Previsão de desempenho à fadiga}

O número de solicitações responsável por levar o pavimento à ruptura por fadiga é apresentado nas Figuras 43 a 48. Nas Estruturas I e II, os casos de completa aderência entre as camadas (Caso A) resultaram em uma vida de fadiga maior que os demais casos. A Estrutura I (Figuras 43 e 44) teve uma vida de fadiga aproximadamente 6 e 102 vezes maior que os demais casos, quando o revestimento esteve perfeitamente ligado à base, de BGS e BGTC, respectivamente. 
Na Estrutura II (Figuras 45 e 46), a vida do pavimento no Caso A alcançou um valor aproximadamente 28 e 36 (base com BGS e BGTC, respectivamente) vezes maior que o caso de não aderência entre as camadas (Caso I). A vida de fadiga da estrutura com base de BGS foi afetada de forma semelhante pelas duas interfaces estudadas, o que não ocorreu na estrutura com base de BGTC, quando a vida do pavimento foi mais sensível à interação na interface entre as camadas asfálticas.

A condição de interface entre as camadas também impactou a vida do pavimento da Estrutura III (Figuras 47 e 48), no entanto, o Caso A (camadas completamente aderidas) não apresentou o pavimento com uma vida mais longa que os demais casos para a estrutura com base de BGS (Figura 47).

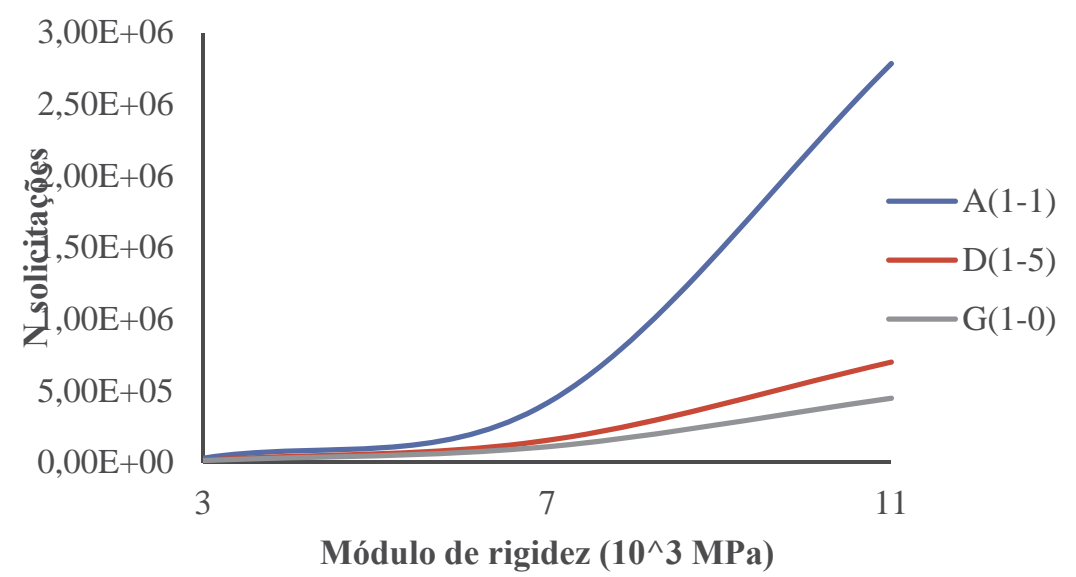

Figura 43. Curva de fadiga da Estrutura I com base de BGS

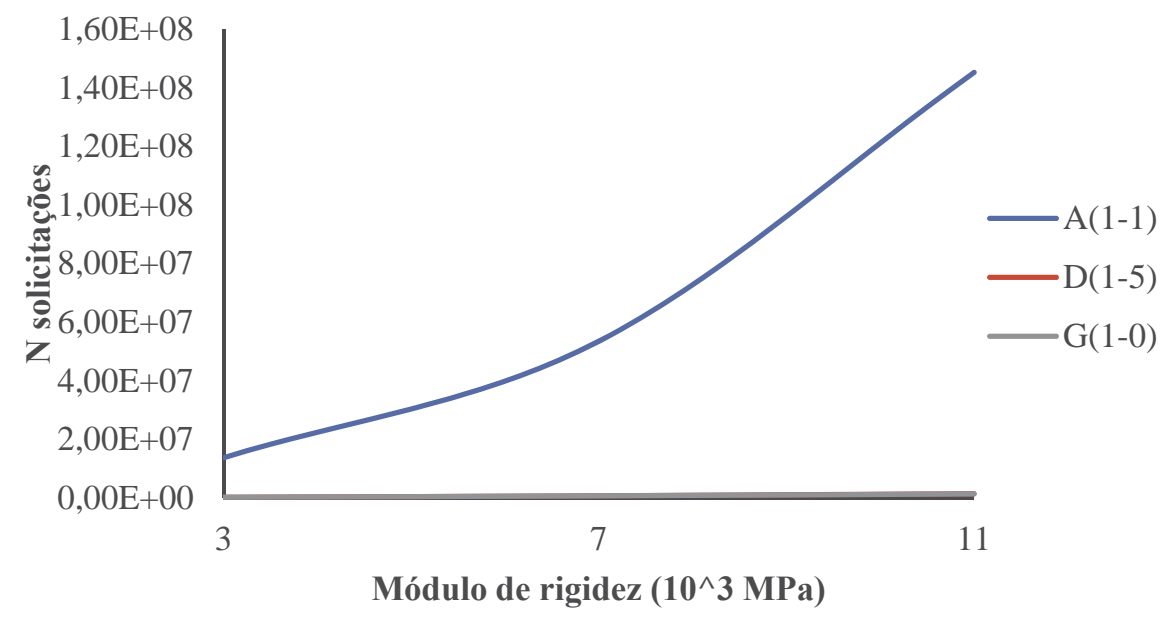

Figura 44. Curva de fadiga da Estrutura I com base de BGTC 


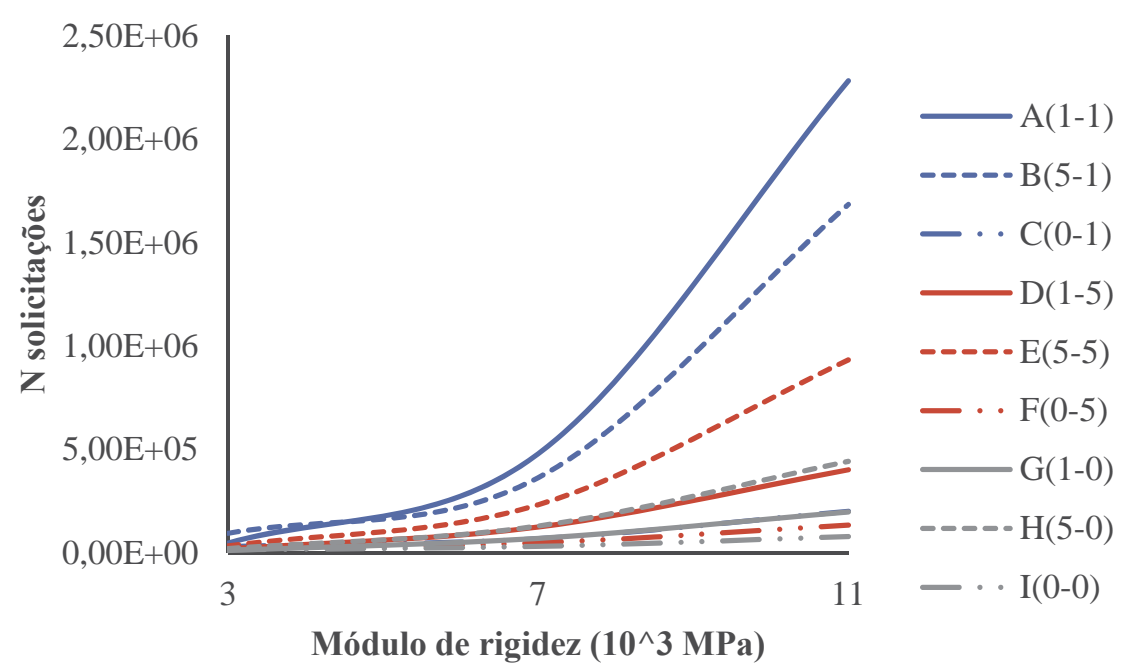

Figura 45. Curva de fadiga da Estrutura II com base de BGS

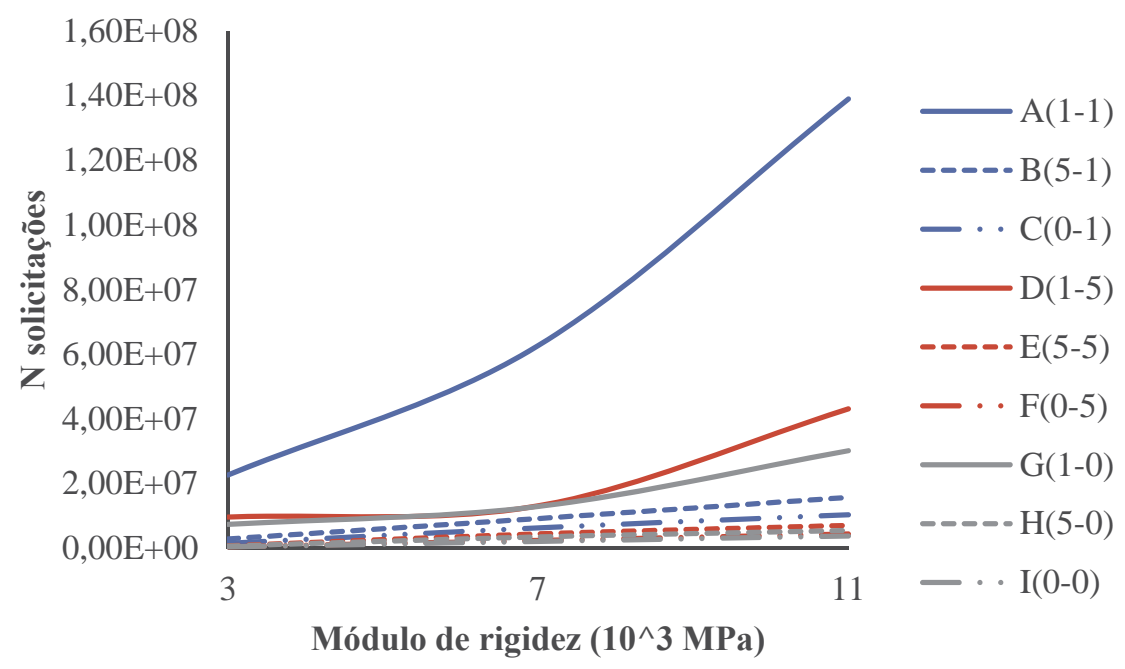

Figura 46. Curva de fadiga da Estrutura II com base de BGTC

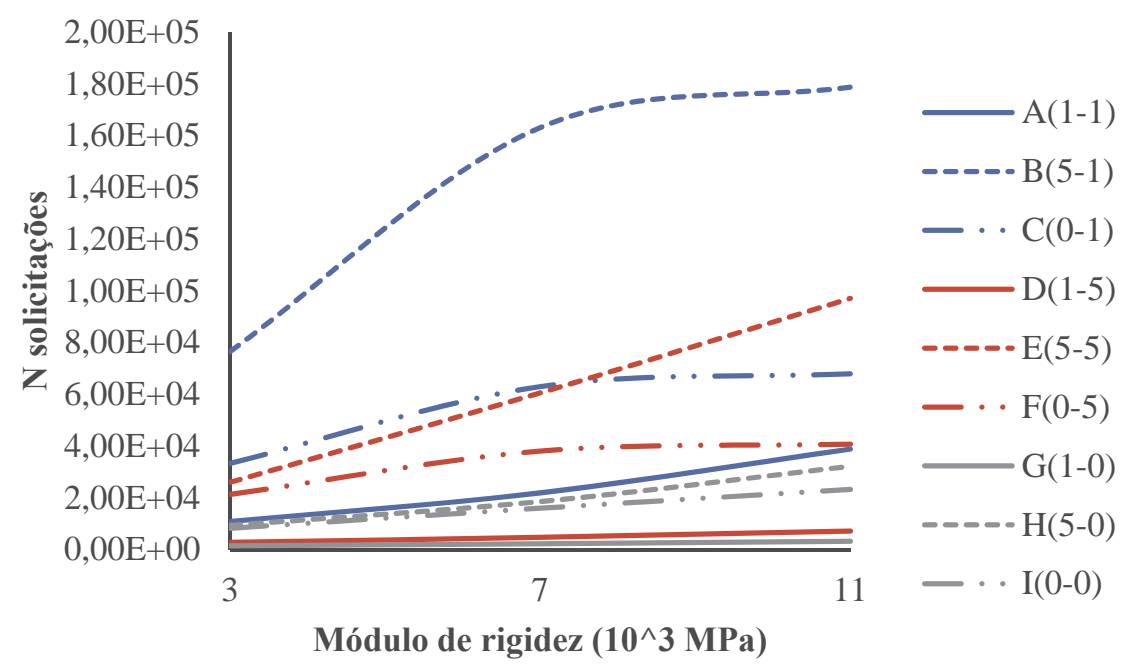

Figura 47. Curva de fadiga da Estrutura III com base de BGS 


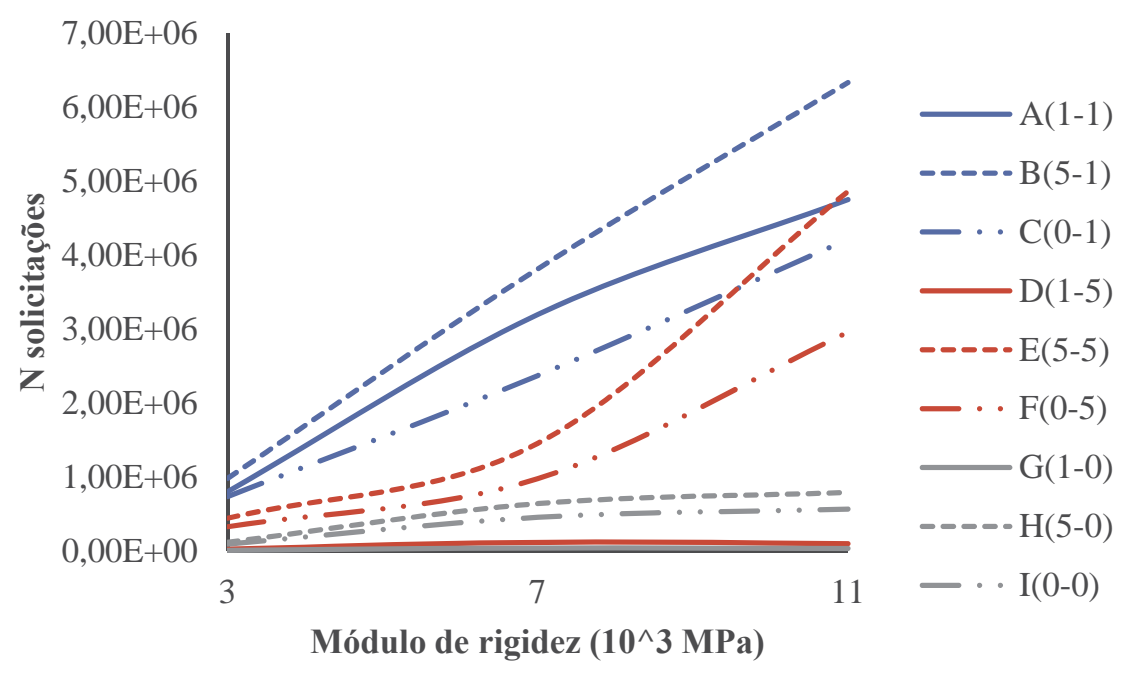

Figura 48. Curva de fadiga da Estrutura III com base de BGTC

\subsubsection{Previsão de desempenho à deformação permanente}

O número de solicitações responsável por levar o pavimento à falha por deformação permanente é apresentado nas Figuras 49 a 54. A vida de deformação permanente das três estruturas avaliadas, com base de BGS ou BGTC, foi claramente mais longa quando havia uma completa ligação entre as camadas (Caso A).

A estrutura I (Figuras 49 e 50) teve uma vida de deformação permanente aproximadamente 3 e 10 vezes maior que os demais casos, quando o revestimento esteve perfeitamente ligado à base, de BGS e BGTC, respectivamente.

Na Estrutura II (Figuras 51 e 52), a vida do pavimento no Caso A alcançou um valor aproximadamente 17 vezes maior que o caso I (aderência nula), para os dois tipos de base. Quando as camadas estavam perfeitamente aderidas, a vida de deformação permanente da Estrutura III (Figuras 43 e 54) com base de BGS e BGTC foi, respectivamente, 10 e 7 vezes superior ao previsto para a condição de camadas não aderidas. Dentre as duas interfaces analisadas, a vida de deformação permanente das estruturas II e III foi mais sensível a condição de contato entre a camadas asfáltica e a base do pavimento. 


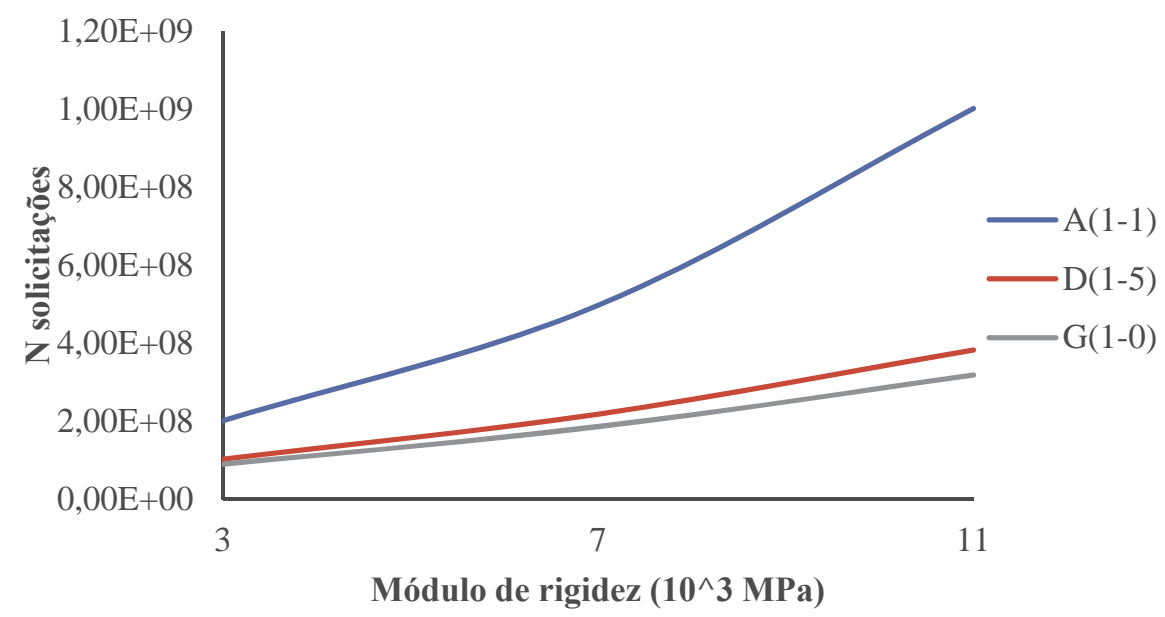

Figura 49. Curva de deformação permanente da Estrutura I com base de BGS

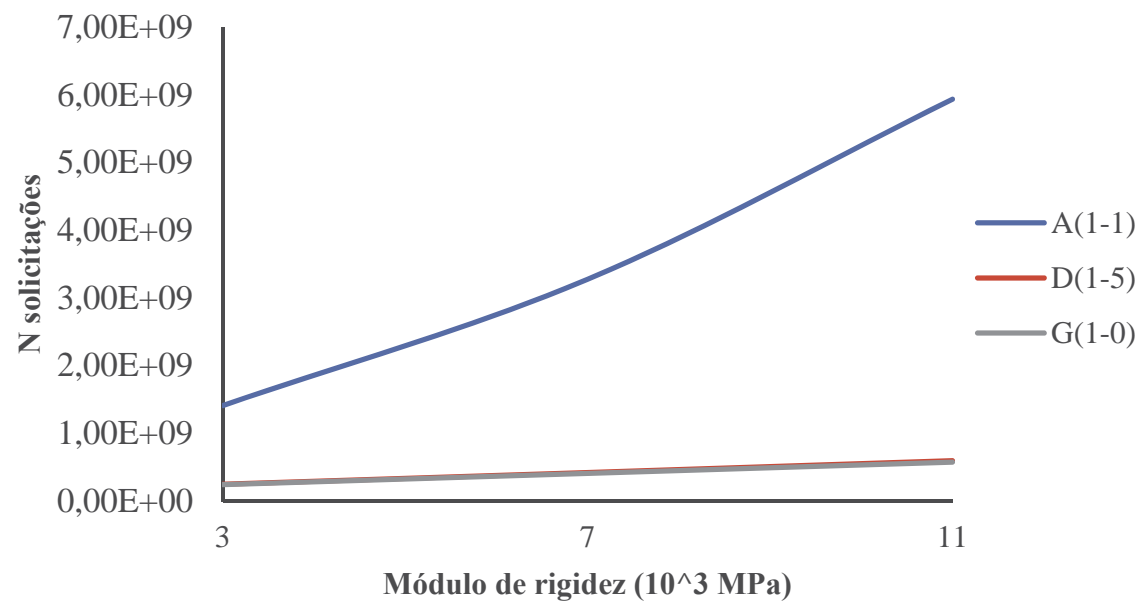

Figura 50. Curva de deformação permanente da Estrutura I com base de BGTC

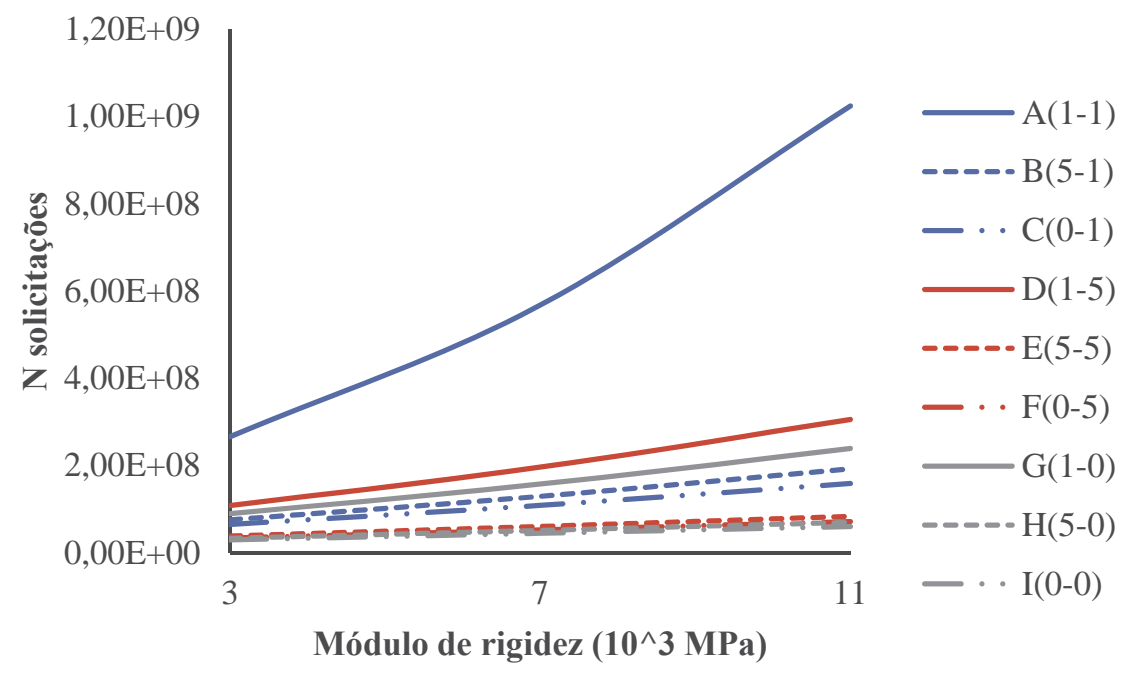

Figura 51. Curva de deformação permanente da Estrutura II com base de BGS 


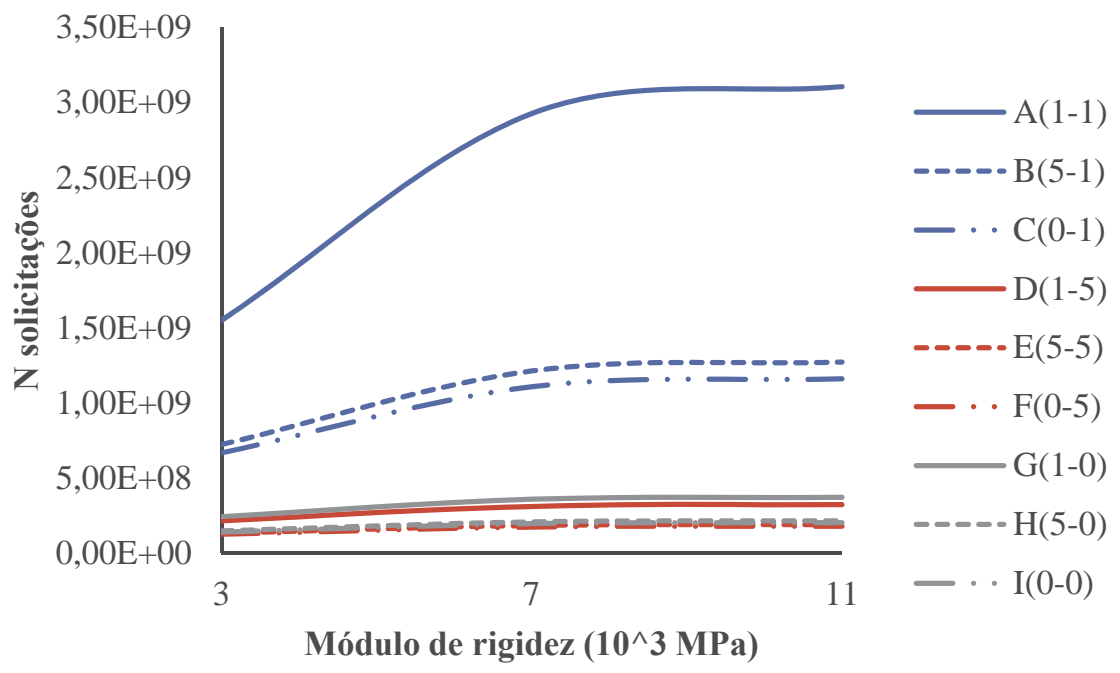

Figura 52. Curva de deformação permanente da Estrutura II com base de BGTC

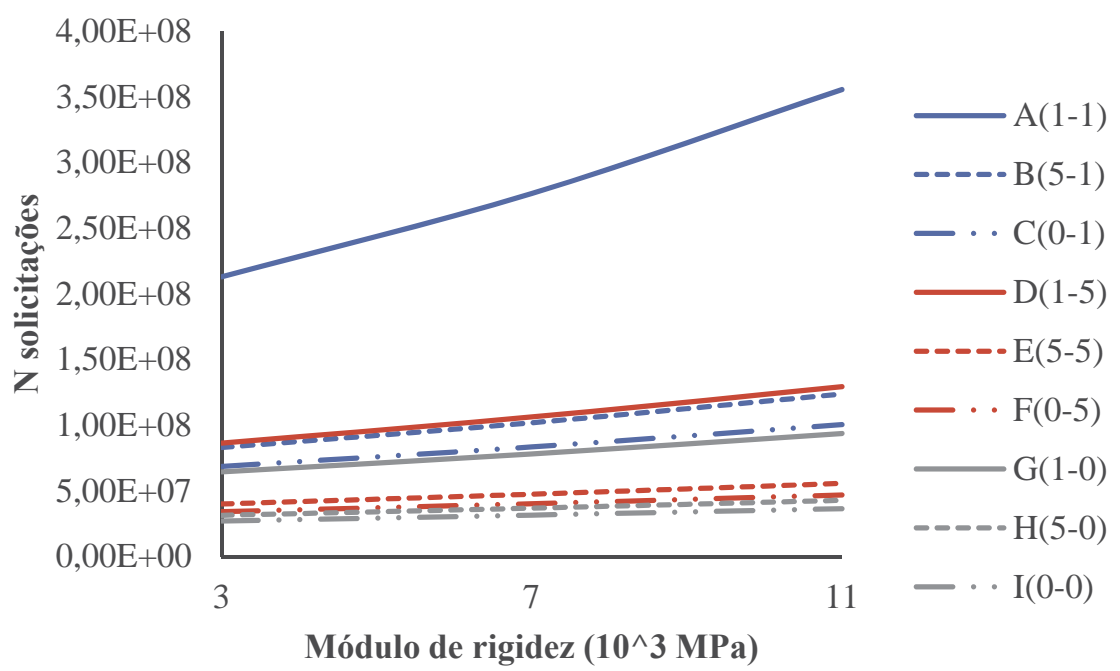

Figura 53. Curva de deformação permanente da Estrutura III com base de BGS

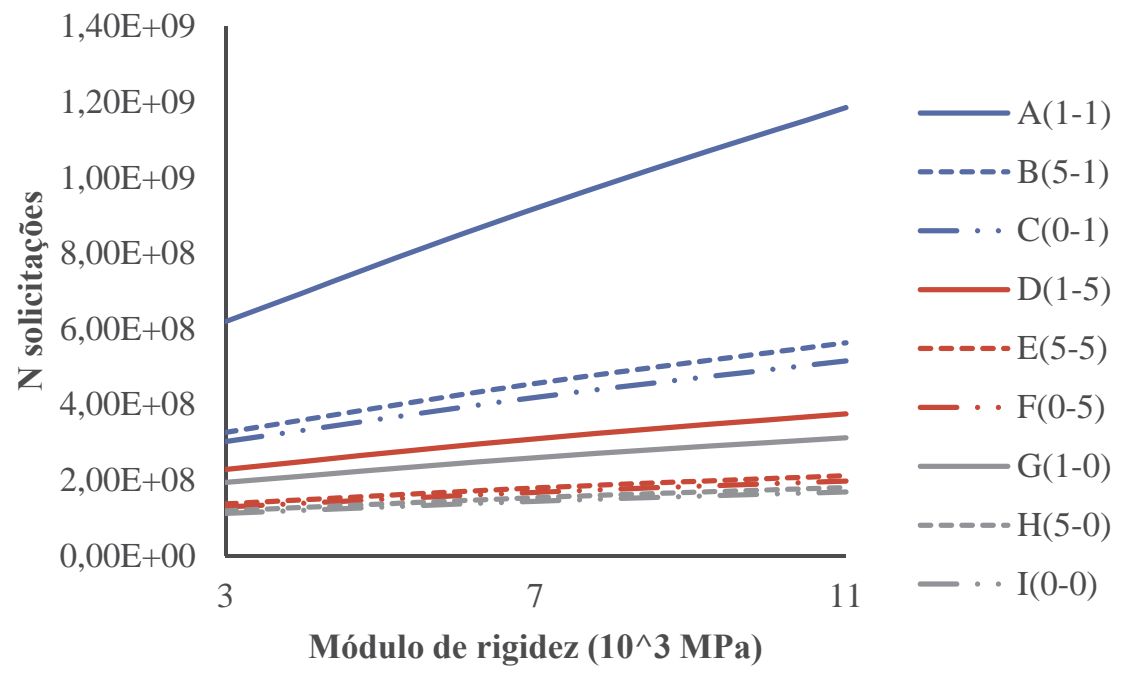

Figura 54. Curva de deformação permanente da Estrutura III com base de BGTC 


\section{CONCLUSÕES}

Neste capítulo são apresentadas as principais conclusões da pesquisa em função dos objetivos estabelecidos e dos resultados obtidos, bem como sugestões para trabalhos complementares.

A condição de contato entre as camadas asfálticas e entre a camada asfáltica e a base, principal aspecto analisado neste trabalho, influencia as deformações máximas em um pavimento, não só na camada superficial como também em suas camadas inferiores.

A condição de contato entre as camadas tem um maior efeito sobre a durabilidade do pavimento quanto à fadiga das camadas asfálticas e cimentadas do que à deformação permanente. O efeito da condição de interface entre as camadas altera as deformações horizontais máximas não só em magnitude como também na sua localização ao longo da estrutura, ou seja, a condição crítica à fadiga do pavimento pode ser alcançada por camadas diferentes em decorrência da condição de aderência na interface entre as camadas.

Em todas as estruturas analisadas, ficou evidente o impacto da condição de interface entre as camadas na vida do pavimento e que há influência da rigidez da camada asfáltica. Quanto mais rígido o material asfáltico, maior é o efeito da condição de aderência entre as camadas na vida do pavimento à fadiga e à deformação permanente. Ou seja, sendo as camadas asfálticas reconhecidamente viscoelásticas e sua rigidez dependente da temperatura e velocidade do tráfego, conclui-se que o efeito da aderência entre as camadas no comportamento estrutural do pavimento é maior em temperaturas menores e tráfego com maior velocidade.

O efeito da aderência entre camadas na vida do pavimento é afetado pela rigidez da camada superior e também pela rigidez da camada abaixo da interface. Dessa forma, o efeito da aderência está relacionado à razão entre os módulos de resiliência das duas camadas em contato.

A conformidade dos resultados obtidos com as simulações computacionais e os observados na literatura, somada à variedade de instrumentos de modelagem de contato oferecidos pelo programa computacional ABAQUS, reforçam o benefício da sua utilização e dos parâmetros de entrada empregados neste trabalho, nas análises estruturais dos pavimentos.

A análise estatística realizada mostrou efeito significativo da condição de interface sobre o comportamento estrutural de pavimentos, em virtude das respostas estruturais relacionadas aos 
critérios de fadiga e deformação permanente terem sido afetados pela condição de contato entre as camadas do pavimento.

$\mathrm{Na}$ maioria das estruturas analisadas, a vida do pavimento mostra-se mais longa quando as camadas estão perfeitamente aderidas. Em função disso, destaca-se a importância de procedimentos e cuidados construtivos, como por exemplo a pintura de ligação, visando proporcionar uma melhor conexão entre as camadas e, consequentemente, pavimentos mais duradouros.

A consideração de completa aderência entre as camadas de um pavimento pelos métodos empírico-mecanísticos de dimensionamento, pode não ser a mais apropriada, uma vez que, quando essa condição não é alcançada em campo, os pavimentos são subdimensionados, ou seja, sofrem deformações maiores do que as deformações estimadas e atingem o colapso antes do tempo previsto em projeto.

Portanto, a aderência entre as camadas dos pavimentos está diretamente relacionada à durabilidade de pavimentos novos e de camadas de reforço, sendo de grande importância a sua consideração em todo o processo, desde o dimensionamento até as etapas manutenção e reabilitação.

Em função dos resultados obtidos e das limitações da presente pesquisa, aponta-se a seguir sugestões para trabalhos que complementam o conhecimento do efeito da condição de interface no comportamento dos pavimentos flexíveis.

Os problemas mais comuns relacionados à aderência inadequada entre as camadas do pavimento são corrugação e trincas por deslizamento. Esses defeitos são encontrados frequentemente em áreas de frenagem, aceleração e conversão dos veículos. Desse modo, sugere-se incorporar ao estudo as componentes horizontais dos esforços do tráfego na análise do efeito da aderência no comportamento dos pavimentos.

Sugere-se uma calibração dos parâmetros de entrada da modelagem da interface entre as camadas (módulo de reação cisalhante e coeficiente de atrito), suportada por ensaios de cisalhamento direto na interface de camadas com características típicas dos pavimentos brasileiros. 
Em função da singularidade do comportamento das camadas asfálticas inferiores, sugere-se o estudo específico do comportamento estrutural das camadas asfálticas sob diferentes condições não só de rigidez, mas também espessura e magnitude do carregamento. 


\section{REFERÊNCIAS}

A.R.E. - AUSTIN RESEARCH ENGINEERS, INC. (1975). Asphalt Concrete Overlays of Flexible Pavements - Vol. 1 - Development of New Design Criteria - Report FHWA-RD-75-75

- Federal Highway Administration - Washington, D.C.

ABAQUS (2017a). Getting Started with ABAQUS, Keywords Edtion 14, 2014. Recuperado de http://abaqus.software.polimi.it/v6.14/books/gsk/default.htm - Acessado em: 29/01/2018

ABAQUS (2017b). Getting Started with ABAQUS, interactive Edition, Version 14, 2014. Recuperado de http://abaqus.software.polimi.it/v6.14/books/gsa/default.htm - Acessado em: $29 / 01 / 2018$

Asaduzzaman, M., Abe, N., \& Hayano, K. (2015). Effect of Interface Bond Condition on Pavement Life: A Case Study on National Highway-5, Bangladesh. E1, 70(3).

Brown, S. F., \& Brunton, J. M. (1984). The influence of bonding between bituminous layers. HIGHWAYS \& TRANSPORTATION, 31(5).

Charmot, S., Romero, P., \& Dunning, M. (2005). Forensic analysis of slippage cracking. In Proceeding of the 84th TRB annual meeting. Washington.

Cho, Y. H., McCullough, B., \& Weissmann, J. (1996). Considerations on finite-element method application in pavement structural analysis. Transportation Research Record: Journal of the Transportation Research Board, (1539), 96-101.

CNT (2017a). Confederação Nacional Transportes - Pesquisa CNT de Rodovias 2017 Relatório Gerencial.

CNT (2017b). Confederação Nacional Transportes - Recuperado de http://www.cnt.org.br/imprensa/ noticia/dnit-apresenta-novo-metodo-dimensionamento Acessado em: 29/01/2018

De Beer, M., Kannemeyer, L., \& Fisher, C. (1999). Towards improved mechanistic design of thin asphalt layer surfacings based on actual tyre/pavement contact stress-in-motion (SIM) data in South Africa. In Proceedings: 7th International Conference on Asphalt Pavements For Southern Africa. 
DER-SP (2005). Departamento de Estradas e Rodagem do Estado de São Paulo. ET-DEP00/20, 2005 - Imprimação Betuminosa Ligante - Especificação Técnica, São Paulo, SP.

DNIT (2006). Manual de restauração de Pavimentos Asfálticos - Publicação IPR-720 Departamento Nacional de Infraestrutura de Transportes. Instituto de pesquisa rodoviária, Rio de Janeiro, RJ.

Fernandes Jr, J. L. (1994). Investigação dos Efeitos das Solicitações do Tráfego sobre o Desempenho de Pavimentos. São Carlos. Tese (Doutorado) - Escola de Engenharia de São Carlos, Universidade de São Paulo, São Carlos.

Feyissa, B. A. (2009). Analysis and modeling of rutting for long life asphalt concrete pavement. (Doctoral dissertation). Technische Universität Darmstad, Germany

Franco, F. A. C. P. (2007). Método de dimensionamento mecanístico-empírico de pavimentos asfálticos-SisPav. Tese (doutorado) - Universidade Federal do Rio de Janeiro. Rio de Janeiro, RJ.

Franco, F.A.C.P. (2004), Avaliação dos modelos de previsão do dano de fadiga em misturas asfálticas, In: Trabalhos técnicos do $17^{\circ}$ Encontro de Asfalto, Rio de Janeiro, dezembro, p. 100117.

Haas, R., Hudson, W. R., \& Zaniewski, J. P. (1994). Modern pavement management, 2nd Ed. Krieger Publishing Co.- Malabar, Florida. USA.

HARIYADI, E. S., AURUM, K. P., \& SUBAGIO, B. S. (2013). Theoretical Study of Bonding Condition at the Interface between Asphalt Pavement Layers. Journal of the Eastern Asia Society for Transportation Studies, 10, 1590-1597.

Hibbit, K. (2005). Sorensen Inc. ABAQUS/standard User's Manual. Version 6.5. Hibbitt, Karlsson, \& Sorensen. Inc. Providence (RI).

Hu, X., \& Walubita, L. F. (2010). Effects of layer interfacial bonding conditions on the mechanistic responses in asphalt pavements. Journal of Transportation Engineering, 137(1), 28-36.

Huang, Y. H. (2004). Pavement analysis and design. $2^{\circ}$ ed. Pearson Prentice Hall, New Jersey, USA. 
Jackson, R. L., \& Green, I. (2005). A finite element study of elasto-plastic hemispherical contact against a rigid flat. Journal of tribology, 127(2), 343-354.

Kim, M. (2007). Three-dimensional finite element analysis of flexible pavements considering nonlinear pavement foundation behavior. University of Illinois at Urbana-Champaign.

Kruntcheva, M. R., Collop, A. C., \& Thom, N. H. (2000). Theoretical and practical aspects of the importance of bonding in a pavement structure. Project report PGR, 8 .

Kruntcheva, M. R., Collop, A. C., \& Thom, N. H. (2005). Effect of bond condition on flexible pavement performance. Journal of transportation engineering, 131(11), 880-888.

Kruntcheva, M. R., Collop, A. C., \& Thom, N. H. (2006). Properties of asphalt concrete layer interfaces. Journal of Materials in Civil Engineering, 18(3), 467-471.

Medina, J. D., \& MOTTA, L. M. G. D. (1997). Mecânica dos pavimentos. Rio de Janeiro: Editora UFRJ, 23.

Mohammad, L. N., Bae, A., Elseifi, M. A., Button, J. W., \& Scherocman, J. A. (2009). Interface shear strength characteristics of emulsified tack coats. Journal of the Association of Asphalt Paving Technologists, 78.

Monismith, C. L., \& Brown, S. F. (1999). Developments in the structural design and rehabilitation of asphalt pavements over three quarters of a century. Journal of the Association of Asphalt Paving Technologists A, 68, 128-251.

Nguyen, N. L., Van Dong, D. A. O., NGUYEN, M. L., \& Huu, D. (2016, June). Investigation of Bond Between Asphalt Layers in Flexible Pavement. In 8th RILEM International Conference on Mechanisms of Cracking and Debonding in Pavements (pp. 519-525). Springer, Dordrecht.

Pacheco, L. M. (2014). Análise paramétrica da resistência ao cisalhamento de misturas asfálticas. Dissertação de mestrado. Universidade Federal do Rio Grande do Sul, Porto Alegre.

Raab, C., \& Partl, M. N. (2004a). Interlayer shear performance: experience with different pavement structures. In Proceedings of the 3rd Eurasphalt And Eurobitume Congress Held Vienna, May 2004 (Vol. 1). 
Raab, C., \& Partl, M. N. (2004b). Effect of tack coats on interlayer shear bond of pavements. In Proceedings of the 8th conference on Asphalt Pavements for Southern Africa (CAPSA'04) (Vol. 12, p. 16).

Raab, C., Grenfell, J., El Halim, A. A., \& Partl, M. N. (2016). Comparison of Interlayer Bond Behavior Due to Ageing. In 8th RILEM International Symposium on Testing and Characterization of Sustainable and Innovative Bituminous Materials(pp. 323-334). Springer, Dordrecht.

Romanoschi, S. A. (1999). Characterization of Pavement Layer Interfaces. PhD Dissertation. Louisiana State University, Baton Rouge, USA.

Romanoschi, S., \& Metcalf, J. (2001a). Characterization of asphalt concrete layer interfaces. Transportation Research Record: Journal of the Transportation Research Board, (1778), 132-139.

Romanoschi, S., \& Metcalf, J. (2001b). Effects of interface condition and horizontal wheel loads on the life of flexible pavement structures. Transportation Research Record: Journal of the Transportation Research Board, (1778), 123-131.

SHELL (1998). Bitumen Stress Analysis in Roads BISAR 3.0 User's Manual. Shell International Petroleum Company Limited.

Sukumaran, B., Willis, M., \& Chamala, N. (2005). Three dimensional finite element modeling of flexible pavements. In Advances in Pavement Engineering (pp. 1-12).

Sun, X. (2011). Modeling analysis of pavement layer interface bonding condition effects on cracking performance. PhD Dissertation, University of Florida. Florida.

Sutanto, M. (2009). Assessment of bond between asphalt layers. Nottingham: The University of Nottingham. PhD thesis, University of Nottingham.

Tashman, L., Nam, K., \& Papagiannakis, A. T. (2006). Evaluation of the influence of tack coat construction factors on the bond strength between pavement layers (No. WA-RD 645.1). Washington State Department of Transportation. 
Tsai, C. T., \& Mall, S. (2000). Elasto-plastic finite element analysis of fretting stresses in prestressed strip in contact with cylindrical pad. Finite elements in analysis and design, 36(2), 171187.

Tschegg, E. K., Kroyer, G., Tan, D. M., Stanzl-Tschegg, S. E., \& Litzka, J. (1995). Investigation of bonding between asphalt layers on road construction. Journal of Transportation Engineering, 121(4), 309-316.

Uddin, W., Zhang, D., \& Fernandez, F. (1994). Finite element simulation of pavement discontinuities and dynamic load response. Transportation Research Record, (1448).

Uzan, J., Livneh, M., \& Eshed, Y. (1978). Investigation of adhesion properties between asphaltic-concrete layers. In Association of Asphalt Paving Technologists Proc (Vol. 47).

Wu, S., Chen, H., Zhang, J., \& Zhang, Z. (2017). Effects of interlayer bonding conditions between semi-rigid base layer and asphalt layer on mechanical responses of asphalt pavement structure. International Journal of Pavement Research and Technology, 10(3), 274-281.

Yao, H., Liu, Y., You, Z. P., Li, L., \& Goh, S. W. (2012). Discrete element simulation of bending beam rheometer tests for asphalt binder. International Journal of Pavement Research and Technology, 5(3), 161-168.

Yassenn, O. M., Rohani, I., Endut, D., Ishak, S. Z., \& Yaseen, H. M. (2015). Finite Element Modelling of Flexible Pavement. parameters, 2(1).

Yoder, E. J., \& Witczak, M. W. (1975). Principles of pavement design. John Wiley \& Sons. 2nd Edition, New York, USA.

Yoo, P. J., Al-Qadi, I. L., Elseifi, M. A., \& Janajreh, I. (2006). Flexible pavement responses to different loading amplitudes considering layer interface condition and lateral shear forces. The International Journal of Pavement Engineering, 7(1), 73-86.

Zaghloul, S. M., \& White, T. (1993). Use of a three-dimensional, dynamic finite element program for analysis of flexible pavement. Transportation research record, (1388).

Ziari, H., \& Khabiri, M. M. (2007). Interface condition influence on prediction of flexible pavement life. Journal of Civil Engineering and Management, 13(1), 71-76. 